RODRIGO BARBOSA BRONZERI

\title{
Um novo conceito para uma bomba d'água de vazão variável baseada em um acoplamento magnético
}

São Paulo 



\title{
RODRIGO BARBOSA BRONZERI
}

\section{Um novo conceito para uma bomba d'água de vazão variável baseada em um acoplamento magnético}

\author{
Versão Corrigida
}

Tese apresentada à Escola Politécnica da Universidade de São Paulo para obtenção do título de Doutor em Ciências.

Área de Concentração:

Sistemas de Potência

Orientador: Prof. Dr. Ivan Eduardo Chabu

São Paulo

2021 
Autorizo a reprodução e divulgação total ou parcial deste trabalho, por qualquer meio convencional ou eletrônico, para fins de estudo e pesquisa, desde que citada a fonte.

\section{Catalogação-na-publicação}

\section{Bronzeri, Rodrigo}

Um novo conceito para uma bomba d'água de vazão variável baseada em um acoplamento magnético / R. Bronzeri -- São Paulo, 2021.

$130 \mathrm{p}$.

Tese (Doutorado) - Escola Politécnica da Universidade de São Paulo. Departamento de Engenharia de Energia e Automação Elétricas.

1.acoplamento magnético 2.correntes induzidas 3.bomba de vazão variável I.Universidade de São Paulo. Escola Politécnica. Departamento de Engenharia de Energia e Automação Elétricas II.t. 
BRONZERI, R. B. Um novo conceito para uma bomba d'água de vazão variável baseada em um acoplamento magnético. Tese (Doutorado) - Escola Politécnica da Universidade de São Paulo, São Paulo, 2021.

Trabalho aprovado em: 07 de Dezembro de 2021.

Banca Examinadora

Prof. Dr. : Ivan Eduardo Chabu

Instituição: EP-USP

Julgamento: Aprovado

Prof. Dr. : Gilberto Francisco Martha de Souza

Instituição: EP-USP

Julgamento: Aprovado

Prof. Dr. : Julio Carlos Teixeira

Instituição: UFABC - Externo

Julgamento: Aprovado

Prof. Dr. : Luiz Lebensztajn

Instituição: EP-USP

Julgamento: Aprovado

Prof. Dr. : Nelson Jhoe Batistela

Instituição: UFSC - Externo

Julgamento: Aprovado 
Aos 07 dias do mês de dezembro de 2021, no(a) realizou-se a Defesa da Tese do(a) Senhor(a) Rodrigo Barbosa Bronzeri, apresentada para a obtenção do titulo de Doutor intitulada:

"Um novo conceito para uma bomba d’água de vazão variável baseada em um acoplamento magnético"

Após declarada aberta a sessão, o(a) Sr(a) Presidente passa a palavra ao candidato para exposiçäo e a seguir aos examinadores para as devidas arguições que se desenvolvem nos termos regimentais. Em seguida, a Comissão Julgadora proclama o resultado:

\begin{tabular}{|c|c|c|c|}
\hline Nome dos Participantes da Banca & Função & $\begin{array}{l}\text { Sigla da CPG } \\
\text { FP- USP }\end{array}$ & $\begin{array}{l}\text { Resultado } \\
\text { APRO } \cup A D O\end{array}$ \\
\hline $\begin{array}{l}\text { Ivan Eduardo Chabu } \\
\text { Gilberto Francisco Ma }\end{array}$ & Titular & $E P$ - USP & $A P R O V_{A D O}$ \\
\hline Julio Carlos Teixeira & Titular & UFABC - Externo & APROVADO \\
\hline Luiz Lebensztajn & Titular & EP - USP & $A P R_{0} V A D U$ \\
\hline Nelson Jhoe Batistela & Titular & UFSC - Externo & APROVADO \\
\hline
\end{tabular}

Resultado Final: APROVADO

Parecer da Comissão Julgadora *

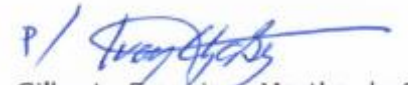

Gilberto Francisco Martha de Souza

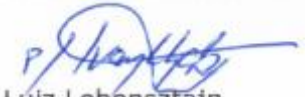

Luiz Lebensztajn

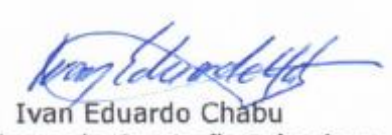

Presidente da Comissão Julgadora

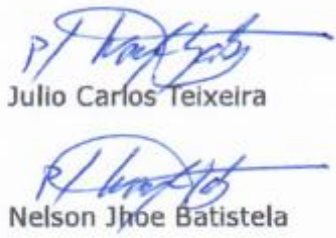




\section{Agradecimentos}

Este trabalho certamente não é apenas a conclusão de mais uma etapa da minha vida acadêmica ou, simbolicamente, o início de outra. Significa o fechamento de um ciclo enorme na busca pelo conhecimento e aprimoramento, com muitos altos e baixos, mas também com muita persistência e apoio.

Ao longo desses anos, além das transformações em minha vida profissional, muitos desafios pessoais se entrelaçaram com as demandas e obrigações. Muitos encontros e descobertas transformaram medos em realizações. Desde a chegada da Alice, minha filha, a vida tomou outro significado. O amor e apoio da minha companheira de vida trouxe a coragem e determinação para persistir, mesmo em momentos em que a resiliência foi colocada em teste.

Por esse e outros motivos, os meus agradecimentos iniciam por você, Rafaele, por toda ajuda e paciência. Aos meus pais Cláudio e Jane, e à minha Tia Neuza, pela educação e por sempre terem lutado para nos dar - a mim e aos meus irmãos - o conforto mais do que necessário para levarmos os estudos adiante. Os exemplos dados por vocês são

a base de tudo que considero digno e honesto. Aos meus irmãos Plínio e Bruno, pelos desabafos e pelo companheirismo de uma vida.

Gostaria de agradecer ao professor orientador Ivan Chabu pelo constante apoio e por ter acreditado no aspecto original deste trabalho. Aos professores Julio Teixeira e Gilberto de Souza pelas revisões e valiosas sugestões desde a etapa de qualificação. Aos professores Nelson Jhoe Batistela e Luiz Lebensztajn pela participação na banca de defesa e pelas importantes sugestões que ajudaram a aprimorar a versão original deste trabalho. Aos meus amigos da Melling do Brasil e Pricol, em especial ao Eduardo Gubbiotti Ribeiro, João Meira, Paulo Bressan e Ayres Filho, por todo auxílio durante o desenvolvimento deste conceito. Ao grande amigo Gabriel Pausic, que mesmo de longe nunca hesitou em ajudar ou compartilhar experiências. 

"Viver não é necessário;

o que é necessário é criar."

(Fernando Pessoa) 



\section{Resumo}

BRONZERI, R. B. Um novo conceito para uma bomba d'água de vazão variável baseada em um acoplamento magnético. 2021. 130p. Tese (Doutorado) - Escola Politécnica da Universidade de São Paulo, São Paulo, 2021.

Este trabalho apresenta as etapas para validar uma nova topologia de acoplamento magnético com aplicação direta em bombas d'água automotivas. Iniciando pelos estudos analíticos, um modelo em duas dimensões para simulação por elementos finitos foi construído, cuja efetividade foi comprovada com a medição da eficiência de um protótipo. Baseado na tecnologia de acoplamentos magnéticos por correntes induzidas, a quantidade de potência transferida entre eixos pode ser ajustada em função da temperatura operacional desejada para os motores de combustão interna. Essa tecnologia consome menos corrente elétrica em comparação a bombas d'água acionadas por motores elétricos, uma vez que a fonte principal de energia é o motor de combustão. Outra vantagem é o acionamento do eixo de saída com o torque residual, que utiliza o magnetismo gerado pelos ímãs permanentes na ausência de potência elétrica, tornando-se uma função importante para proteção contra superaquecimento em casos de panes elétricas. Os resultados apresentados neste trabalho validam o novo dispositivo e apontam para propostas de melhorias visando aumentar sua eficiência, facilitando assim novos desenvolvimentos e trabalhos futuros.

Palavras-chave: Bomba d'água de vazão variável, acoplamento magnético por correntes induzidas, bomba d'água automotiva. 



\section{Abstract}

BRONZERI, R. B. New concept validation of variable flow water pump based on a magnetic coupling. 2021. 130p. Thesis (Doctorate) - Polytechnic School of the University of São Paulo, São Paulo, 2021.

This work presents the steps for validating a new topology of magnetic coupling with direct application in automotive water pumps. Starting from analytical studies, a model in two dimensions for simulation by finite elements was created, whose effectiveness was proven with the performance measured by the construction of a prototype. Based on the eddy current coupling technology, the amount of power transferred can be adjusted according to the desired engine operating temperature. This technology consumes less electrical current in comparison to a motor-driven water pump, since the primary pumping power source is the combustion engine. Another advantage is the residual torque operating mode, that uses the magnetism generated by permanent magnets in the absence of electrical power, which is an important function to protect the engine against overheating in case of an electrical failure. The results presented here validate the concept regarding the controllability of the device and highlights points to improve the machine's performance, thus facilitating new developments and future work.

Keywords: Variable flow water pump, eddy-current magnetic coupling, automotive water pump. 



\section{Lista de ilustrações}

Figura 1 - Motor de combustão interna alternativo. . . . . . . . . . . . . . . . 29

Figura 2 - Transferência de potência mecânica por meio de uma correia e polias. 30

Figura 3 - Bomba d'água utilizada como referência. . . . . . . . . . . . . . 30

Figura 4 - Comportamento da bomba d'água com o fluido refrigerante (B0401065GM6277) a $25^{\circ} \mathrm{C}$ e em função da velocidade da polia (potência de entrada). 31

Figura 5 - Comportamento da bomba d'água com o fluido refrigerante (B0401065GM6277) a $25^{\circ} \mathrm{C}$ e em função da vazão (potência de saída). . . . . . . . . 31

Figura 6 - Circulação forçada do líquido refrigerante. . . . . . . . . . . . . . 36

Figura 7 - Comportamento da válvula termostática em função da temperatura do motor. . . . . . . . . . . . . . . . 36

Figura 8 - Válvula termostática, funcionamento e curva característica (expansão versus temperatura), modelo DILAVESTL ${ }^{T M}$ P90. . . . . . . . . . . 37

Figura 9 - Válvula termostática com elemento gerador de calor em contato com a cera. Controle da temperatura é feito pela ECU por meio de um solenoide. 38

Figura 10 - Válvula termostática com corpo de borboleta. . . . . . . . . . . . . . . 39

Figura 11 - Comparativo entre válvula corpo de borboleta e convencional para um motor de seis cilindros. . . . . . . . . . . . . . . . . . 39

Figura 12 - Válvula (ON/OFF) proposta pela Melling do Brasil. . . . . . . . . . . . . 40

Figura 13 - Novo projeto proposto pela Melling do Brasil, que permite controlar diferentes vazões, por meio do controle da posição da membrana. . . . . . . 41

Figura 14 - llustração do controle da posição da membrana para diferentes momentos. 42

Figura 15 - Calibração do sensor hall para aproveitar toda faixa de operação. . . . . 42

Figura 16 - Controle da posição da membrana com base no objetivo especificado pela ECU. . . . . . . . . . . . . . . . . . . . . 43

Figura 17 - Vazão como resultado do controle da posição da membrana. . . . . . . . 43

Figura 18 - Configuração para acoplamento (à esquerda) e desacoplamento (à direita). 44

Figura 19 - Vista parcial seccionada detalhando o disco de fricção, a polia da correia e o disco da ventoinha. . . . . . . . . . . . . . . . . . . 45

Figura 20 - Bomba de vazão variável proposta por Faller, que une fricção e magnetismo. 46 
Figura 21 - Representação de um acoplamento magnético. . . . . . . . . . . . . . . 50

Figura 22 - Curva característica de um acoplamento magnético. . . . . . . . . . . . 51

Figura 23 - Definição dos eixos no sistema de coordenadas. . . . . . . . . . . . . . 53

Figura 24 - Cálculo do fluxo por polo $\left(\phi_{a c}\right)$ a partir da equação das correntes induzidas $\left(J_{z}\right)$ no meio ferromagnético.

Figura 25 - Cálculo do fluxo por polo $\left(\phi_{a c}\right)$ em função da quantidade de energia dissipada $(W)$ no cilindro. . . . . . . . . . . . . . . . 66

Figura 26 - Introdução da não linearidade dos materiais ferromagnéticos. . . . . . . 67

Figura 27 - Equação que define o fluxo magnético por polo $\phi_{a c}$. . . . . . . . . . . . 67

Figura 28 - Equação que define a reação de armadura Fr. . . . . . . . . . . . . . 68

Figura 29 - Aspectos externos da bomba d'água de vazão variável. . . . . . . . . . 70

Figura 30 - Cortes usados para definição dos planos a partir da vista frontal e da vista lateral direita. . . . . . . . . . . . . . . . . . . 70

Figura 31 - Divisão da máquina em três subconjuntos. O entreferro entre cada subconjunto é de $0,25 \mathrm{~mm} \ldots \ldots \ldots \ldots$. . . . . . . . . . . . . . .

Figura 32 - Divisão da máquina em três subconjuntos. O entreferro entre cada subconjunto é de $0,25 \mathrm{~mm}$. . . . . . . . . . . . . . . . . . 73

Figura 33 - Corte transversal a partir da visão lateral do modelo em três dimensões. 74

Figura 34 - Visão frontal de um polo e os ímãs permanentes. . . . . . . . . . . . . . 75

Figura 35 - Desenho com as dimensões de uma das peças do rotor do acoplamento. 76

Figura 36 - Segundo quadrante da curva de magnetização. . . . . . . . . . . . . . 77

Figura 37 - Dimensional e polarização do ímã permanente. . . . . . . . . . . . . . . 78

Figura 38 - Resultado da simulação com temperatura ambiente em $20^{\circ} \mathrm{C}$. . . . . . 78

Figura 39 - Resultado da simulação com temperatura ambiente em $150^{\circ} \mathrm{C}$. . . . . . 79

Figura 40 - Simulação por elementos finitos usando o software Magnet. . . . . . . . 80

Figura 41 - Plano longitudinal superior da máquina ilustrando os caminhos percorridos pelo fluxo magnético nos três modos de operação. . . . . . . . . . . 83

Figura 42 - Modos de operação: torque e corrente em função do tempo. . . . . . . . . 83

Figura 43 - Modelo 3D indicando a concentração do campo magnético na região onde os ímãs estão posicionados. Vista transversal utilizada como referência para o posicionamento. . . . . . . . . . . . . . . 85

Figura 44 - Modelo 2D da simplificação proposta. . . . . . . . . . . . . . . . . 86

Figura 45 - Polarização dos ímãs permanentes. . . . . . . . . . . . . . . . . . . . 87 
Figura 46 - Resultado da simulação 2D e as respectivas linhas de campo. . . . . . . 87

Figura 47 - Circuito elétrico utilizado nas simulações por elementos finitos. . . . . . 88

Figura 48 - Resultado da simulação por elementos finitos apresentando o fluxo magnético resultante em função da polarização dos ímãs permanentes. . . .

Figura 49 - Simulação dinâmica relacionando torque e fluxo magnético por polo com velocidade de $400 \mathrm{rpm} . \ldots . \ldots$. . . . . . . . . . . . . 90

Figura 50 - Comparativo com base no torque simulado versus analítico em função do fluxo por polo.

Figura 51 - Resultado da simulação para o modelo 2D mostrando as correntes induzidas na superfície interna do cilindro $(0-A)$ e sua profundidade de penetração (0-J).

Figura 52 - Comparativo com base no torque simulado versus analítico em função da densidade de corrente. . . . . . . . . . . . . . . . . . . . 92

Figura 53 - Comportamento do torque em função do tempo. . . . . . . . . . . . . . 93

Figura 54 - Comportamento do fluxo magnético na superfície interna do cilindro com origem 0 indicada pela figura $48 \ldots \ldots . \ldots . \ldots 93$

Figura 55 - Plano longitudinal e transversal destacando o posicionamento dos componentes da máquina. . . . . . . . . . . . . . . . . . . 996

Figura 56 - Componentes confeccionados e prontos para a montagem. . . . . . . . 97

Figura 57 - Montagem parcial e posicionamento do eletroímã e leitura da resistência (4 fios) . . . . . . . . . . . . . . . . . . . 98

Figura 58 - Método de montagem do protótipo. . . . . . . . . . . . . . . . . . . . . 99

Figura 59 - Subconjunto com o rotor, polos magnéticos e ímãs permanentes em destaque. . . . . . . . . . . . . . . . . 100

Figura 60 - Posicionamento dos ímãs e sensor hall para medir o escorregamento. . 100

Figura 61 - Transdutor de torque modelo T34ST . . . . . . . . . . . . . . . . . . . 101

Figura 62 - Teste de desempenho de bombas d'água. . . . . . . . . . . . . . . . . . 101

Figura 63 - Bomba variável conectada ao equipamento para teste. . . . . . . . . . . . 102

Figura 64 - Bomba variável conectada ao equipamento para teste. . . . . . . . . . . 102

Figura 65 - Característica do torque em função da velocidade. . . . . . . . . . . . . 103

Figura 66 - Característica da vazão em função da velocidade. . . . . . . . . . . . . . 103

Figura 67 - Torque $\left(\mathrm{T}_{F E A}\right)$ obtido com corrente elétrica de 2,23 A. . . . . . . . . . 105

Figura 68 - Torque $\left(T_{F E A}\right)$ obtido com corrente elétrica de 4,0 A. . . . . . . . . . 105 
Figura 69 - Comparação entre torque do protótipo $\left(\mathrm{T}_{P R O T O}\right)$ e o simulado $\left(\mathrm{T}_{F E A}\right)$ em função da velocidade de escorregamento. . . . . . . . . . . . . . . 105

Figura 70 - Comparação dos resultados com a bomba d'água variável contra os valores nominais da bomba d'água mecânica e a bomba com o pino de travamento, com o fluido refrigerante a $25^{\circ} \mathrm{C} \ldots \ldots$. . . . . . . . 106

Figura 71 - Eficiência do acoplamento da bomba de vazão variável em função da velocidade de entrada, com o fluido refrigerante a $25^{\circ} \mathrm{C} \ldots \ldots$

Figura 72 - Torque residual gerado apenas pelos ímãs permanentes. . . . . . . . . 108

Figura 73 - Posicionamento dos sensores de temperatura . . . . . . . . . . . . . 109

Figura 74 - Comportamento da vazão em função da temperatura e tempo de teste. . 111

Figura 75 - Variação de pressão $\left(\Delta_{p}\right)$ em função da vazão e temperatura. . . . . . . 111

Figura 76 - Resultado do teste evidenciando o controle da vazão, torque residual e

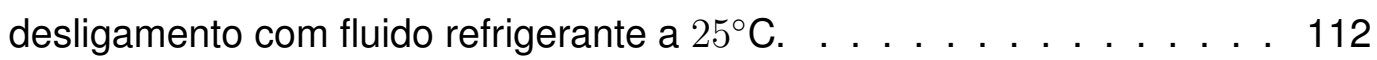

Figura 77 - Ambiente Labview para controle da velocidade da polia e aquisição dos dados. . . . . . . . . . . . . . . . . . . . 113

Figura 78 - Foto do dispositivo durante o teste. . . . . . . . . . . . . . 113

Figura 79 - Comparação do diferencial de pressão $\Delta p$ em função da máxima vazão.

Bomba mecânica convencional (Mpump - Máx ${ }_{v a z o}$ ) como referência. . . 114

Figura 80 - Circuito magnético para meio polo magnético. . . . . . . . . . . . . . . 121

Figura 81 - Comprovação do sentido de magnetização. . . . . . . . . . . . . . . . . 125

Figura 82 - Comprovação do sentido de magnetização. . . . . . . . . . . . . . . 126

Figura 83 - Segundo quadrante da curva de magnetização de um ímã e a relação das variáveis para cálculo do $B r$. . . . . . . . . . . . . . . . 127

Figura 84 - Valores para o fluxo magnético coletados para 20 amostras. . . . . . . . 127

Figura 85 - Comparativo entre o valor de catálogo e os valores obtidos com tolerância

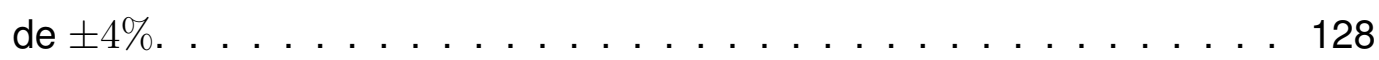




\section{Lista de tabelas}

Tabela 1 - Principais componentes do motor alternativo. . . . . . . . . . . . . . . 29

Tabela 2 - Principais componentes do dispositivo proposto. . . . . . . . . . . . . . 46

Tabela 3 - Principais componentes da máquina e seus respectivos números. . . . 72

Tabela 4 - Principais dados do dispositivo proposto e seus respectivos valores. . . 76

Tabela 5 - Dados característicos do ímã permanente $(\mathrm{N} 42 \mathrm{SH})$. . . . . . . . . . . 77

Tabela 6 - Variáveis para cálculo de Bg. . . . . . . . . . . . . . . . . 80

Tabela 7 - Principais dados do dispositivo proposto e seus respectivos valores. . . 89

Tabela 8 - Diferença percentual do fluxo por polo $\left(\phi_{a c}\right)$ para o aço puro. . . . . . . 91

Tabela 9 - Diferença percentual do fluxo por polo $\left(\phi_{a c}\right)$ para o aço SAE1020. . . . . 91

Tabela 10 - Diferença percentual da corrente induzida $(\mathrm{Jm})$ para o aço puro. . . . . 91

Tabela 11 - Diferença percentual da corrente induzida $(\mathrm{Jm})$ para o aço SAE1020. 92

Tabela 12 - Tabela descrevendo os principais componentes destacados pela figura 55. 96

Tabela 13 - Característica da bobina e do fio AWG23 . . . . . . . . . . . . . . . . . 96

Tabela 14 - Comparativo entre o número de voltas teórico e o obtido durante a montagem do protótipo. . . . . . . . . . . . . . . . . . . . . 98

Tabela 15 - Resultado do teste para corrente de $4 \mathrm{~A}$ e temperatura ambiente de $25^{\circ} \mathrm{C} .104$

Tabela 16 - Resultado do teste para corrente de 2.23 A e temperatura ambiente de $25^{\circ}$ C . . . . . . . . . . . . . . . . . . 104

Tabela 17 - Estimativa da temperatura do eletroímã para uma tensão aplicada de 13,2 volts e fluido com temperatura de $32^{\circ} \mathrm{C} \ldots \ldots 109$

Tabela 18 - Estimativa da temperatura do eletroímã para uma tensão aplicada de

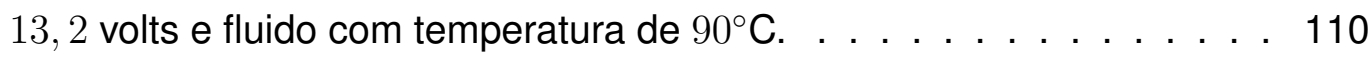

Tabela 19 - Variáveis para cálculo de Bg. . . . . . . . . . . . . . . . . . . . . . . 122

Tabela 20 - Variáveis para cálculo de Bg. . . . . . . . . . . . . . . . . . . . . . . . 122

Tabela 21 - Variáveis relacionadas com o cálculo a partir da utilização da bobina de Helmholtz. . . . . . . . . . . . . . . . . . . . 126 



\section{Lista de abreviaturas e siglas}

$\begin{array}{ll}\text { AWG } & \text { American Wire Gauge } \\ \text { GPM } & \text { Galões por minuto } \\ \text { Ipm } & \text { Litros por minuto } \\ \text { RPM } & \text { Rotações por minuto } \\ \text { Vdc } & \text { Tensão contínua em Volts } \\ \text { BLDC } & \text { Motor sem escovas brushless-DC } \\ \text { 2D } & \text { Duas dimensões } \\ \text { 3D } & \text { Três dimensões } \\ \text { EPA } & \text { United States Environmental Protection Agency } \\ \text { UCS } & \text { Union of Concerned Scientists } \\ \text { ECU } & \text { Engine Control Unit }\end{array}$





\section{Lista de símbolos}

A Corrente elétrica em ampères
$A_{1}, A_{2}$
Constantes arbitrárias
B Densidade de fluxo magnético
$\mathrm{B}_{\max } \quad$ Valor de pico para a densidade de fluxo magnético
$\mathrm{B}_{f} \quad$ Densidade de fluxo em função do campo magnético na região do entre- ferro

$\mathrm{B}_{r} \quad$ Densidade de fluxo magnético em função da reação de armadura na região do entreferro

d Profundidade de penetração da corrente de Foucault

D Diâmetro do cilindro na região do entreferro

e

Base do logaritmo neperiano equivalente a 2.718

$\mathrm{E}$

Campo elétrico

f

Frequência

9

Entreferro

$\mathrm{H} \quad$ Intensidade de campo magnético ou campo magnetizante

$\mathrm{H}_{m} \quad$ Valor de pico do componente fundamental de $\mathrm{H}$ na superfície do cilindro na região do entreferro

J Densidade de corrente

$\mathrm{J}_{\text {zmax }} \quad$ Valor de pico do componente fundamental de $\mathrm{J}$ na superfície do cilindro na região do entreferro

L $\quad$ Comprimento da região ativa do cilindro

M Constante da máquina 
n Velocidade de escorregamento no eixo de saída do acoplamento magnético

$\mathrm{n}_{r} \quad$ Velocidade no eixo motor

N Número de espiras

p Pares de polos magnéticos

Pmec Energia mecânica

Sativa Área total da região ativa

T Torque, newton-metro

W Unidade de potência

Fmm Força magnetomotriz

$\alpha \quad$ Inverso da profundidade de penetração da corrente de Foucault em metro $^{-1}$

$\lambda \quad$ Comprimento de onda definido pelo distanciamento entre os centros de polos magnéticos adjacentes (passo polar)

$\mu \quad$ Permeabilidade relativa

$\mu_{0} \quad$ Permeabilidade magnética do vácuo

$\pi$

3.14159

$\rho \quad$ Resistividade

$\phi \quad$ Fluxo magnético

$\phi_{a c} \quad$ Fluxo magnético por polo

$\omega \quad$ Frequência de escorregamento para o cálculo da penetração das correntes induzidas

$\omega \quad$ Frequência angular

P Permeabilidade 
$\mathrm{R}$

$\mathrm{F}_{g} \quad$ Força magnetomotriz total no entreferro

$\mathrm{F}_{r} \quad$ Reação de armadura em função da força magnetomotriz 



\section{Sumário}

INTRODUÇÃo . . . . . . . . . . . . . . . . . . . . 27

O SISTEMA DE ARREFECIMENTO . . . . . . . . . . . . . . . . . . . 35

$2.1 \quad$ Resfriamento forçado por circulação de água $\ldots \ldots$. . . . . . . . 35

$2.2 \quad$ Válvula termostática $\ldots \ldots \ldots \ldots \ldots \ldots$

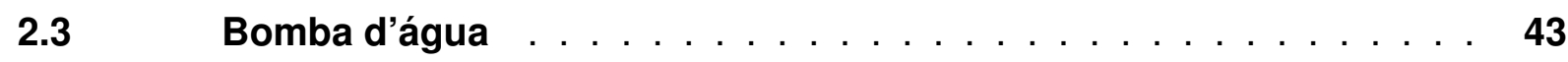

ACOPLAMENTO MAGNÉTICO POR CORRENTE DE FOUCAULT . . . 49

$3.1 \quad$ O Acoplamento por Foucault $\ldots \ldots \ldots \ldots$

$3.2 \quad$ Equacionamento . . . . . . . . . . . . . . 52

$3.3 \quad$ Distribuição da densidade de corrente $\ldots \ldots \ldots \ldots$

3.4 Campo magnético presente na região ativa em função da distribuição das correntes induzidas . . . . . . . . . . . . . . . . . . . 57

$3.5 \quad$ Indução no entreferro $\ldots \ldots \ldots \ldots \ldots$

$3.6 \quad$ Energia dissipada pelas correntes induzidas . . . . . . . . . . 60

3.7 Introdução da não linearidade em função da saturação do material ferromagnético . . . . . . . . . . . . . . . . 62

3.8 Cálculo do fluxo por polo a partir da não linearidade do material ferromagnético ...................... 62

$3.9 \quad$ Estudo da reação de armadura . . . . . . . . . . . . . . . 64

3.10 Apresentação resumida das principais equações matemáticas que descrevem o comportamento da máquina . . . . . . . . . . . 65

4 CONCEPÇÃO DA BOMBA D’ÁGUA DE VAZÃO VARIÁVEL COM ACOPLAMENTO MAGNÉTICO . . . . . . . . . . . . . . . . . . . . . 69

$4.1 \quad$ Definição da região ativa da máquina $\ldots \ldots$. . . . . . . . . . . 69

$4.2 \quad$ Características construtivas . . . . . . . . . . 71

$4.3 \quad$ Ativação da máquina . . . . . . . . . . . . . . 73

$4.4 \quad$ o rotor do acoplamento magnético $\ldots \ldots \ldots \ldots$

$4.5 \quad$ Cálculo da constante de máquina $M \ldots \ldots \ldots \ldots$ 
$4.6 \quad$ Definição dos ímãs permanentes . . . . . . . . . . . . . . . . . . 77

$4.7 \quad$ Definição do ponto de operação . . . . . . . . . . . . . . . . 80

$4.8 \quad$ Modos de operação $\ldots \ldots \ldots \ldots \ldots$

$5 \quad$ SIMULAÇÃO POR ELEMENTOS FINITOS EM DUAS DIMENSÕES . 85

$5.1 \quad$ Definição do modelo em duas dimensões . . . . . . . . . . . . . . . 85

5.2 Comparação entre as simulações e os cálculos matemáticos para o $\phi_{a c} \mathbf{e} J_{m} \ldots \ldots \ldots \ldots \ldots \ldots$

5.3 Fator para correção do fluxo por polo necessário com escorregamento nulo . . . . . . . . . . . . . . . . . . . . . . . 92

CONSTRUÇÃO DO PROTÓTIPO DA BOMBA D’ÁGUA DE VAZÃO VARIÁVEL E TESTES dE VALIDAÇÃO . . . . . . . . . . . . . . . . . . . . 95

$6.1 \quad$ A montagem $\ldots \ldots \ldots \ldots \ldots$

$6.2 \quad$ Equipamento para teste de desempenho . . . . . . . . . . 100

$6.3 \quad$ Desempenho hidráulico . . . . . . . . . . . . . . . . . 102

6.4 Testes de desempenho e comparação com o modelo para simulação em duas dimensões . . . . . . . . . . . . . . . . . . . . . . . 103

6.5 Comparação com os dados nominais da bomba d'água original. . . 106

$6.6 \quad$ Características relevantes à dissipação térmica . . . . . . . . . . 108

$6.7 \quad$ Comportamento dinâmico do dispositivo . . . . . . . . . . . . . . . 112

6.8 Comparação dos comportamentos para as diferentes tecnologias . 114

CONCLUSÃo . . . . . . . . . . . . . . . . . . 115

REFERÊNCIAS . . . . . . . . . . . . . . . . . . 117

ANEXO A - MÉTODO PARA CÁLCULO DO FLUXO MAGNÉTICO COM BASE NA GEOMETRIA DE MEIO POLO MAGNÉTICO. 121

ANEXO B - MÉTODO PARA CALCULAR A REMANÊNCIA (BR) DOS ÍMÃS PERMANENTES E COMPROVAÇÃO DO SENTIDO DE MAGNETIZAÇÃO. . . . . . . . . . . . . . . . . . 125 


\section{Introdução}

Nos últimos anos, os esforços para reduzir a quantidade de emissões de gases de efeito estufa dos veículos foram intensificados. De acordo com a agência de proteção abiental americana (EPA) e a união dos cientistas (UCS), o transporte é a maior fonte de poluição do ar nos Estados Unidos, estimando que um veículo de passageiros típico emite cerca de 4, 6 toneladas métricas de dióxido de carbono por ano (AGENCY, 2018).

O sistema de propulsão elétrica vem se consolidando cada vez mais como uma estratégia favorável para reduzir significativamente as emissões de gases de efeito estufa. No entanto, ainda é limitado pela tecnologia empregada na fabricação das baterias e infraestrutura de recarga. Paralelamente a essa significativa transformação tecnológica, no curto prazo, a forma mais viável de diminuir a emissão de gases de efeito estufa, diminuindo o consumo de combustível, é aumentar a eficiência do motor de combustão interna (KIM et al., 2010; JUNG et al., 2013). Neste caso, o rendimento está diretamente relacionado com a temperatura de operação. Assim, controlar sua temperatura visando mantê-lo em seu melhor ponto de operação, tem como reflexo a redução no consumo de combustível.

A temperatura de operação de motores a combustão interna ideal tem grande dependência do combustível utilizado e, de forma geral, esse valor deve estar em torno de $90^{\circ} \mathrm{C}$ (BRUNETTI, 2012a, p. 388). Com isso, para todos os seus regimes de operação, essa temperatura ideal deve ser atingida no menor tempo possível. Pode-se destacar também como variáveis: a temperatura inicial do motor, condições climáticas e percurso no qual o veículo é submetido.

Parte do trabalho gerado pela combustão é transformado em atrito e calor. Consequentemente, elementos para arrefecimento foram incorporados ao motor para diminuir a temperatura resultante da combustão e altamente danosa aos seus componentes internos. Entre os métodos utilizados, o mais eficiente utiliza um sistema forçado de circulação de água (BRUNETTI, 2012b, p. 46).

As melhorias na eficiência foram feitas com a introdução de novos dispositivos eletromecânicos (WANG et al., 2015) ao longo dos anos, como válvulas termostáticas inteligentes (PARK et al., 2012), bombas d'água de velocidade variável movidas por motores elétricos (LEE; JUNG, 2012; WANG, 2016; RIBEIRO et al., 2007) e bombas com embreagem 
viscosa (SCOTT, 2004).

No caso de bombas com motores elétricos é mais comum aplicá-las em veículos comerciais (PIERBURG, 2021), que podem consumir até 36,5 A de corrente elétrica com tensão máxima de 16,0 Vdc, chegando a um fluxo de 210,0 l/min com pressão 0,55 bar (TECOMOTIVE, 2021). A vantagem é poder controlar com precisão o fluxo do líquido de arrefecimento e manter constante a velocidade do rotor da bomba (impeller). A desvantagem é que não possui proteção contra falhas elétricas e sua aplicação é limitada pelo consumo de corrente. Já as bombas com embreagem viscosa possuem alto valor de produção dada a complexidade em se manusear o elemento viscoso. Portanto, devido à limitação de potência para aplicações com motores elétricos e à complexidade na produção de bombas com a tecnologia dos acoplamentos viscosos, tem-se buscado uma alternativa tecnológica capaz de proporcionar baixo consumo de corrente elétrica e permitir flexibilidade no controle do fluxo do líquido refrigerante (fluido refrigerante).

A forma encontrada para reduzir o consumo de energia elétrica foi manter o dispositivo conectado ao motor do veículo (virabrequim) por uma correia e ajustar magneticamente a quantidade de torque transmitido à bomba d'água. $O$ fato da polia ser confeccionada com material ferromagnético permite, além de alojar a correia para receber a força mecânica, a circulação das correntes induzidas em sua face interna, criando assim a região ativa do acoplamento. É devido à interação entre o campo magnético gerado pelas correntes induzidas e o campo presente nos polos magnéticos do rotor de acoplamento que ocorre a transmissão do torque.

Neste contexto e com o objetivo de dar uma visão geral sobre o sistema de arrefecimento, a figura 1 destaca os principais elementos de um motor alternativo de combustão interna e seus respetivos nomes são, então, apresentados pela Tabela 1. Pela figura, nota-se o posicionamento da bomba d'água (1) próxima do ventilador (26) e da válvula termostática (2). A transmissão da energia mecânica para a bomba d'água se faz por uma correia solidária ao movimento do virabrequim (18). Este, por sua vez, está conectado ao pistão (31) através da biela (20). A energia consumida pela bomba d'água, portanto, é calculada a partir da rotação $\left(\mathrm{n}_{r}\right)$ de sua polia e do torque $(T)$, cujo valor relaciona-se diretamente com a pressão e vazão do sistema em função do circuito imposto ao líquido refrigerante (fluido refrigerante B0401065-GM6277 misturado com água com relação de 1:2). Desta forma, qualquer variação na velocidade do motor de combustão interna é transmitida à polia da bomba d'água, refletindo assim na variação da vazão e pressão do sistema fornecida pela 
bomba d'água.
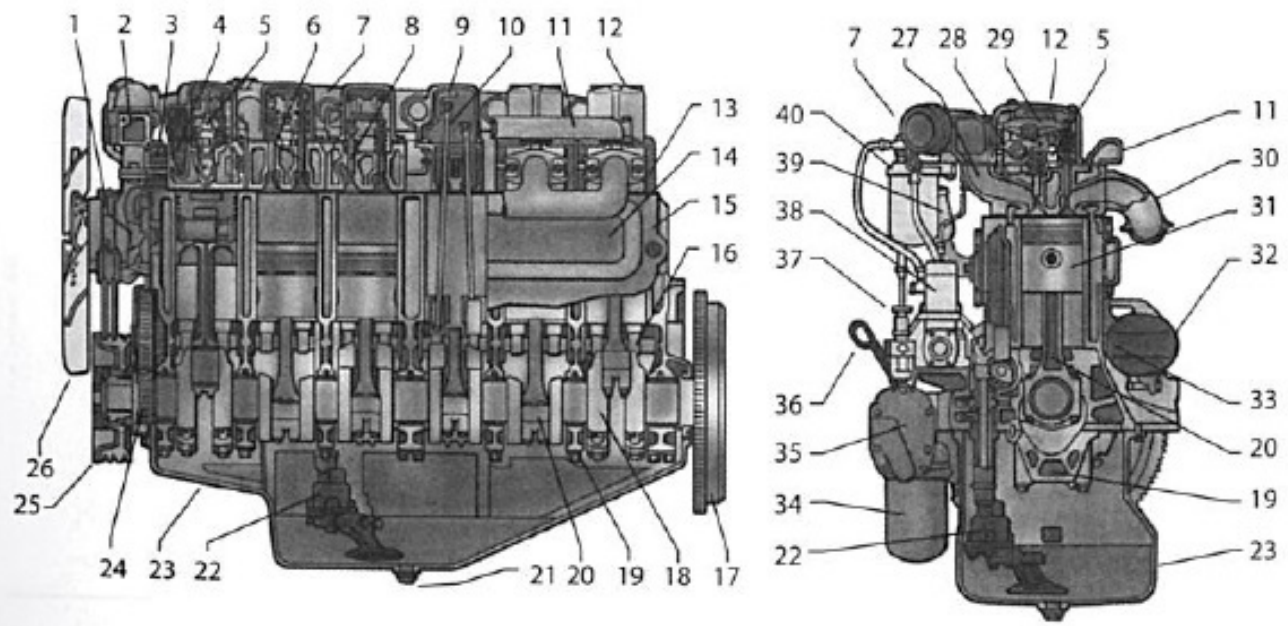

Figura 1 - Motor de combustão interna alternativo.

Fonte: (BRUNETTI, 2012b, p. 29)

Tabela 1 - Principais componentes do motor alternativo.

\begin{tabular}{|l|l|l|}
\hline 1.Bomba-d'água & 2.Válvula termostática & 3.Compressor de ar \\
\hline 4.Duto de admissão & 5.Injetor de combustível & 6.Válvula de escapamento \\
\hline 7.Coletor de admissão & 8.Válvula de admissão & 9. Linha de combustível \\
\hline 10.Haste de válvula & 11.Duto de água & 12.Tampa de combustível \\
\hline 13.Cabeçote & 14.Tampa lateral & 15.Bloco \\
\hline 16.Eixo comando de válvula & 17.Volante & 18.Virabrequim \\
\hline 19.Capa de mancal & 20.Biela & 21.Bujão de cárter \\
\hline $\begin{array}{l}\text { 22.Bomba de óleo } \\
\text { 25.Amortecedor do virabre- } \\
\text { quim }\end{array}$ & 23.Cárter & $\begin{array}{l}\text { 24.Engrenagem do } \\
\text { quim }\end{array}$ \\
\hline $\begin{array}{l}\text { 28.Balancim da válvula de ad- } \\
\text { missão }\end{array}$ & $\begin{array}{l}\text { 29.Balancim da válvula de es- } \\
\text { capamento de admissão }\end{array}$ & 30.Coletor de escapamento \\
\hline 31.Pistão & 32.Motor de partida & 33.Dreno de água \\
\hline 34.Filtro de óleo & 35.Radiador de óleo & 36.Vareta de nível de óleo \\
\hline $\begin{array}{l}\text { 37.Bomba manual de combus- } \\
\text { tível }\end{array}$ & $\begin{array}{l}\text { 38.Bomba injetora de combus- } \\
\text { tível }\end{array}$ & 39. Respiro do cárter \\
\hline 40.Filtro de combustível & & \\
\hline
\end{tabular}

Fonte: (BRUNETTI, 2012b, p. 29)

A conexão entre o virabrequim e a bomba d'água é melhor apresentada pela figura $2^{1}$, onde nota-se a conexão feita pela correia entre as polias dos dispositivos que dependem da potência mecânica fornecida pela combustão interna. Destacam-se como exemplo de dispositivos que se conectam ao virabrequim o alternador e o ventilador.

1 Disponível em: <http://www.howacarworks.com/cooling-systems/replacing-a-water-pump>. Acesso em: 22 ago. 2021. 


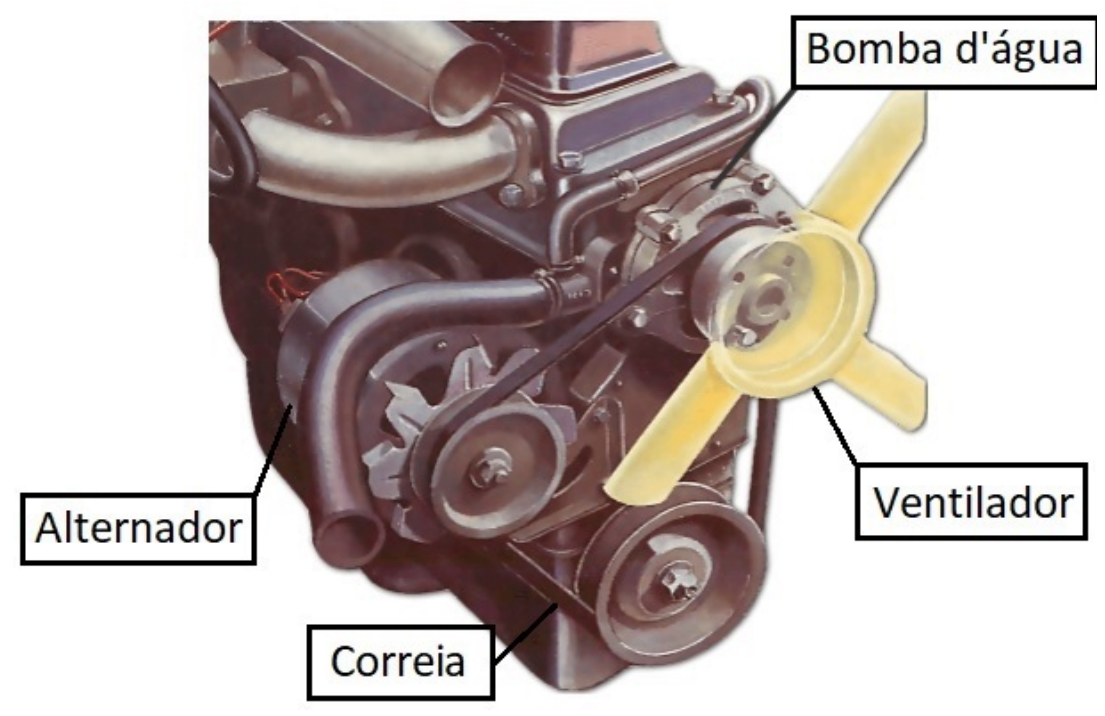

Figura 2 - Transferência de potência mecânica por meio de uma correia e polias.

Fonte: Página do site "howacarworks.com".

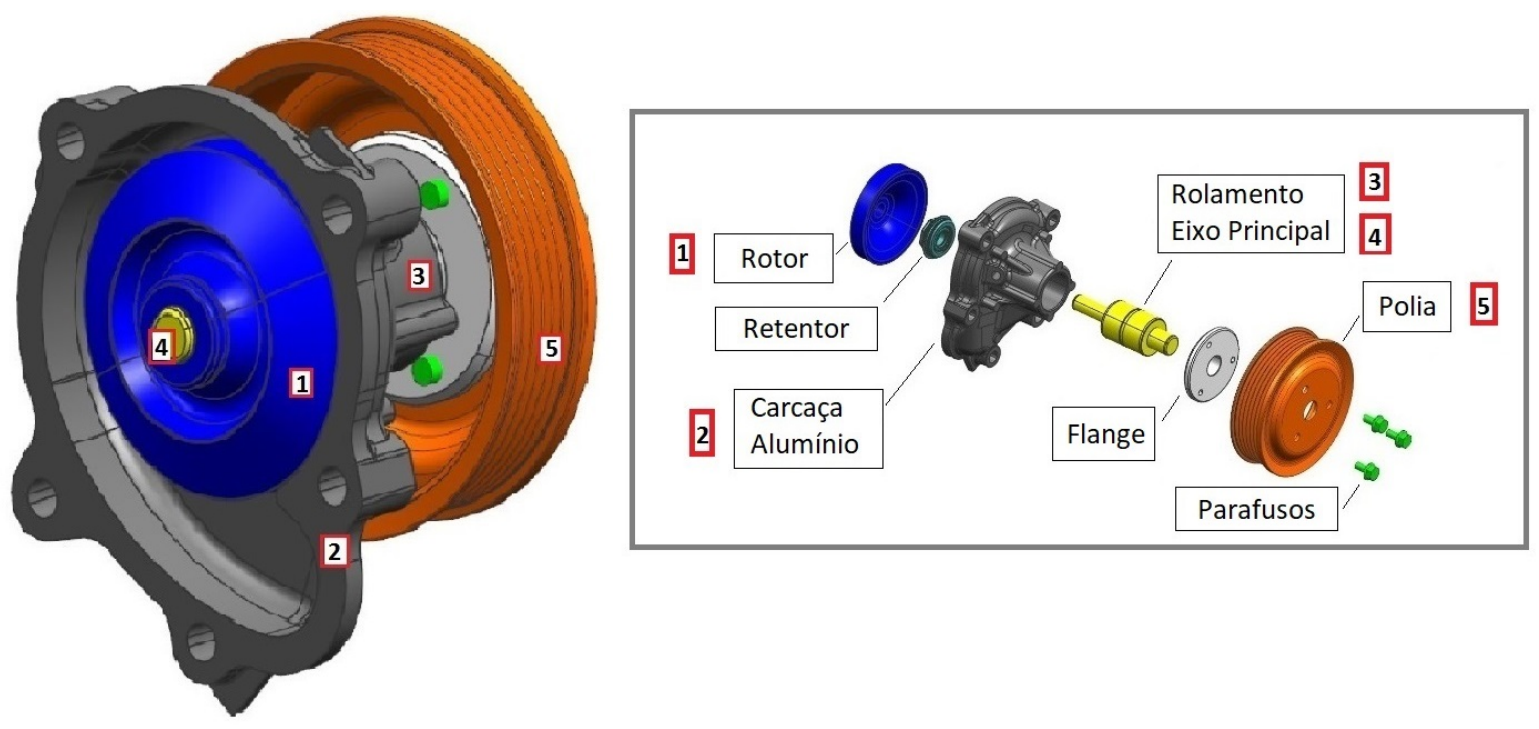

Figura 3 - Bomba d'água utilizada como referência.

A figura 3 apresenta os principais elementos de uma bomba d'água convencional. Ela é composta pela polia, rolamento, retentor e rotor basicamente. Como mencionado anteriormente, a polia é solidária ao movimento do virabrequim e sua velocidade é proporcional à velocidade de giro do motor. Os gráficos apresentados pelas figuras 4a e 4b mostram o comportamento do torque e vazão em função da velocidade de giro da polia, cuja relação com a velocidade do motor é de $1: 1,47$ para este caso. Já os gráficos apresentados pelas figuras $5 a$ e $5 b$ mostram o comportamento da pressão do sistema e do torque, ambos em função da vazão. Vale ressaltar que os dados apresentados são característicos de um item em produção e refletem a demanda de energia máxima característica desse projeto. 


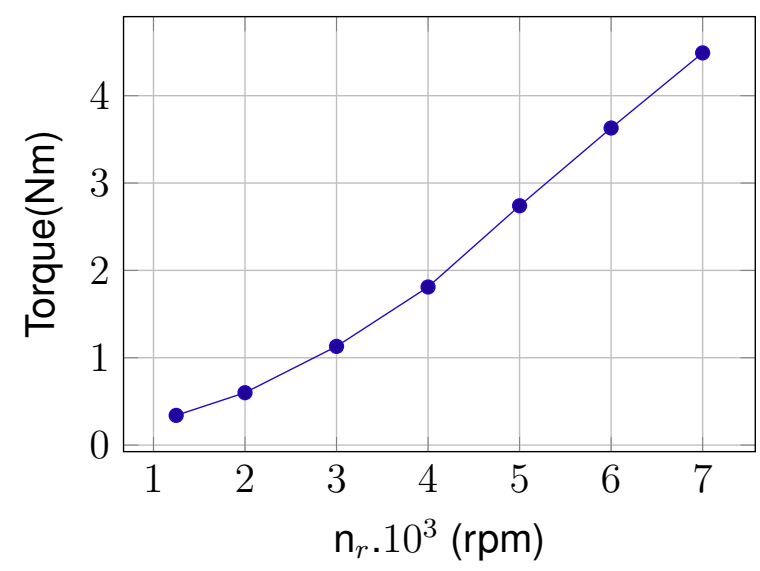

(a) Torque em função da velocidade da polia

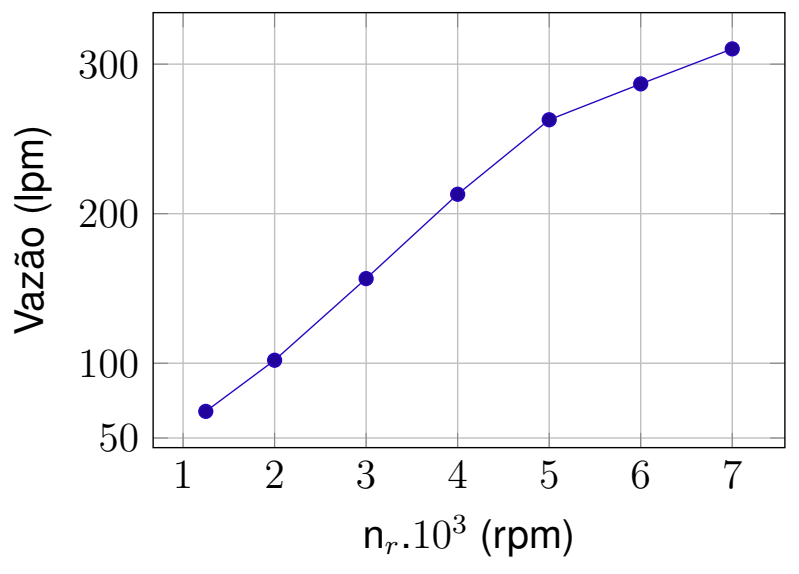

(b) Vazão em função da velocidade da polia

Figura 4 - Comportamento da bomba d'água com o fluido refrigerante (B0401065-GM6277) a $25^{\circ} \mathrm{C}$ e em função da velocidade da polia (potência de entrada).

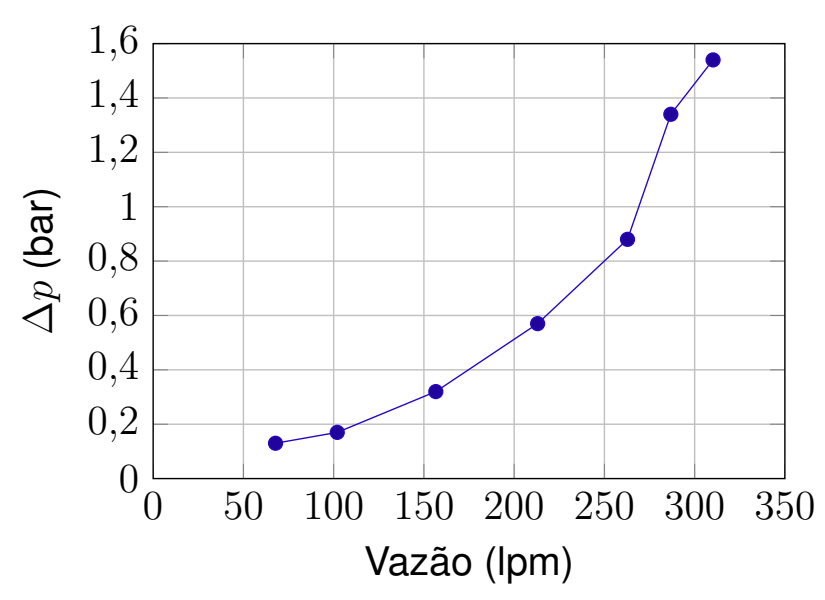

(a) Diferencial de pressão em função da vazão

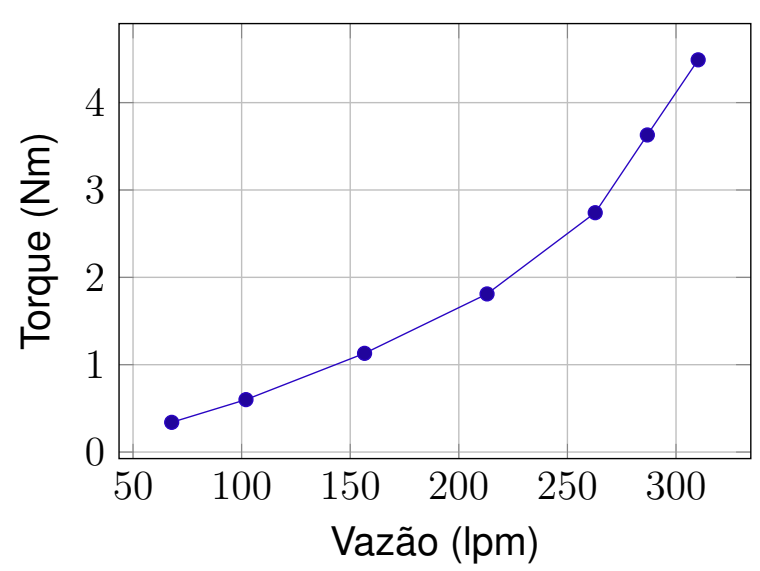

(b) Torque em função da vazão

Figura 5 - Comportamento da bomba d'água com o fluido refrigerante (B0401065-GM6277) a $25^{\circ} \mathrm{C}$ e em função da vazão (potência de saída).

É com base nessas características do sistema e pelo comportamento da bomba d'água mecânica que ocorre a necessidade em desenvolver uma bomba de vazão variável. Em alguns momentos consome-se mais energia do motor de combustão do que o necessário. Nem sempre quando o motor está com rotação de 7000 rpm, por exemplo, deseja-se a vazão total (cerca de $310 \mathrm{lpm}$ ). Ajustar essa potência consumida conforme a demanda tem sido, nos últimos anos, um grande desafio para a indústria.

O objetivo deste trabalho é desenvolver uma alternativa tecnológica capaz de ser incorporada à bomba d'água e que possibilite o controle do torque transmitido do motor de combustão ao eixo da bomba. Ao controlar o torque ajusta-se, consequentemente, a velocidade do rotor da bomba com influência direta na vazão e pressão do sistema. O ponto de partida foi a leitura de um dos artigos publicados por Davies (DAVIES, 1963), que trata 
do equacionamento dos acoplamentos magnéticos por corrente de Foucault. A principal característica deste tipo de acoplamento é que o controle da transferência do torque entre o eixo de entrada e o eixo de saída se dá pelo ajuste da corrente elétrica fornecida ao eletroímã, adotando uma arquitetura similar à máquina de Lundell (MUKAl et al., 1999). A transferência de energia ocorre pelos efeitos do magnetismo gerado e, portanto, elimina assim qualquer contato mecânico entre eixos.

Composto por sete capítulos, este trabalho inicia-se no capítulo 2, apresentando com maiores detalhes o sistema de arrefecimento e seus principais componentes. Neste sentido, alguns projetos oferecidos como alternativa ao mercado para melhorar a eficiência do sistema e que serviram de base para este trabalho também são apresentados como forma de contextualizar a solução proposta.

O capítulo 3 faz uma revisão bibliográfica focada no modelamento matemático do comportamento dos acoplamentos magnéticos por corrente de Foucault. Esse modelamento é fundamental para a compreensão dos efeitos do fluxo magnético que circula nos elementos da máquina proposta. Outro objetivo é a construção de ferramentas que possibilitem o correto dimensionamento das máquinas em função dos requisitos levantados conforme a necessidade de cada aplicação.

Uma vez conhecidas as características fundamentais da topologia estudada, o capítulo 4 apresenta o conceito criado (BRONZERI et al., 2019) e seu modelamento, tendo como base uma bomba d'água mecânica em produção. A proposta em adaptar uma bomba com o comportamento conhecido é utilizar as limitações físicas impostas por sua aplicação e definir uma linha base (baseline) para o projeto, tendo em vista suas características funcionais.

Partindo, portanto, de uma definição construtiva dos elementos da máquina, o capítulo 5 trata da simulação em duas dimensões, considerando os aspectos mais importantes de sua topologia, que refletem diretamente a transmissão de energia entre eixos. Para essa análise, simplificações foram necessárias dada a sua complexa geometria.

O capítulo 6 apresenta a montagem do protótipo a partir do modelo apresentado na etapa de conceito, bem como os resultados de desempenho obtidos para dois valores de potência elétrica, seguindo o formato adotado na etapa de simulação por elementos finitos. Desta forma, pôde-se comprovar que o modelo simplificado adotado para simulação apresenta boa previsibilidade comportamental quando comparado com os dados obtidos a partir do protótipo. Por fim, toda a análise em relação ao desempenho tem como base 0 
comportamento da bomba d'água original. O capítulo termina apresentando evidências que comprovam a controlabilidade do dispositivo.

O capítulo 7 apresenta as conclusões deste trabalho, comparando os resultados obtidos durante o levantamento do desempenho da bomba de vazão variável, com o dados característicos das bombas elétricas encontradas no mercado. Essa comparação mostra um ótimo cenário de economia de potência elétrica ao aplicar bombas com acoplamento magnético. O capítulo termina ressaltando os desafios para os desenvolvimentos futuros, identificando os principais aspectos para melhoria. Com base no ferramental construído ao longo deste trabalho, propostas podem ser estudadas visando melhorar o desempenho da máquina (BRONZERI; CHABU, 2021). 



\section{O Sistema de arrefecimento}

O sistema de arrefecimento vem sofrendo modificações ao longo do tempo, incorporando cada vez mais dispositivos com certo grau de complexidade e controlabilidade. Isso tem se intensificado com o aumento das exigências internacionais relacionadas aos níveis de emissões de gases poluentes, obrigando as montadoras a desenvolverem sistemas mais eficientes e, consequentemente, a incorporarem dispositivos mais complexos.

Este capítulo apresenta a composição do sistema de arrefecimento, seus principais componentes e alguns dispositivos desenvolvidos nos últimos anos. O objetivo é posicionar este trabalho no atual cenário, onde o desenvolvimento tecnológico é impulsionado pela necessidade em se reduzir as emissões de gases poluentes.

\subsection{Resfriamento forçado por circulação de água}

O fluido para arrefecimento do motor é, na verdade, um composto químico (etileno glicol e aditivos) diluído com água a uma taxa equivalente a 50\%, normalmente. Sua circulação no motor é promovida por uma bomba d'água centrífuga, que pode ser mecânica - como apresentada pela figura 3 - ou elétrica, impulsionada por um motor elétrico sem escovas (BLDC). Esta última é mais aplicada em circuitos secundários ou motores menores, como motocicletas. O circuito pelo qual passa o fluido de arrefecimento é representado pela figura 6 , onde destacam-se o elemento radiador, por onde ocorre a retirada de calor do fluido, e a válvula termostática.

Como a bomba d'água mecânica é passiva e solidária ao motor de combustão, a válvula termostática foi incorporada ao sistema como forma de controlar a temperatura. Sua função é controlar o fluxo de fluido que circula pelo radiador em função da temperatura de operação e sua aplicação é fundamental durante a partida a frio, período em que o motor precisa atingir rapidamente sua temperatura de operação.

A partida a frio é a primeira etapa de funcionamento do motor de combustão. Representa o momento em que o motor encontra-se desligado e seu acionamento é solicitado. $O$ tempo para atingir a temperatura de $90^{\circ} \mathrm{C}$ representa um período em que o motor opera em uma faixa de baixo rendimento. Neste período, a bomba d'água trabalha contra a necessidade de aquecimento do motor. A válvula termostática não permite que o fluido chegue 
até o radiador (circuito indicado pelo item 5, figura 6), mantendo-o em um circuito fechado dentro do motor até atingir sua temperatura ideal. $O$ diagrama apresentado pela figura 7 ilustra esse comportamento.
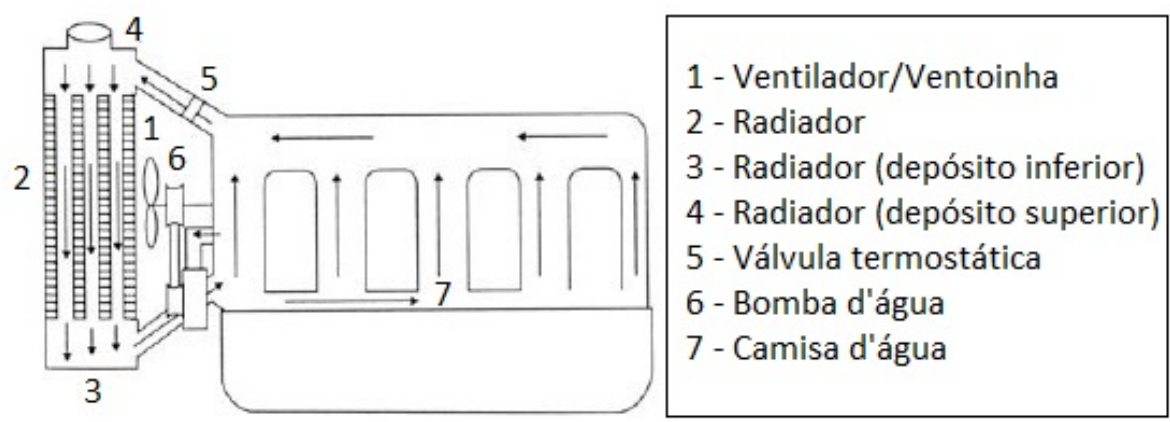

Figura 6 - Circulação forçada do líquido refrigerante.

Fonte: (BRUNETTI, 2012a, p. 389)

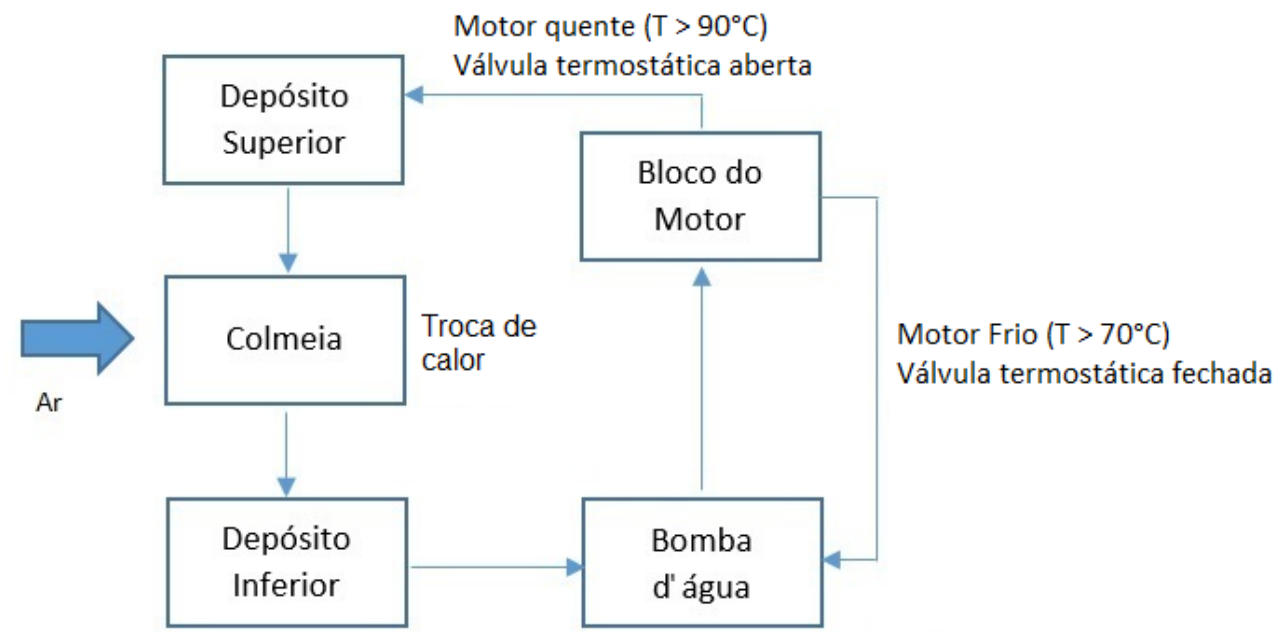

Figura 7 - Comportamento da válvula termostática em função da temperatura do motor.

Fonte: (BRUNETTI, 2012a, p. 389)

\subsection{Válvula termostática}

O conceito mais simples de válvula termostática e amplamente difundido tem como base um elemento de cera, onde a vazão resultante é proporcional à temperatura do fluido. Mais adiante poderá ser observado que este mesmo princípio também é aplicado em bombas d'água de vazão variável (embreagem viscosa).

A expansão e contração da cera em resposta à mudança de temperatura causa movimento do atuador, o que permite o controle em um sistema externo. Em termos gerais, 
as ceras são constituídas por cadeias lineares de hidrocarbonetos, os chamados n-alcanos. Essas cadeias cerosas lineares são altamente regulares e, portanto, prontamente formam cristais altamente organizados e densamente compactados. Em contraste, no estado líquido as ceras são altamente flexíveis e se expandem rapidamente consumindo mais volume. Como resultado, eles exibem inerentemente uma grande mudança dimensional entre o estado sólido e líquido, ou seja, na fusão. Essas moléculas lineares mostram uma relação direta entre o ponto de fusão e o comprimento da cadeia. Essa combinação de características permite o desenvolvimento de ceras e misturas sob medida, com a capacidade de controlar o grau de expansão a uma temperatura específica. Essas ceras de expansão projetadas podem, portanto, ser usadas como um atuador termo-mecânico, selando o composto de cera em um dispositivo fechado equipado com um atuador móvel. A expansão e contração da cera em resposta à mudança de temperatura causa movimento do atuador, o que permite o controle em um sistema externo (MACHIELSE, 2021).

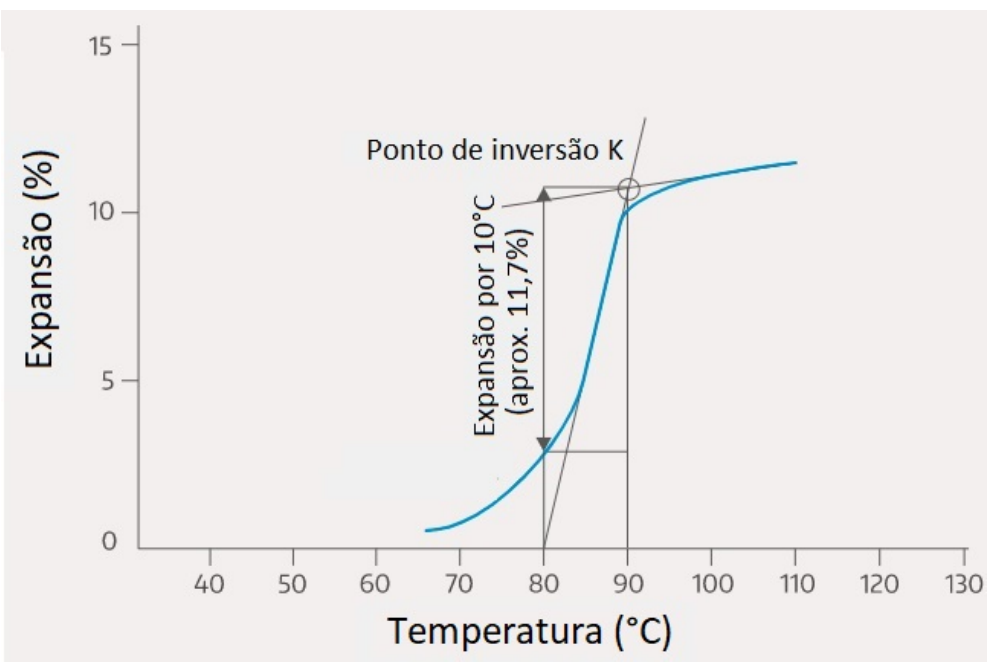

Figura 8 - Válvula termostática, funcionamento e curva característica (expansão versus temperatura), modelo DILAVESTL ${ }^{T M}$ P90.

Fonte: Paramelt

A figura $8^{1}$ ilustra o comportamento de uma válvula termostática com aplicação no setor automotivo (DILAVESTL ${ }^{T M} \mathrm{P} 90$ ), onde percebe-se a busca pela linearidade no deslocamento do atuador com uma expansão linear do volume ocupado pela cera (aproximadamente $11 \%$ ) entre $80^{\circ} \mathrm{C}$ e $90^{\circ} \mathrm{C}$ de temperatura. O ponto de inversão $\mathrm{K}$ define a temperatura em que a máxima expansão é praticamente atingida, portanto, representando

1 Disponível em:<https://www.paramelt.com/specialty-waxes/thermostat-expansion-waxes/>. Acesso em: 10 ago. 2021. 
a máxima abertura da válvula, refletindo assim na máxima vazão de fluido direcionado ao radiador.

Por depender exclusivamente do comportamento da cera em função da temperatura de operação do sistema e com a finalidade de acelerar a abertura da válvula, uma versão com uma bobina que permita aquecer o elemento de cera foi desenvolvida, vide figura $9^{2}$.

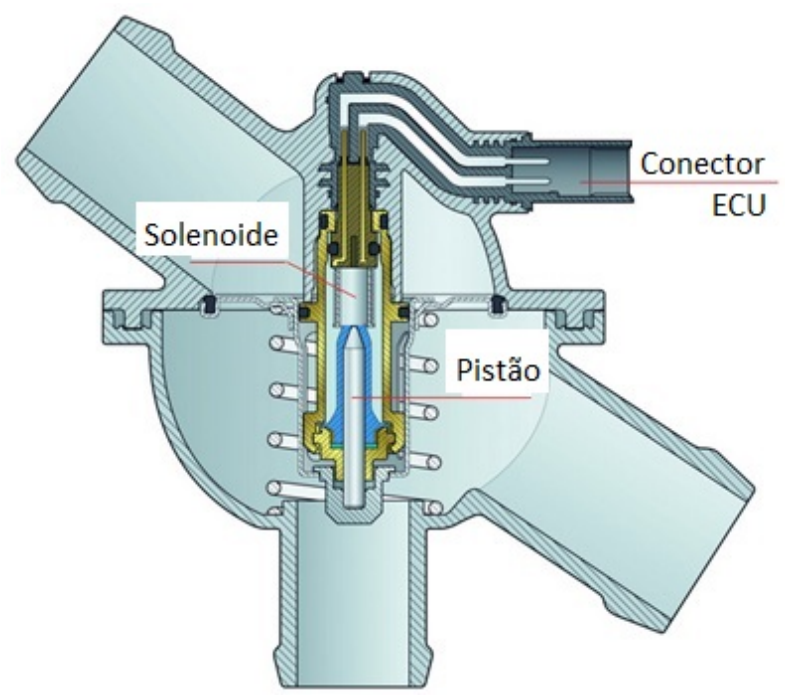

Figura 9 - Válvula termostática com elemento gerador de calor em contato com a cera. Controle da temperatura é feito pela ECU por meio de um solenoide.

Fonte: Página do site "counterman.com"

A bobina fica, portanto, submersa no elemento de cera. Isso permite controlar a válvula dependendo da demanda imposta ao veículo, como, por exemplo, um trajeto montanhoso cheio de subidas e descidas.

Ao longo do tempo outros modelos foram surgindo, com destaque para projetos com motores de passo (CREED; BRADSHAW, 1990) (válvula corpo de borboleta, vide figura 10) e por membrana (FILHO et al., 2013). A figura 11 apresenta um comparativo entre a válvula corpo de borboleta versus a válvula termostática com elemento de cera. Nota-se que a temperatura ideal é atingida cerca 7 minutos depois da partida a frio, enquanto que no sistema com a válvula termostática esse tempo é de aproximadamente 20 minutos. Ao manter a válvula totalmente fechada durante o ciclo de aquecimento (warm-up) e não permitir que o fluido seja direcionado ao radiador, a elevação da temperatura operacional ocorre em uma velocidade superior, melhorando o rendimento do motor. A figura 10 apresenta a estrutura mecânica da invenção, sendo a posição (96) a localização do motor de passo e a 
posição (98) a engrenagem para transferência do torque.

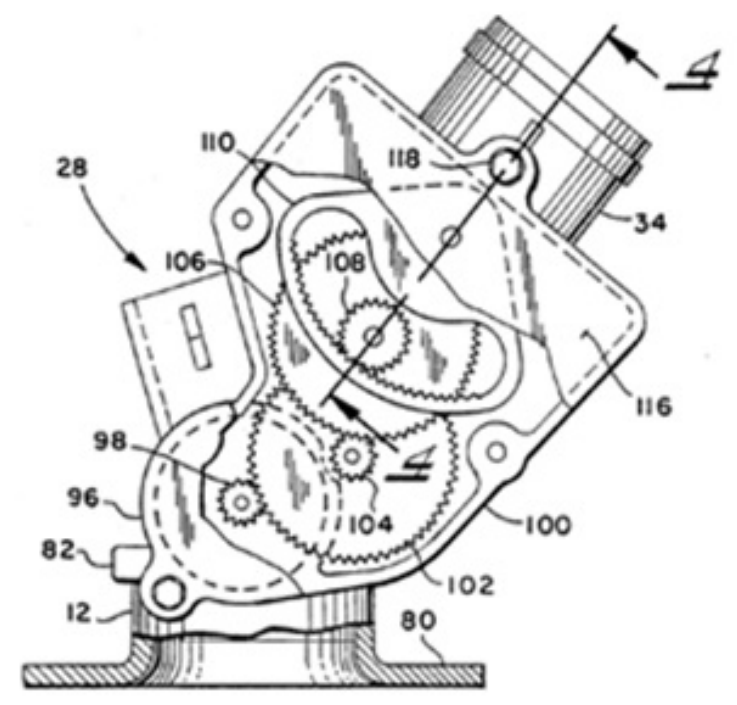

Figura 10 - Válvula termostática com corpo de borboleta.

Fonte: (Google Patents, US Patent 4,930,455)

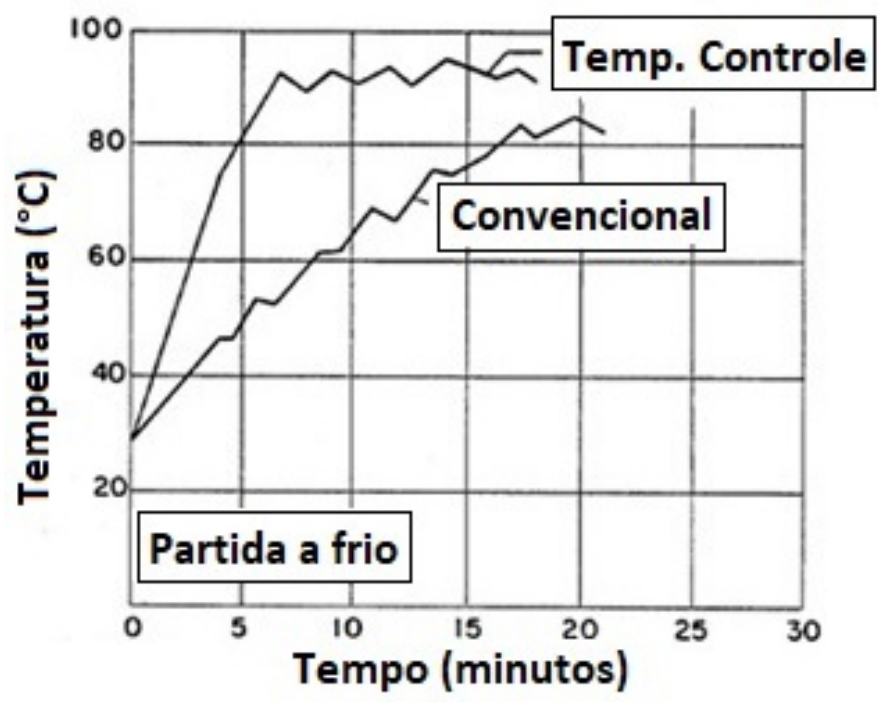

Figura 11 - Comparativo entre válvula corpo de borboleta e convencional para um motor de seis cilindros.

Fonte: (Google Patents, US Patent 4,930,455)

Já o conceito de válvulas por membrana (FILHO et al., 2013) é completamente diferente, vide figura 12. Seu funcionamento é baseado no controle da pressão na câmara de entrada (74). Assim como nos outros modelos, a vazão de saída é proporcional a quantidade fornecida pela bomba d'água.

Seu controle é feito por uma válvula solenoide (130). Quando se pretende interromper a passagem do fluido, a solenoide é acionada fechando a passagem alternativa (84). Desta 


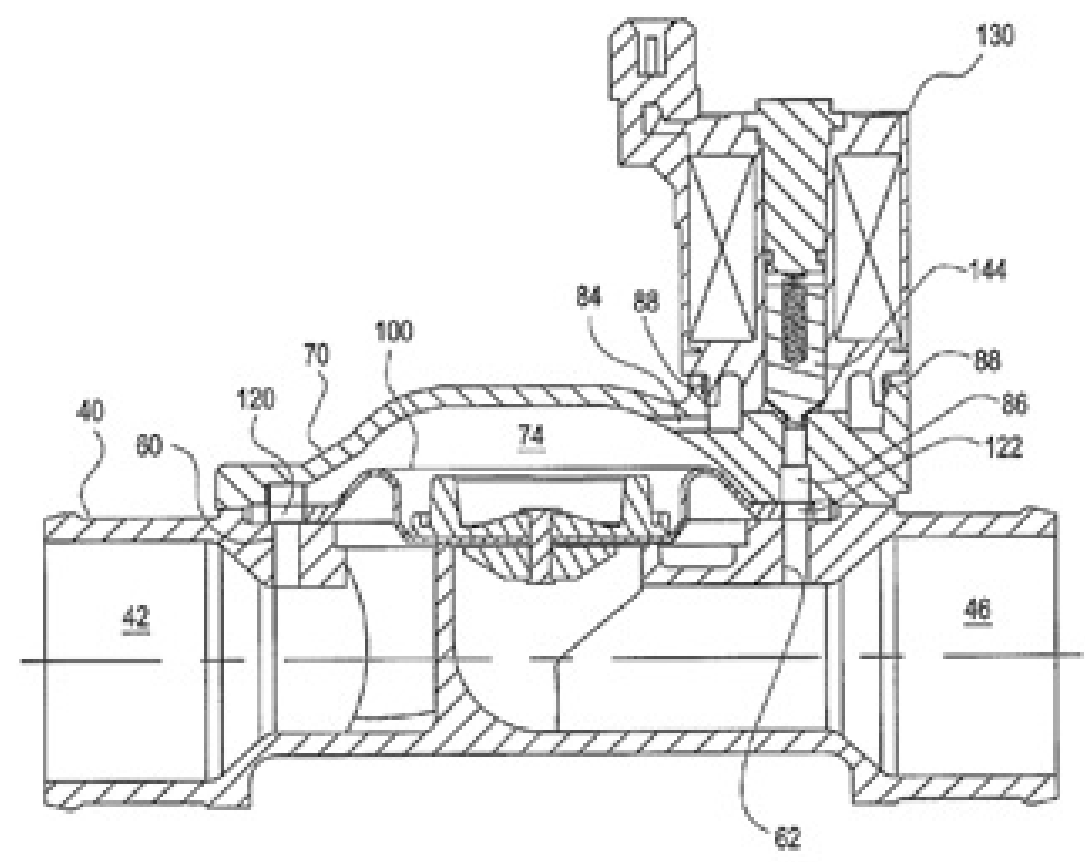

Figura 12 - Válvula (ON/OFF) proposta pela Melling do Brasil.

Fonte: (Google Patents, US Patent 4,930,455)

forma, a pressão na câmara (74) aumenta, empurrando a membrana (100) para baixo. Quando se pretende abrir a válvula termostática, o solenoide é então desligado, permitindo que o fluido passe pelo caminho alternativo (84), aliviando a pressão na câmara de entrada (74). Essa passagem alternativa é um caminho para o fluido que liga a câmara (74) à saída (46).

Esse modelo (ON/OFF), cuja patente foi concedida em 2013, limita-se a abrir ou fechar a passagem do fluido refrigerante. Nesta configuração não é possível controlar diferentes vazões e, com o objetivo de concorrer em aplicações onde os ajustes são necessários, algumas adaptações foram sugeridas no projeto original.

Visando então proporcionar o controle para fornecer diferentes vazões, um novo projeto foi proposto, vide figura 13 (FILHO et al., 2016), gerando assim um novo requerimento de patente. O objetivo, portanto, passou a ser o de controlar a posição intermediária da membrana entre as posições de máxima vazão e fechamento. Para tanto, adicionou-se ao projeto original um sensor magnético por efeito hall (150) e um ímã permanente. A distância entre o sensor e o ímã denominou-se TARGET (160). Esse nome se dá pelo fato de que o objetivo do sistema eletrônico é controlar a distância entre o sensor e o ímã permanente.

O controle da posição é possível ajustando a pressão na câmara de entrada (74) por meio do acionamento da válvula solenoide (130). O controle eletrônico pode ser tanto 


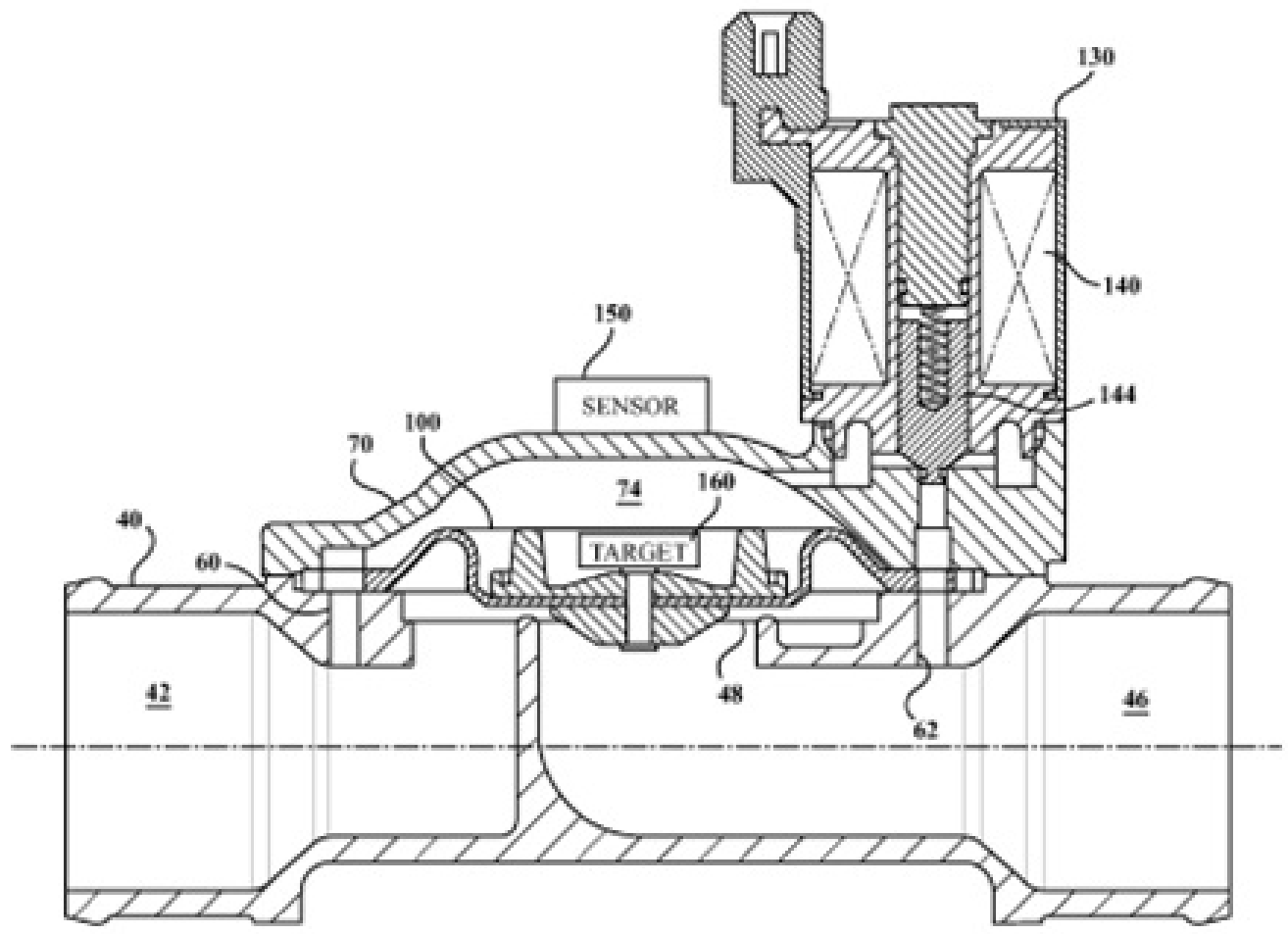

Figura 13 - Novo projeto proposto pela Melling do Brasil, que permite controlar diferentes vazões, por meio do controle da posição da membrana.

Fonte: (Google Patents, US Patent 4,930,455)

feito pela unidade de controle (ECU), quanto incorporado ao produto, feito por meio da transformação da tensão de saída do sensor hall em posição. Controlando-se a posição da membrana, de forma direta, é possível controlar a vazão.

Para explicar como funciona esta proposta, a figura 14 ilustra três momentos diferentes, sendo: momento $A$ quando a válvula está completamente aberta (máxima vazão), $B$ quando a válvula está completamente fechada (vazão zero) e $C$ quando o controlador está mantendo a membrana em uma determinada posição (vazão intermediária). Um exemplo da calibração feita para o sensor hall é apresentado na figura 15. As figuras 16 e 17 apresentam resultados de desempenho para uma vazão máxima equivalente a 1,9 Ipm (vazão imposta pela bomba d'água).

Olhando apenas para as válvulas termostáticas apresentadas, nota-se claramente a busca por soluções mais eficientes, que permitam um controle mais efetivo da vazão do fluido refrigerante, para assim melhor ajustar a temperatura do motor.

A aplicação das válvulas está relacionada ao fato das bombas d'água não permitirem o ajuste de sua velocidade, fornecendo uma vazão de forma desproporcional à demanda. 

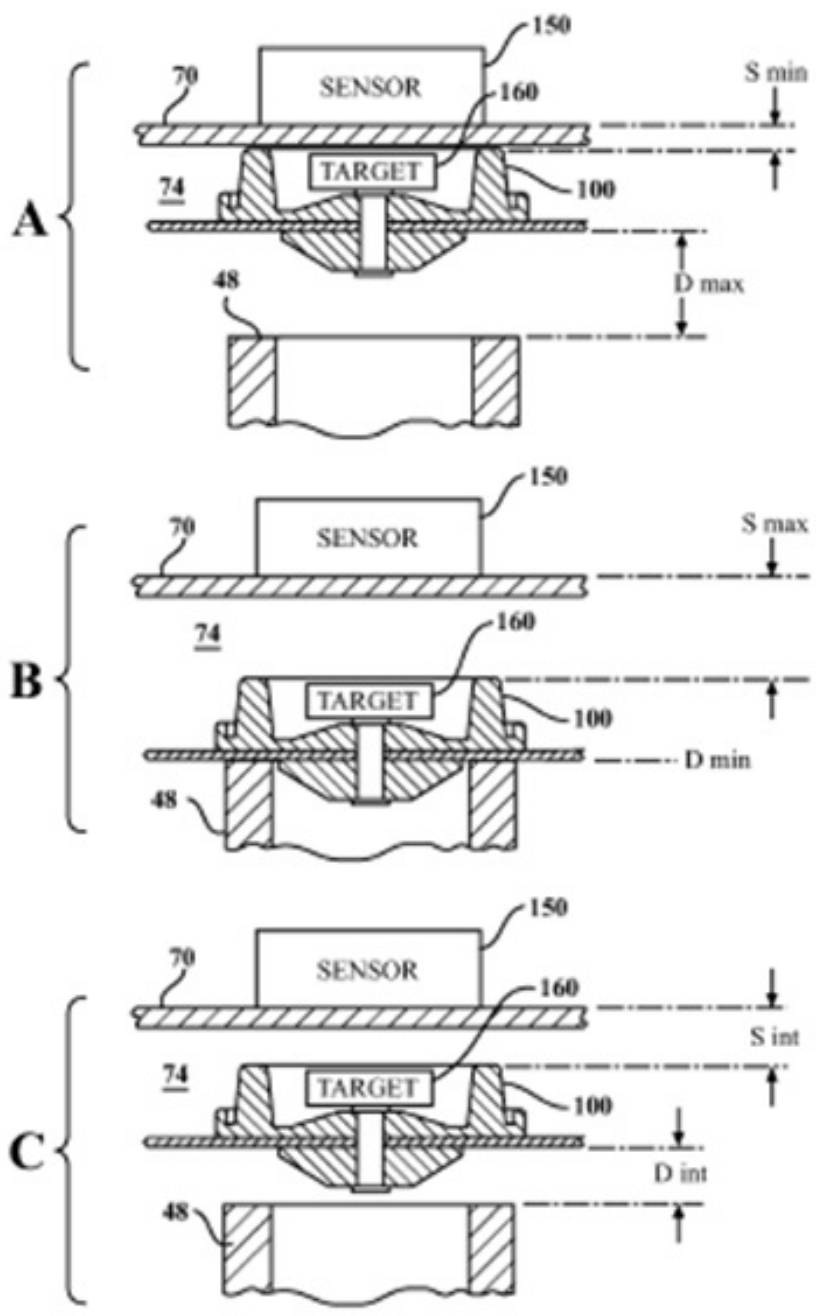

Figura 14 - llustração do controle da posição da membrana para diferentes momentos.

Fonte: (Google Patents, US Patent App. 14/914,735)

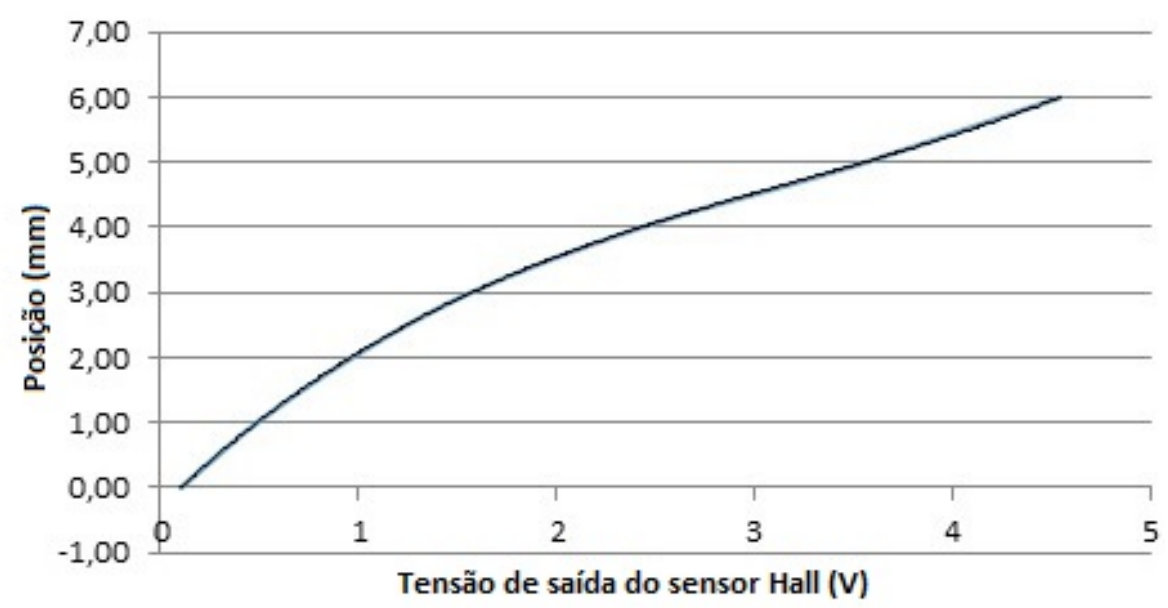

Figura 15 - Calibração do sensor hall para aproveitar toda faixa de operação.

Fonte: (Google Patents, US Patent App. 14/914,735) 


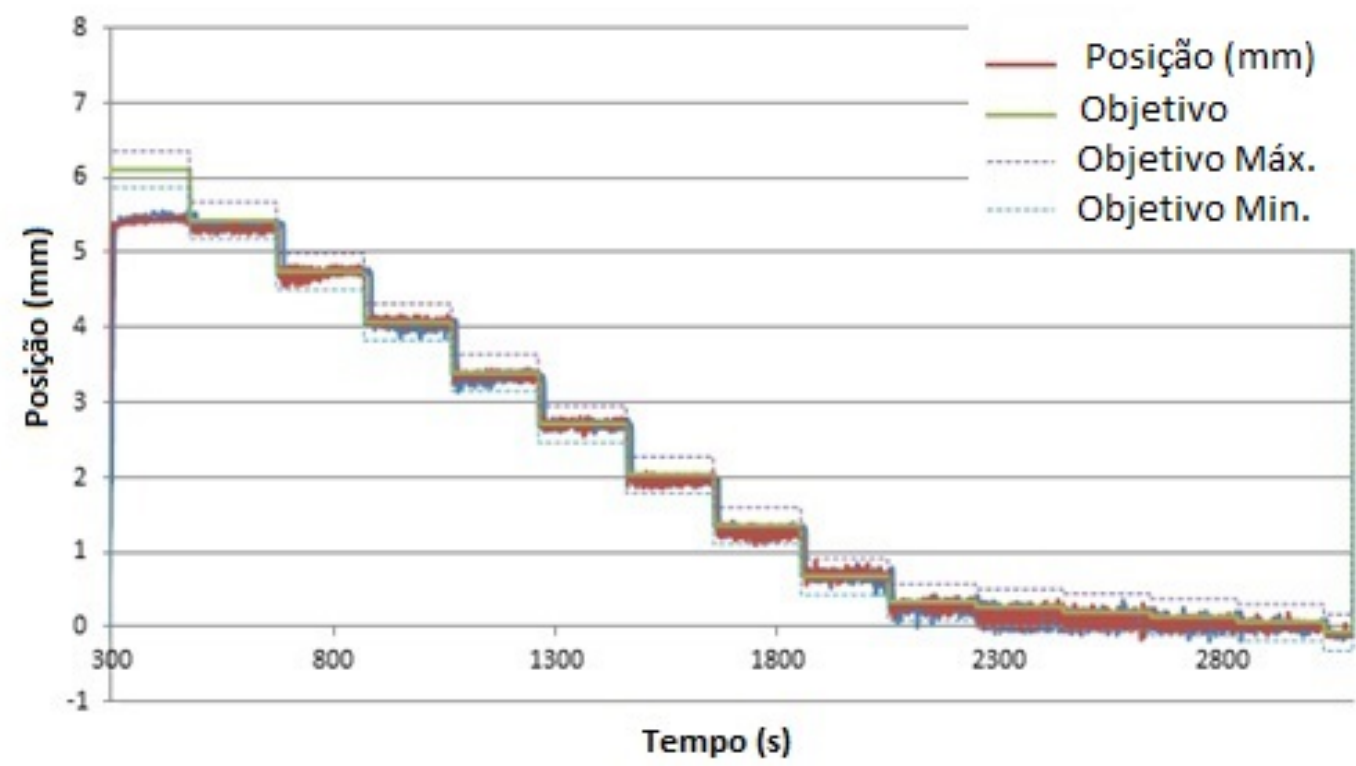

Figura 16 - Controle da posição da membrana com base no objetivo especificado pela ECU.

Fonte: (Google Patents, US Patent App. 14/914,735)

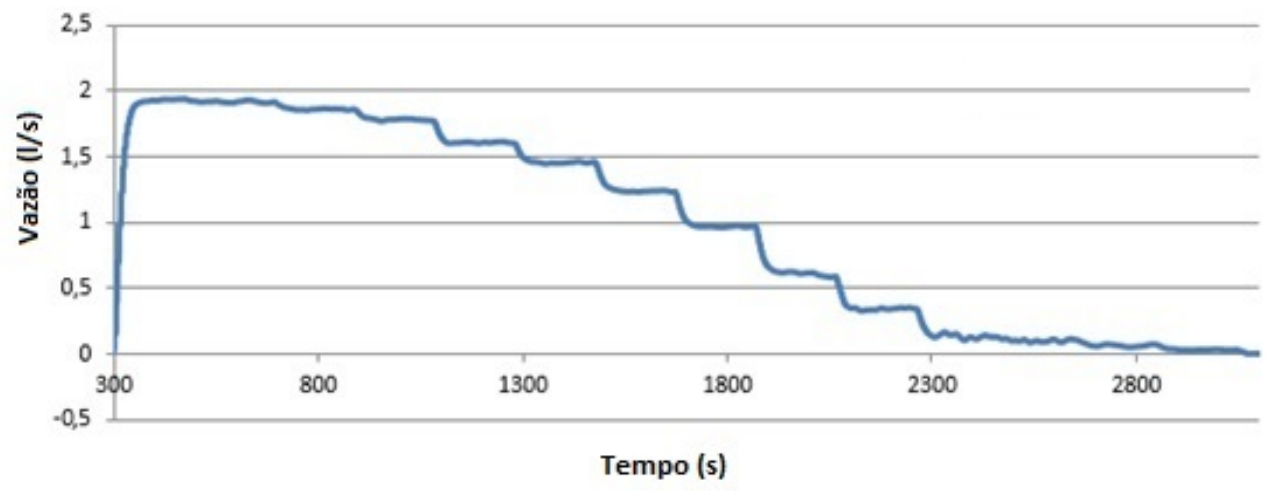

Figura 17 - Vazão como resultado do controle da posição da membrana. Fonte: (Google Patents, US Patent App. 14/914,735)

A seguir serão apresentados alguns projetos de bombas d'água de vazão variável, feitos visando aprimorar este comportamento.

\subsection{Bomba d'água}

Da mesma forma que encontram-se diversas propostas para as válvulas termostáticas, uma quantidade enorme de propostas para as bombas d'água também sugiram nestes últimos anos. Sua função primária torna desafiadora a proposta de criar um dispositivo para um bombeamento ajustável. Por conta da alta potência mecânica consumida (cerca de 3000 Watts), bombas com embreagem viscosa são a aposta de fabricantes como a 
BorgWarner para aplicações heavyduty, como caminhões por exemplo. Estas bombas, por sua vez, possuem alto custo agregado pois utilizam silicone ${ }^{3}$ como o material para contato entre as partes mecânicas (SCOTT, 2004). O próprio desenvolvimento de um silicone apropriado para as condições extremas exigidas por aplicações automotivas, seu manuseio e a estrutura da máquina para funcionar pelo atrito entre o silicone e os eixos de entrada e saída, elevam o custo de desenvolvimento dada a alta complexidade.

Em paralelo ao surgimento de bombas puramente elétricas (PARK et al., 2010) (LEE; JUNG, 2012) (HARRIS et al., 2002), consideradas o estado da arte, bombas ON/OFF que utilizam embreagem eletromagnética também conquistaram algum mercado. A Melling do Brasil (atual Movent) possui uma patente concedida para este tipo de dispositivo (MEIRA et al., 2014), que utiliza disco de fricção para acoplamento acionado magneticamente, vide figura 18, item (70). O torque para bombeamento é transferido da polia para o eixo (24), quando a embreagem está acoplada.
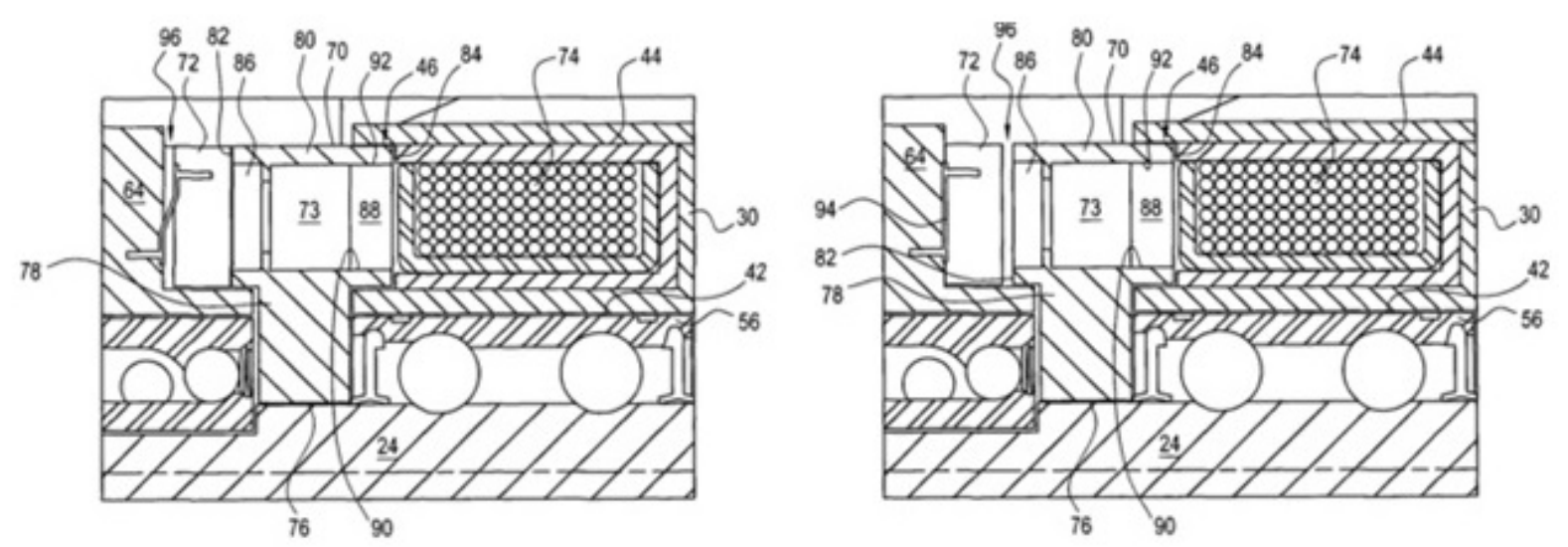

Figura 18 - Configuração para acoplamento (à esquerda) e desacoplamento (à direita). Fonte: (Google Patents, US Patent 8,714,939)

Resumidamente, o sistema de embreagem eletromagnética inclui um disco de fricção (70), um anel de embreagem (72), ímãs permanentes (73), mola (94) e um solenoide (74). Quando não há energia no solenoide, o sistema está acoplado, vide figura 18 à esquerda. Ao energizar a bobina, o campo magnético do ímã (73) é anulado, prevalecendo então a força da mola (94), desacoplando o sistema, vide figura 18 à direita.

O principal ponto negativo desta tecnologia é o desgaste mecânico, porém possui a característica de proteção contra panes elétricas (fail-safe), onde caso ocorra uma falha no sistema elétrico, a bomba permanecerá acoplada.

3 <https://en.wikipedia.org/wiki/DOT_5> 
Neste contexto são inúmeras as variações encontradas em patentes publicadas para bombas de vazão variável. A maioria utiliza-se de algum elemento mecânico, como o disco de fricção ou mola. A patente que mais chamou a atenção até o presente momento foi concedida em 2005 (FALLER; WOLF, 2005) e é referenciada pela patente da Melling (MEIRA et al., 2014). As figuras 19 e 20 mostram o projeto com detalhes, sendo que a tabela 2 apresenta a função de cada componente.

O acoplamento por corrente de Foucault é composto por um disco anelar de aço fundido presente na roda da ventoinha (feita de alumínio) e ímãs permanentes (distribuídos de forma anelar), que estão localizados sobre a polia. Não há contato entre os ímãs e a roda da ventoinha, portanto há um pequeno entreferro entre as partes. Assim o torque é transmitido entre os ímãs e o disco anelar, quando há movimento da polia.

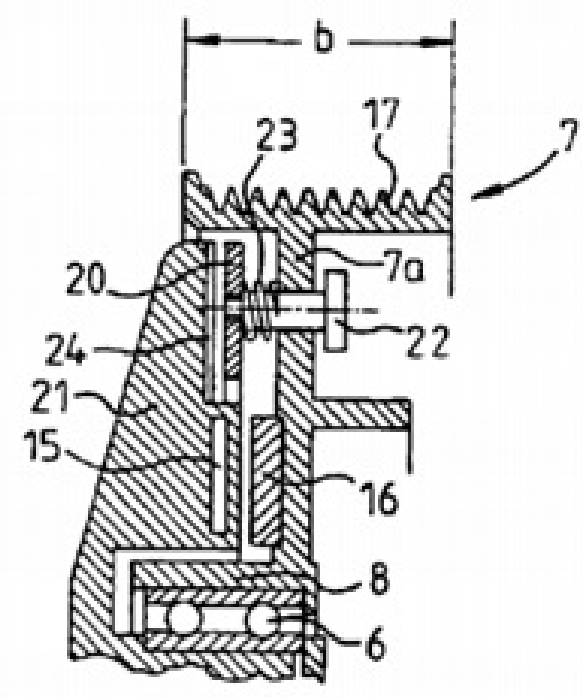

Figura 19 - Vista parcial seccionada detalhando o disco de fricção, a polia da correia e o disco da ventoinha.

Fonte: (Google Patents, US Patent 6,915,887)

Sabe-se que existe um escorregamento no eixo que movimenta a bomba. Porém, a velocidade resultante é suficiente para operar a bomba d'água de tal forma que garanta uma vazão do fluido refrigerante suficiente para muitos casos.

Existindo a necessidade de uma velocidade mais elevada para a bomba d'água, uma corrente então é aplicada na bobina. Como resultado, ocorre a atração magnética do disco anelar de armadura. Com isso, a mesma velocidade presente na polia agora movimenta tanto a bomba d'água quanto a roda da ventoinha, uma vez que a força magnética vence a força de compressão da mola. O torque assim é transmitido por contato. 


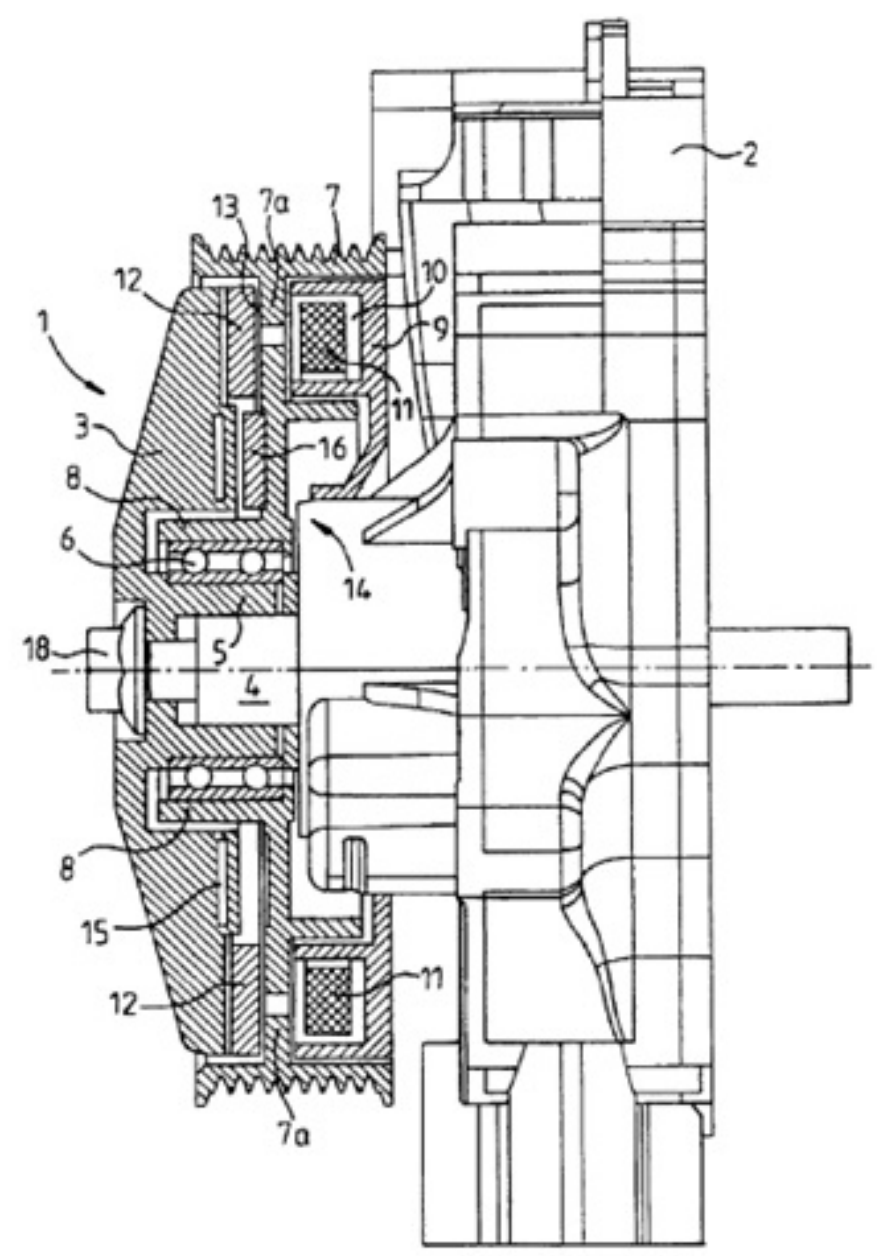

Figura 20 - Bomba de vazão variável proposta por Faller, que une fricção e magnetismo.

Fonte: (Google Patents, US Patent 6,915,887)

Tabela 2 - Principais componentes do dispositivo proposto.

\begin{tabular}{|l|l|}
\hline 1. Dispositivo & 14. Acoplamento (Foucault) \\
\hline 2. Bomba d'água & 15. Disco anelar de aço \\
\hline 3. Roda ventoinha & 16. ímã permanente \\
\hline 4. Eixo & 17. Suporte anelar correia \\
\hline 5. Bucha infeiror & 18. Parafuso \\
\hline 6. Bucha superior & 19. Disco anelar (armadura) \\
\hline 7. Polia da correia & 20. Disco anelar (armadura) \\
\hline 7a. Parte do disco anelar & 21. Roda ventoinha \\
\hline 8. Eixo oco & 22. Parafuso \\
\hline 9. Estator & 23. Mola de compressão \\
\hline 10. Alojamento da bobina & 24. Revestimento fricção \\
\hline 11. Bobina/Solenoide & \\
\hline 12. Disco anelar (armadura) & \\
\hline 13. Air gap & \\
\hline
\end{tabular}

Fonte: (Google Patents, US Patent 6,915,887) 
Dada sua configuração magnética, o sistema é projetado para uma certa demanda quando está desacoplado (corrente zero na bobina). Neste modo também opera de forma passiva em função da velocidade do motor à combustão, porém, a uma razão menor por conta do escorregamento. Quando há corrente na bobina suficiente para que ocorra o acoplamento, a máxima transmissão torque é alcançada por contato. Isso significa que não há efetivamente um ajuste que permita alterar a velocidade do dispositivo. O que ocorre na prática é a divisão da potência fornecida pela correia. No caso de falha elétrica, o sistema opera apenas por meio do acoplamento magnético por corrente de Foucault. 



\section{Acoplamento magnético por corrente de}

\section{Foucault}

Este trabalho tem como objetivo estudar e desenvolver um dispositivo capaz de ajustar a velocidade da bomba d'água por meio de um controle eletrônico, de forma magnética, evitando atritos entre peças mecânicas.

Uma pesquisa inicial mostrou que acoplamentos magnéticos por corrente de Foucault permitem transmissão de potência de forma não pulsátil. Isso significa que o torque transmitido pelo acoplamento é estável e proporcional à rotação do eixo motor, onde a taxa de transmissão é controlada eletricamente ao ajustar a corrente fornecida ao eletroímã. A utilização deste dispositivo integrado a uma bomba d'água automotiva, possibilitando ajustar eletronicamente sua vazão, buscando sempre o ponto ótimo de operação do motor de combustão, torna este trabalho inovador.

Três artigos escritos por E. J. Davies (DAVIES, 1963), (DAVIES, 1966), (DAVIES et al., 1975) e a dissertação de Mestrado apresentada pelo Dietrich (DIETRICH, 2000) serviram como base inicial dos estudos sobre os princípios e dimensionamento do dispositivo. Com base nessas informações, a ideia foi construir um dispositivo integrado a uma bomba para testes iniciais e com isso estudar o comportamento do dispositivo e suas características para controle. Em seguida, desenvolver um dispositivo mais adequado à aplicação específica, visando otimizar seu tamanho e desempenho.

\subsection{O Acoplamento por Foucault}

O acoplamento magnético ocorre a partir da indução de correntes de Foucault por meio do campo magnético gerado internamente e direcionado à região ativa da máquina, quando o eixo de entrada encontra-se em movimento. A figura 21 (DAVIES et al., 1975) mostra essa configuração de forma simplificada. Neste caso, o elemento gerador de campo magnético, denominado bobina de campo anelar (eletroímã), está ligado ao eixo de saída e a região ativa é estabelecida na face interna do cilindro, dada as suas características construtivas e magnéticas. A transmissão de torque é altamente dependente da corrente fornecida ao eletroímã. Importante ressaltar que não há dependência na polarização do 
campo magnético. Asim, o sentido da corrente elétrica imposta ao eletroímã para essa topologia é indiferente.

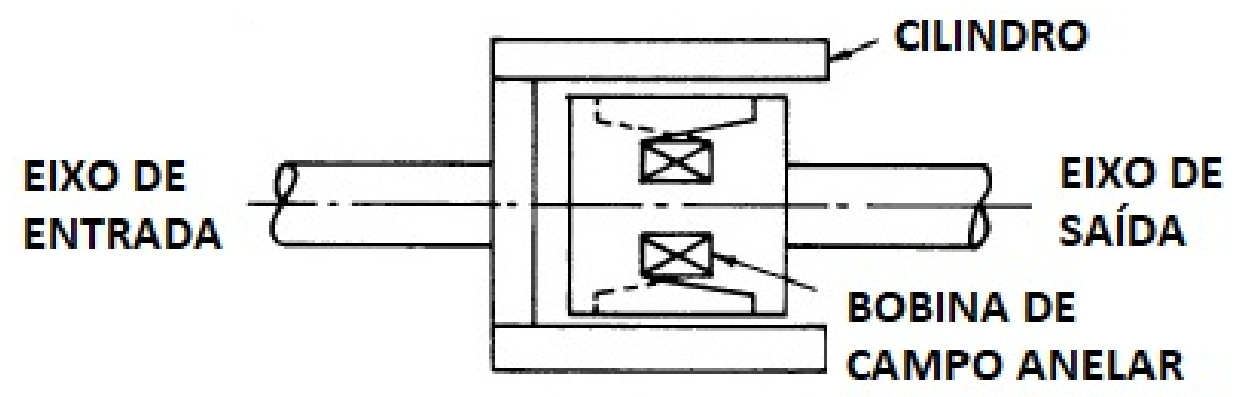

Figura 21 - Representação de um acoplamento magnético.

Fonte: (DAVIES, 1963)

Uma vez estabelecido o fluxo magnético pelo solenoide, para que ocorra transmissão de torque entres os eixos é necessário que o eixo de entrada esteja em movimento. $O$ eletroímã é envolvido pelo rotor do acoplamento e ligado ao eixo de saída. O rotor, por sua vez, possui uma configuração heteropolar sendo que a indução de corrente de Foucault na face interna do cilindro ocorre através da alternância dos polos magnéticos. Como resultado desta indução são gerados campos magnéticos, que tendem a se alinhar ao campo gerado pelos polos do dispositivo. Esse movimento de alinhamento é responsável por transmitir a energia do eixo de entrada para o eixo de saída.

A grande vantagem é que este alinhamento ocorre de forma não pulsátil, porém assíncrona. É exatamente o assincronismo - ou escorregamento - que caracteriza a transmissão de torque para uma determinada potência elétrica. Um exemplo disso é apresentado pela figura 22. Observa-se que o torque é representado em função do escorregamento e da corrente consumida.

Os primeiros estudos sobre freios por correntes parasitas conhecidos, conforme mencionado por Davis, foram publicados por Rudenberg (1906) e Rosenberg (1923). Para esses estudos a permeabilidade do ferro era considerada constante, o que limita muito 0 modelo comportamental destes dispositivos para toda a faixa de operação e tem como base a equação de difusão. Esta equação é quem define o comportamento das correntes induzidas em meios lineares. Rosenberg atinge bons resultados considerando as densidades de corrente e fluxo no cilindro. Grun, em 1959, segue a mesma linha de pensamento.

Em 1946 Gibbs publica seus resultados considerando a não linearidade para a 
permeabilidade do ferro, servindo como ponto de partida para o trabalho de Davis. Outros trabalhos sobre acoplamentos foram publicados pelos russos Glazenk (1958) e Sharov (1957), lembrando que Davis publica seu estudo em 1963.

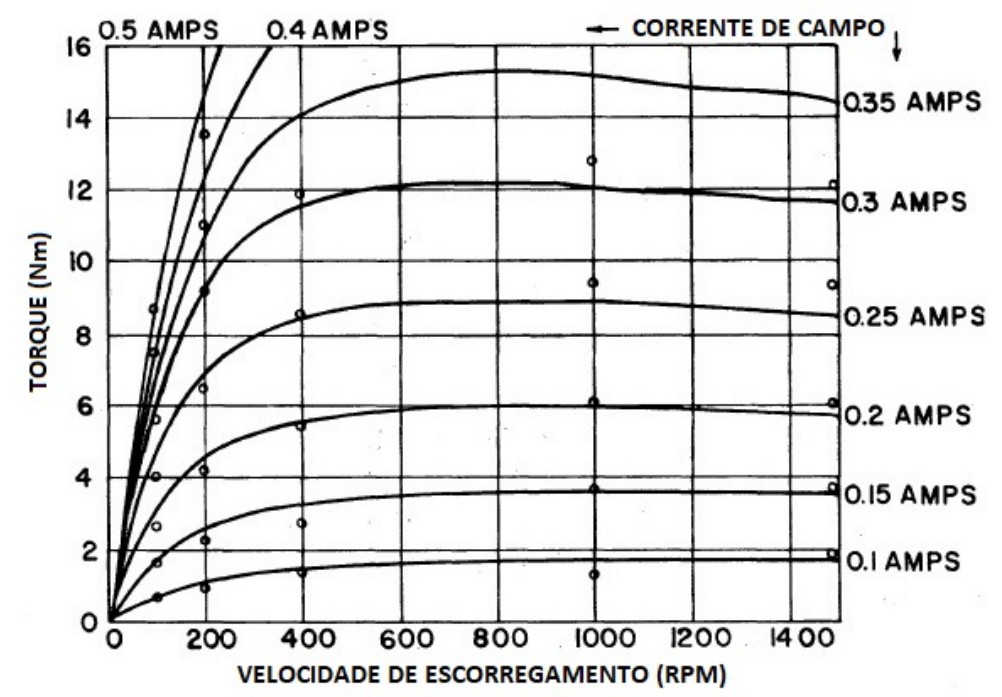

Figura 22 - Curva característica de um acoplamento magnético.

Fonte: (DAVIES, 1963)

Glazenk baseia-se nas equações de Rosenberg, portanto considera a linearidade do ferro. Sharov, porém, apresenta como o fluxo e a reação de armadura podem ser relacionados vetorialmente, usando as teorias para máquinas síncronas, mas sem muito aprofundamento.

O trabalho de Davis, portanto, tem como base o estudo apresentado por Gibbs e se diferencia ao introduzir o comportamento não linear dos elementos ferromagnéticos no equacionamento proposto. Essa contribuição resultou, como veremos a seguir, em um conjunto de equações que modelam o comportamento do dispositivo, permitindo certa previsibilidade. Com essas equações podemos dimensionar o dispositivo, estimar a transmissão de torque em função do escorregamento entre eixos e prever, assim, sua eficiência.

Como mencionado, os estudos iniciais desenvolveram suas teorias com base na equação de difusão em meios lineares, que por sua vez descrevem o fenômeno de correntes induzidas. 


\subsection{Equacionamento}

Matematicamente, as correntes induzidas são representadas por uma equação de difusão. Essa equação parte da lei de indução magnética conhecida como Maxwell-Faraday, conforme equação 3.1, que relaciona a intensidade de campo elétrico não-conservativo com a densidade de fluxo magnético. Portanto, cargas em movimento em algum material com certa resistividade $\rho$, geram, ao longo do tempo, campo magnético, ou vice-versa.

$$
\vec{\nabla} \times \vec{E}=\frac{-\partial \vec{B}}{\partial t}
$$

Seguindo tal lei, pode-se substituir o campo elétrico pela relação entre a densidade de corrente $J$ e a resistividade elétrica do material pelo qual esta se propaga $\rho$ (DIETRICH, 2000):

$$
\vec{\nabla} \times(\rho \vec{J})=\frac{-\partial \vec{B}}{\partial t}
$$

Substituindo $\vec{B}$ por $\mu \mu_{0} \vec{H}$ e considerando $\mu$ independente de $\vec{H}$ :

$$
\vec{\nabla} \times \vec{J}=-\frac{\mu \mu_{0}}{\rho} \cdot \frac{\partial \vec{H}}{\partial t}
$$

Aplicando o rotacional para que se possa satisfazer a relação $\nabla \times(\nabla \times \vec{P})=$ $\nabla(\nabla \cdot \vec{P})-\nabla^{2} \vec{P}$, sendo $\vec{P}$ um vetor qualquer, chega-se na equação (3.4).

$$
\vec{\nabla}(\vec{\nabla} \cdot \vec{J})-\nabla^{2} \vec{J}=\nabla \times\left(-\frac{\mu \mu_{0}}{\rho} \cdot \frac{\partial \vec{H}}{\partial t}\right)
$$

Sendo $\vec{\nabla} \cdot \vec{J}=0$ o resultado da equação da continuidade de correntes, chega-se na equação (3.5).

$$
\nabla^{2} \vec{J}=\frac{\mu \mu_{0}}{\rho} \cdot \frac{\partial}{\partial t} \vec{\nabla} \times \vec{H}
$$

A equação de difusão em meios lineares é obtida através da relação $\vec{\nabla} \times \vec{H}=\vec{J}$, conforme abaixo (DIETRICH, 2000): 


$$
\nabla^{2} \vec{J}=\frac{\mu \mu_{0}}{\rho} \cdot \frac{\partial}{\partial t} \vec{J}
$$

A equação (3.6) é utilizada para representar o comportamento das correntes induzidas em meios lineares e será de extrema importância para determinar variáveis relacionadas ao dimensionamento da máquina. Para isso, algumas simplificações foram adotadas. Adotouse que a variação do vetor densidade de corrente $\vec{J}$ é senoidal na região ativa do material exposto à indução e que circulam apenas na direção axial para um bloco semi-infinito de ferro.

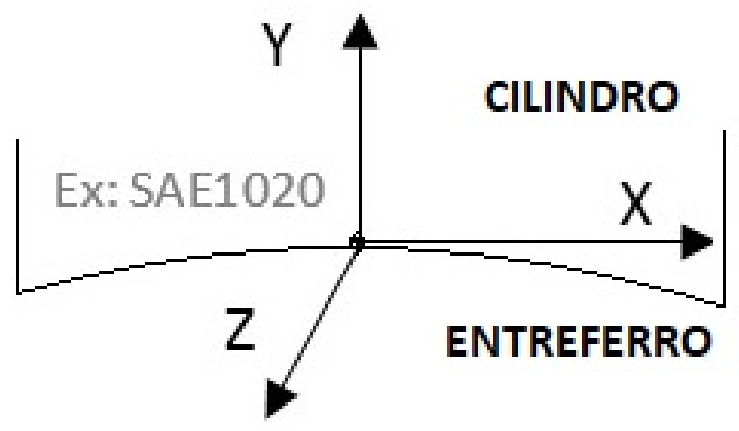

Figura 23 - Definição dos eixos no sistema de coordenadas.

Como ponto de partida para o equacionamento é necessário adotar um sistema de coordenadas, definindo como sua origem a região ativa. A figura 23 ilustra a nomenclatura adotada para os eixos, sendo que $x, y \mathrm{e} z$ indicam respectivamente as direções tangente, radial e axial à região ativa (ponto de origem).

Como será visto no decorrer deste capítulo, o objetivo deste equacionamento é caracterizar as relações entre a indução de corrente na região ativa e o torque transferido. A partir dessa relação, também tem-se como objetivo determinar o fluxo magnético por polo em função do torque transferido, da velocidade de escorregamento e das principais características geométrica da máquina. O estudo inicia-se a partir da distribuição das correntes induzidas.

\subsection{Distribuição da densidade de corrente}

A indução de corrente na área ativa depende da variação do fluxo magnético fornecido através dos polos magnéticos do rotor interno da máquina. Portanto, o número de 
pares de polos $p$ e a velocidade de rotação do eixo de entrada determinam a frequência com que se alternam os polos magnéticos entre norte e sul na região ativa da máquina.

Assumindo que as correntes induzidas se propagam apenas axialmente, tem-se (DAVIES, 1963):

$$
J_{x}=J_{y}=0 \Rightarrow \vec{J}=J_{z} \overrightarrow{e_{z}}
$$

Supondo que $J_{z}=$ cte ao longo da direção $\overrightarrow{e_{z}}$, uma vez desprezados os efeitos de borda, tem-se que:

$$
\frac{\partial^{2}}{\partial z^{2}} \vec{J}=0
$$

Uma vez adotadas essas simplificações, é possível aplicá-las na equação 3.6, o que resulta:

$$
\frac{\partial^{2}}{\partial x^{2}} \vec{J}_{z}+\frac{\partial^{2}}{\partial y^{2}} \vec{J}_{z}=\frac{\mu \mu_{0}}{\rho} \cdot \frac{\partial}{\partial t} \vec{J}
$$

A solução conhecida para a equação (3.9) em regime senoidal é apresentada da seguinte forma (DAVIES, 1963):

$$
J_{z}=J(y) \cdot \cos \left(\omega \cdot t-\frac{2 \pi}{\lambda} \cdot x\right)
$$

Escrevendo no formato exponencial, tem-se que:

$$
J_{z}=R e\left[J(y) \cdot e^{j\left(\omega \cdot t-\frac{2 \pi}{\lambda} \cdot x\right)}\right]
$$

Com essa solução conhecida, observa-se uma função $J(y)$ que será encontrada a partir das condições de contorno, $\lambda$ que representa o comprimento de onda (arco entre os pares de polos) e a velocidade angular $w$ que contempla o número de polos da máquina. $O$ operador Re representa a parte real da equação.

Substituindo na equação (3.9) o resultado atingido pela equação (3.11), tem-se que:

$$
\frac{\partial^{2}}{\partial x^{2}} \vec{J}_{z}+\frac{\partial^{2}}{\partial y^{2}} \vec{J}_{z}=\frac{\mu \mu_{0}}{\rho} \cdot \frac{\partial}{\partial t}\left[J(y) \cdot e^{j\left(\omega \cdot t-\frac{2 \pi}{\lambda} \cdot x\right)}\right]
$$

Derivando em função de $x$ e $t$ :

$$
-\frac{4 \pi^{2}}{\lambda^{2}} J(y) \cdot e^{j\left(\omega \cdot t-\frac{2 \pi}{\lambda} \cdot x\right)}+\frac{\partial^{2}}{\partial y^{2}} J(y) \cdot e^{j\left(\omega \cdot t-\frac{2 \pi}{\lambda} \cdot x\right)}=\frac{\mu \mu_{0} j \omega}{\rho} \cdot J(y) \cdot e^{j\left(\omega \cdot t-\frac{2 \pi}{\lambda} \cdot x\right)}
$$


É possível simplificar esta equação, reescrevendo-a da seguinte forma:

$$
\frac{\partial^{2} J(y)}{\partial y^{2}}-J(y)\left[\frac{4 \pi^{2}}{\lambda^{2}}+\frac{\mu \mu_{0} j \omega}{\rho}\right]=0
$$

Assumindo $\alpha^{2}=\mu \mu_{0} w / 2 \rho$ e lembrando que $\alpha^{-1}$ representa a profundidade de penetração da corrente de Foucault, tem-se que:

$$
\frac{\partial^{2} J(y)}{\partial y^{2}}-J(y)\left[\frac{4 \pi^{2}}{\lambda^{2}}+j 2 \alpha^{2}\right]=0
$$

Com o objetivo de manipular a equação (3.15), de forma que leve a uma solução conhecida, criou-se a variável $k$ da seguinte maneira:

$$
k^{2}=\left(\frac{4 \pi^{2}}{\lambda^{2}}+j 2 \alpha^{2}\right)
$$

Assim, a equação (3.15) resulta em:

$$
\frac{\partial^{2} J(y)}{\partial y^{2}}-k^{2} J(y)=0
$$

A solução conhecida para a equação (3.17) é dada a seguir (DAVIES, 1963):

$$
J(y)=A_{1} e^{k y}+A_{2} e^{-k y}
$$

A equação (3.18) representa o comportamento das correntes induzidas no sentido do eixo y e portanto deve expressar a forma como essas correntes penetram no material ferromagnético. Sabe-se que seu módulo $J_{z}$ possui comportamento exponencial, tendo como origem - e seu valor máximo - a superfície da região ativa, aproximando-se de zero a medida que a profundidade aumenta. Com isso determinam-se duas condições de contorno.

A primeira para quando $y \rightarrow \infty$, tem-se que:

$$
\begin{array}{r}
J_{z} \rightarrow 0, J(y) \rightarrow 0 \\
\therefore A 1=0
\end{array}
$$

A segunda para quando $y \rightarrow 0$, tem-se que:

$$
\begin{aligned}
J_{z} \rightarrow J_{z_{\max }}, J(y) & \rightarrow J_{z_{\max }} \\
\therefore A 2 & =J_{z_{\max }}
\end{aligned}
$$


Considerando, portanto, as condições de contorno e reescrevendo a equação (3.18), tem-se que:

$$
J(y)=J_{z_{\max }} e^{-k y}
$$

Sendo assim, substituindo $J(y)$ na equação (3.11), tem-se que:

$$
J_{z}=R e\left[J_{z_{\max }} e^{-k y} \cdot e^{j\left(\omega \cdot t-\frac{2 \pi}{\lambda} \cdot x\right)}\right]
$$

Vale lembrar que a variável $k$ foi definida pela equação (3.16) como sendo um número complexo. Reescrevendo essa variável em coordenadas polares, tem-se que:

$$
\begin{array}{r}
k^{2}=\left(\frac{4 \pi^{2}}{\lambda^{2}}+j 2 \alpha^{2}\right)=R^{2} e^{2 j \phi} \\
\therefore k=R e^{j \phi}=R \cos (\phi)+j R \sin (\phi)
\end{array}
$$

Os valores de $R$ e $\phi$ são definidos a seguir:

$$
\begin{aligned}
& R=\sqrt[4]{\left(\frac{4 \pi^{2}}{\lambda^{2}}\right)^{2}+\left(2 \alpha^{2}\right)^{2}} \\
& 2 \phi=\arctan \left(\frac{2 \alpha^{2}}{4 \pi^{2} / \lambda^{2}}\right)
\end{aligned}
$$

Assim, reescrevendo-se a equação (3.20) aplicando a equação (3.21) :

$$
\begin{array}{r}
J_{z}=R e\left[J_{z_{\max }} e^{-R e^{j \phi y}} \cdot e^{j\left(\omega \cdot t-\frac{2 \pi}{\lambda} \cdot x\right)}\right] \\
J_{z}=\operatorname{Re}\left[J_{z_{\max }} e^{(-R \cos (\phi)-j R \sin (\phi)) y} \cdot e^{j\left(\omega \cdot t-\frac{2 \pi}{\lambda} \cdot x\right)}\right] \\
J_{z}=\operatorname{Re}\left[J_{z_{\max }} e^{(-R \cos (\phi)) y} \cdot e^{\left.j\left(\omega \cdot t-\frac{2 \pi}{\lambda} \cdot x-(R \sin (\phi)) y\right)\right)}\right]
\end{array}
$$

Define-se que:

$$
\begin{aligned}
& \beta=R \cos (\phi) \\
& \gamma=R \sin (\phi)
\end{aligned}
$$

Reescrevendo a equação (3.23) considerando essas novas variáveis, tem-se que :

$$
J_{z}=R e\left[J_{z_{\max }} e^{-\beta y} \cdot e^{j\left(\omega \cdot t-\frac{2 \pi}{\lambda} \cdot x-(\gamma y)\right)}\right]
$$


Lembrando que $\lambda$ representa o comprimento de onda das correntes induzidas no cilindro e $\alpha^{-1}$ a profundidade de penetração, será considerada a seguinte condição de contorno:

$$
\sqrt{2} \alpha>>\frac{2 \pi}{\lambda}
$$

Isso significa que a profundidade de penetração das correntes induzidas serão consideradas muito menores do que o seu comprimento de onda (no caso heteropolar o arco polo a polo). Assim, tem-se:

$$
\begin{array}{r}
R=\sqrt{2} \alpha \\
\phi=\frac{\pi}{4} \\
\beta=\alpha \\
\gamma=\alpha
\end{array}
$$

Portanto, reescrevendo a equação (3.26) com base nessas novas considerações:

$$
J_{z}=R e\left[J_{z_{\max }} e^{-\alpha y} \cdot e^{j\left(\omega \cdot t-\frac{2 \pi}{\lambda} \cdot x-(\alpha y)\right)}\right]
$$

Que também pode ser escrita como (DAVIES, 1963):

$$
J_{z}=J_{z_{\max }} e^{-\alpha y} \cdot \cos \left(\omega \cdot t-\frac{2 \pi}{\lambda} \cdot x-\alpha y\right)
$$

A equação (3.28) define o comportamento da corrente induzida ao logo dos eixos $x$ e $y$. Na direção periférica, nota-se um comportamento senoidal em função da frequência de operação e variação de fase em função da camada de penetração. Observa-se também o comportamento exponencial que influencia o módulo da corrente induzida.

Uma vez equacionado esse comportamento, a seguir será estudado como o campo é gerado a partir desta corrente circulante na região ativa e, consequentemente, como este influencia na geração do torque de acoplamento.

\subsection{Campo magnético presente na região ativa em função da distribuição das correntes induzidas}

Com a expressão calculada para $J_{z}$, pôde-se encontrar a relação com a distribuição de $\vec{H}$ em função da distribuição das correntes induzidas. É portanto uma relação natural e 
baseia-se nas equações (3.1) e (3.3). Além disso, é importante relembrar o sentido axial de propagação, conforme (3.7) e assim definir que $\vec{E}_{z}=\rho J_{z} \overrightarrow{e_{z}}$. Seguindo a equação (3.8), tem-se que o rotacional de $\vec{E}$ será:

$$
\begin{gathered}
\nabla \times \vec{E}=\frac{\partial}{\partial y} E_{z} \overrightarrow{e_{x}}-\frac{\partial}{\partial x} E_{z} \overrightarrow{e_{y}} \\
\frac{\partial}{\partial y} E_{z} \overrightarrow{e_{x}}-\frac{\partial}{\partial x} E_{z} \overrightarrow{e_{y}}=-\mu \mu_{0}\left(\frac{\partial}{\partial t} H_{x} \overrightarrow{e_{x}}-\frac{\partial}{\partial t} H_{y} \overrightarrow{e_{y}}\right)
\end{gathered}
$$

Se considerar o regime permanente senoidal, pode-se substituir $\frac{\partial}{\partial t}$ por $j \omega$ :

$$
\begin{aligned}
\frac{\partial}{\partial y} E_{z} \overrightarrow{e_{x}}-\frac{\partial}{\partial x} E_{z} \overrightarrow{e_{y}} & =-\mu \mu_{0} j \omega\left(H_{x} \overrightarrow{e_{x}}-H_{y} \overrightarrow{e_{y}}\right) \\
\frac{\partial}{\partial y} E_{z} \overrightarrow{e_{x}} & =-\mu \mu_{0} j \omega H_{x} \overrightarrow{e_{x}} \\
\frac{\partial}{\partial x} E_{z} \overrightarrow{e_{y}} & =-\mu \mu_{0} j \omega H_{y} \overrightarrow{e_{y}}
\end{aligned}
$$

Conhecendo a relação entre $E_{z}, H_{x}, H_{y}$ e $\vec{E}_{z}=\rho J_{z} \overrightarrow{e_{z}}$, tem-se que:

$$
E_{z}=\rho J_{z}=\rho J_{z_{\max }} e^{-\alpha y} \cdot e^{j\left(\omega \cdot t-\frac{2 \pi}{\lambda} \cdot x-(\alpha y)\right)}
$$

Desta forma, derivando $E_{z}$ em relação da variável $y$, conforme (3.32), obtém-se:

$$
\frac{\partial}{\partial y} E_{z} \overrightarrow{e_{x}}=-\rho J_{z_{\max }}(\alpha+j \alpha) e^{-\alpha y} \cdot e^{j\left(\omega \cdot t-\frac{2 \pi}{\lambda} \cdot x-(\alpha y)\right)}=-\rho(\alpha+j \alpha) J_{z}
$$

Portanto, conclui-se que (DIETRICH, 2000):

$$
-\rho(\alpha+j \alpha) J_{z}=-\mu \mu_{0} \omega H_{x} \overrightarrow{e_{x}}
$$

Isolando $H_{x}$, tem-se que:

$$
H_{x}=\frac{\rho \alpha(1+j)}{\mu \mu_{0} \omega} J_{z}=\frac{\rho}{\mu \mu_{0} \omega} \cdot \frac{\alpha(1+j)}{J}=\frac{\alpha(1+j)}{2 \alpha^{2}} J_{z}
$$

Escrevendo de forma fasorial, observa-se que o módulo do dividendo é equivalente a $\sqrt{\left(1^{2}+1^{2}\right)}=\sqrt{2}$ e o ângulo $\tan ^{-1}(1 / 1)=0,78 \cdot 180 / \pi=45^{\circ}$. O divisor apresenta módulo unitário e fase nula.

$$
H_{x}=J_{z} \cdot\left(\frac{\sqrt{2}}{2}\right) \cdot\left(\frac{1}{\alpha}\right) \angle 45^{\circ}=J_{z} \cdot\left(\frac{1}{\sqrt{2} \alpha}\right) \angle 45^{\circ}
$$


Agora derivando $E_{z}$ em relação a variável $x$, conforme (3.33), obtém-se:

$$
\frac{\partial}{\partial y} E_{z} \overrightarrow{e_{x}}=-\rho J_{z_{\max }}\left(j \frac{2 \pi}{\lambda}\right) e^{-\alpha y} \cdot e^{j\left(\omega \cdot t-\frac{2 \pi}{\lambda} \cdot x-(\alpha y)\right)}=-\rho\left(j \frac{2 \pi}{\lambda}\right) \cdot J_{z}
$$

Portanto, conclui-se que:

$$
-\rho\left(j \frac{2 \pi}{\lambda}\right) J_{z}=-\mu \mu_{0} j \omega H_{y} \overrightarrow{e_{y}}
$$

Isolando $H_{y}$, tem-se que:

$$
H_{y}=\left(\frac{2 \pi}{\lambda}\right) \cdot\left(\frac{\rho}{\mu \mu_{0} \omega}\right) J_{z}=\left(\frac{2 \pi}{\lambda}\right) \cdot\left(\frac{1}{2 \alpha^{2}}\right) J_{z}=\left(\frac{\pi}{\lambda \alpha^{2}}\right) J_{z}
$$

Desta forma é possível equacionar a relação entre $J_{z}$ e o campo magnético presente na região ativa. Entende-se que no sentido $\vec{e}_{x}$ ocorre uma defasagem de $45^{\circ}$ em função da penetração, enquanto na direção $\vec{e}_{y}$ há uma relação com a corrente induzida em função do comprimento de onda e penetração. Porém, qual destas grandezas é prevalente?

Relembrando a condição de contorno, onde $\sqrt{2} \alpha>>2 \pi / \lambda$, e multiplicando ambos os membros por $J_{z} /\left(2 \alpha^{2}\right)$, tem-se que:

$$
\begin{array}{r}
\frac{J_{z}}{2 \alpha^{2}} \cdot \sqrt{2} \alpha>>\frac{J_{z}}{2 \alpha^{2}} \cdot \frac{2 \pi}{\lambda} \\
\frac{J_{z}}{\sqrt{2} \alpha}>>\frac{J_{z} \pi}{\lambda \alpha^{2}}
\end{array}
$$

Observados os resultados obtidos nas equações (3.42),(3.38) e (3.41), conclui-se que:

$$
\left|H_{x}\right|>>\left|H_{y}\right|
$$

O que resulta na eliminação da distribuição no sentido $\vec{e}_{y}$, por ser muito menor do que a distribuição em $x$. Feito isso, tem-se que (DIETRICH, 2000):

$$
\vec{H}=\frac{J_{z} \angle 45}{\sqrt{2} \alpha} \cdot \vec{e}_{x}
$$

\subsection{Indução no entreferro}

A indução no entreferro ocorre no sentido $\vec{e}_{y}$ e, portanto, será estudado qual o $B_{y}$ necessário para criar o padrão desejado para as correntes, relacionando assim $B_{y}$ com $J_{z_{\text {maz }}}$. 
Sendo:

$$
B_{y}=-\mu \mu_{0} H_{y}
$$

Substituindo $H_{y}$ pelo resultado obtido pela equação (3.41), tem-se:

$$
B_{y}=-\mu \mu_{0}\left(\frac{\pi}{\lambda \alpha^{2}}\right) J_{z}=-\left(\frac{\pi}{\lambda} \cdot \frac{2 \rho}{\omega}\right) J_{z}
$$

No entreferro, tem-se que $y=0$, portanto (DIETRICH, 2000):

$$
\begin{array}{r}
J_{z_{(y=0)}}=J_{z_{\max }} \cos \left(\omega t-\frac{2 \pi}{\lambda} x\right) \\
B_{y_{(y=0)}}=-\frac{2 \pi \rho}{\lambda \omega} J_{z_{\max }} \cos \left(\omega t-\frac{2 \pi}{\lambda} x\right)
\end{array}
$$

Cujo valor médio por polo resulta em:

$$
B_{y}=\frac{2}{\pi}\left(\frac{2 \rho \pi}{\lambda \omega} J_{z_{\max }}\right)=\frac{4 \rho}{\lambda \omega} J_{z_{\max }}
$$

Uma vez equacionado $B_{y}$ é possível calcular o fluxo magnético por polo. Sendo $L$ o seu comprimento ativo e $\lambda / 2$ a sua largura, tem-se que (DAVIES, 1963)(DIETRICH, 2000):

$$
\phi_{a c}=B_{y} . S_{\text {polo }}=\frac{4 \rho}{\lambda \omega} J_{z_{\max }} \frac{L \lambda}{2}=\frac{2 \rho L}{\omega} J_{z_{\max }}
$$

\subsection{Energia dissipada pelas correntes induzidas}

As correntes induzidas, por circularem em um meio com certa resistividade, dissipam potência elétrica em função da frequência com que os polos magnéticos se alternam em uma determinada região ativa da máquina. Essa energia elétrica dissipada na região ativa, desconsiderando perdas como atrito, por exemplo, se iguala à potência mecânica fornecida ao acoplamento pelo eixo de entrada. Isso significa que o fluxo magnético por polo será determinado em função da energia dissipada $W$ durante um certo período de tempo $t$.

Como a energia é dissipada no volume da região ativa, deve-se, portanto, fazer a integração de $\rho J^{2}$ nesta região. Assim, tem-se que (DAVIES, 1963):

$$
W=\iiint \rho J_{z}^{2} d t d x d y=\iiint \rho J_{z_{m a x}}^{2} e^{-2 \alpha y} \cos ^{2}\left(\omega t-\frac{2 \pi}{\lambda}-\alpha y\right) d y d[f(t, x)]
$$

Sendo o valor médio de $\cos ^{2}=1 / 2$, uma vez que $\alpha y$ muda apenas a fase e não o módulo, tem-se que (DAVIES, 1963):

$$
W=\frac{\rho J_{z_{\max }}^{2}}{2} \int_{0}^{\infty} e^{-2 \alpha y} d y=\frac{\rho J_{z_{\max }}^{2}}{4 \alpha}
$$




$$
\begin{array}{r}
H_{\max }=\frac{J_{z_{\max }}}{\sqrt{2} \alpha} \\
J_{z_{\text {max }}}=\sqrt{2} \alpha H_{\max } \\
\therefore W=\frac{\rho \alpha^{2} 2 H_{\max }^{2}}{4 \alpha}=\frac{\rho \alpha}{2} H_{\max }^{2} \\
\alpha^{2}=\frac{\mu \mu_{0} \omega}{2 \rho} \\
W^{2}=\left(\frac{\rho \alpha}{2} H_{\max }^{2}\right)^{2} \\
4 W^{2}=\rho^{2} \alpha^{2} H_{\max }^{4}
\end{array}
$$

Substituindo $\alpha^{2}$, tem-se que:

$$
\begin{array}{r}
4 W^{2}=\frac{\rho^{2} \mu \mu_{0} \omega}{2 \rho} H_{\text {max }}^{4} \\
\frac{8 W^{2}}{\rho \omega}=\mu \mu_{0} H_{\max }^{4} \\
\therefore\left(\mu \mu_{0}\right)^{1 / 4} \cdot H_{\max }=\sqrt[4]{\frac{8 W^{2}}{\rho \omega}}
\end{array}
$$

Pensando agora no cálculo do fluxo por polo e partindo da equação (3.48) e usando a relação entre $J_{z_{\max }}$ e $H_{\max }$ apresentada no cálculo para a equação (3.51), tem-se:

$$
\phi_{a c}=\frac{2 \rho L}{\omega} J_{z_{\max }}=\frac{2 \alpha \rho L}{\omega} \sqrt{2} H_{\max }
$$

Com base na equação (3.51), pode-se considerar que:

$$
\rho \alpha=\frac{2 W}{H_{\max }^{2}}
$$

Sendo assim, tem-se que (DAVIES, 1963):

$$
\phi_{a c}=\frac{2 \alpha \rho L}{\omega} \sqrt{2} H_{\max }=\frac{4 W L}{\omega H_{\max }^{2}} \sqrt{2} H_{\max }=4 \sqrt{2} \frac{W L}{\omega H_{\max }}
$$




\subsection{Introdução da não linearidade em função da saturação do material ferromagnético}

Para que seja possível desenvolver um equacionamento que represente melhor o comportamento destes dispositivos, torna-se fundamental considerar a não linearidade do material ferromagnético que compõe a região ativa. Em outras palavras é reescreve a permeabilidade $\mu$ considerando o seu comportamento não linear. Este comportamento é importante dada a saturação que ocorre por conta das correntes que circulam nele. A relação que pode ser utilizada como forma de aproximação da curva de saturação dos materias ferromagnéticos é apresentada a seguir (DAVIES, 1963):

$$
B=a \cdot H^{b}
$$

Sendo assim, torna-se conveniente relacionar a equação (3.52) com $H$, tendo que (DIETRICH, 2000):

$$
\begin{array}{r}
B=a H^{b} \\
\left(\mu \mu_{0}\right) H=a H^{b} \\
\left(\mu \mu_{0}\right)^{(1 / 4)} H^{(1 / 4)}=a^{(1 / 4)} H^{b / 4} \\
\left(\mu \mu_{0}\right)^{(1 / 4)} H=a^{(1 / 4)} H^{(b+3) / 4}
\end{array}
$$

Adotando que (DIETRICH, 2000):

$$
\begin{array}{r}
c=a^{(1 / 4)}, \quad m=(b+3) / 4 \\
\therefore\left(\mu \mu_{0}\right)^{(1 / 4)} H=c H^{m}
\end{array}
$$

Conforme confirmado experimentalmente por Dietrich (DIETRICH, 2000), os valores apresentados por Davies (DAVIES, 1963) para o aço SAE1020, tem-se que $c$ e $m$ possuem respectivamente os valores 0,97 e 0,77 , o que resulta em:

$$
\left(\mu \mu_{0}\right)^{(1 / 4)} H=0,97 H^{0,77}
$$

\subsection{Cálculo do fluxo por polo a partir da não linearidade do material ferromagnético}

Com o resultado obtido na equação (3.57) é possível reescrever a equação (3.52) para introduzir a não linearidade. Sendo assim, tem-se que: 


$$
\begin{array}{r}
\left(\mu \mu_{0}\right)^{1 / 4} \cdot H_{\max }=\sqrt[4]{\frac{8 W^{2}}{\rho \omega}} \\
0,97 H^{0,77}=\left(\frac{8 W^{2}}{\rho \omega}\right)^{0,25} \\
H=\left(\frac{1}{0,97}\right)^{1,3} \cdot\left(\frac{8 W^{2}}{\rho \omega}\right)^{0,325}=\text { cte }\left(\frac{8 W^{2}}{\rho \omega}\right)^{0,325}
\end{array}
$$

Sendo,

$$
\begin{gathered}
\phi_{a c}=4 \sqrt{2} \frac{W L}{\omega H_{\max }}=\text { cte. } \frac{W L}{\omega H_{\max }}=\text { cte. } \frac{W L}{\omega}\left(\frac{\rho \omega}{8 W^{2}}\right)^{0,325}=\text { cte. } \frac{W L}{\omega}\left(\frac{\rho^{0,325} \omega^{0,325}}{W^{0,65}}\right) \\
\therefore \phi_{a c}=\operatorname{cte} \cdot \frac{W^{0,35} L \rho^{0,325}}{\omega^{0,675}}
\end{gathered}
$$

Sabendo-se que a densidade de potência mecânica $\left(\mathrm{W} / \mathrm{m}^{2}\right)$ está relacionada com o torque $(T)$ e o diâmetro interno da polia $(D)$, tem-se que:

$$
W m e c=\frac{P m e c}{\text { Sativa }}=\frac{2 \pi n T}{\pi D L}=\frac{2 n T}{D L}
$$

Sendo $w=2 \pi n p$, tem-se que (DAVIES, 1963):

$$
\begin{gathered}
\phi_{a c}=\text { cte. } L\left(\frac{2 n T}{D L}\right)^{0,35} \frac{\rho^{0,325}}{(2 \pi n p)^{0,675}} \\
\phi_{a c}=\text { cte. }\left(\frac{\rho^{0,325} L^{0,65}}{D^{0,35} p^{0,67}}\right) \frac{T^{0,35}}{n^{0,325}}
\end{gathered}
$$

Definindo $M$ como a constante de máquina, onde as variáveis que ela representa são valores considerados constantes, exceto a resistividade que varia com a temperatura, tem-se que (DAVIES, 1963):

$$
\begin{gathered}
M=\left(\frac{\rho^{0,325} L^{0,65}}{D^{0,35} p^{0,67}}\right) \\
\therefore \phi_{a c}=\text { cte.M } \frac{T^{0,35}}{n^{0,325}}
\end{gathered}
$$




\subsection{Estudo da reação de armadura}

Finalizando o equacionamento, um fenômeno que precisa ser estudado é a reação de armadura. Essa reação ocorre porque as correntes induzidas também produzem campo magnético. Esse campo então interage com o campo de excitação e precisa ser previsto no cálculo dimensional e magnético. $\mathrm{O}$ cálculo a seguir resultará na força magneto motriz $\left(\mathrm{F}_{r}\right)$ de reação e que afeta o valor necessário de indução para um certo ponto de operação.

O cálculo inicia com a integração da distribuição da corrente induzida $J z$ em $y$, o que resulta no gradiente de corrente na direção $\vec{e}_{x}$.

$$
\begin{array}{r}
\int_{0}^{\infty} J_{z} d y=\lim _{c \rightarrow \infty} \int_{0}^{c} \operatorname{Re}\left[J_{z_{\max }} e^{-\beta y} \cdot e^{j\left(\omega \cdot t-\frac{2 \pi}{\lambda} \cdot x-(\gamma y)\right)}\right] d y= \\
=\operatorname{Re}\left[\frac{J_{z_{\max }}}{\beta+j \gamma} \cdot e^{j\left(\omega \cdot t-\frac{2 \pi}{\lambda} \cdot x\right)}\right]
\end{array}
$$

Calculando portanto a integral do gradiente em relação a $x$, tem-se:

$$
\begin{aligned}
F r= & \int R e\left[\frac{J_{z_{\max }}}{\beta+j \gamma} \cdot e^{j\left(\omega \cdot t-\frac{2 \pi}{\lambda} \cdot x\right)}\right] d x= \\
& =\operatorname{Re}\left[\frac{-\lambda}{j 2 \pi} \cdot \frac{J_{z_{\max }}}{\beta+j \gamma} \cdot e^{j\left(\omega \cdot t-\frac{2 \pi}{\lambda} \cdot x\right)}\right]
\end{aligned}
$$

Substituindo $\beta$ e $\gamma$ e reescrevendo a equação (3.64) no formato exponencial, tem-se que:

$$
F r=R e\left[\frac{\lambda}{j 2 \pi} \cdot \frac{J_{z_{\max }}}{R \cdot e^{j \phi} \cdot e^{-j \pi / 2}} \cdot e^{j\left(\omega \cdot t-\frac{2 \pi}{\lambda} \cdot x\right)}\right]
$$

Impondo agora a condição de contorno onde $\sqrt{2} \alpha>>2 \pi / \lambda$, tem-se que:

$$
R=\sqrt{2} \alpha, \phi=\frac{\pi}{4}
$$

É possível reescrever a equação (3.65), sendo que:

$$
\begin{array}{r}
F r=R e\left[\frac{\lambda}{j 2 \pi} \cdot \frac{J_{z_{\max }}}{\sqrt{2} \alpha \cdot e^{-j \pi / 4}} \cdot e^{j\left(\omega \cdot t-\frac{2 \pi}{\lambda} \cdot x\right)}\right]= \\
=\operatorname{Re}\left[\frac{\lambda}{2 \sqrt{2} \pi \alpha} J_{z_{\max }} e^{j\left(\omega \cdot t-\frac{2 \pi}{\lambda} \cdot x+\frac{\pi}{4}\right)}\right]= \\
=\frac{\lambda}{2 \sqrt{2} \pi \alpha} J_{z_{\max }} \cos \left(\omega \cdot t-\frac{2 \pi}{\lambda} \cdot x+\frac{\pi}{4}\right)
\end{array}
$$


3.10. Apresentação resumida das principais equações matemáticas que descrevem o comportamento da máquina

Dadas as condições de contorno e observando as diferenças entre $J_{z}$ e $F r$, nota-se uma defasagem de $\pi / 4$ de $F r$ em relação a $J_{z}$. Adotando que o módulo da equação (3.66) resulta em:

$$
F r=\frac{\lambda}{2 \sqrt{2} \pi \alpha} J_{z_{\max }}
$$

Sendo $J_{z_{\max }}=\alpha \sqrt{2} H_{\max }$, tem-se:

$$
F r=\frac{\lambda}{2 \sqrt{2} \pi \alpha} \alpha \sqrt{2} H_{\max }=\frac{\lambda}{2 \pi} H_{\max }
$$

Para colocar $F r$ em função do $\phi_{a c}$, tem-se que:

$$
\begin{array}{r}
H_{\max }=4 \sqrt{2} \frac{W L}{\omega \phi_{a c}} \\
\therefore F r=\frac{\lambda}{2 \pi} \cdot 4 \sqrt{2} \frac{W L}{\omega \phi_{a c}}=\frac{2 \sqrt{2}}{\pi \phi_{a c}} \frac{\lambda W L}{\omega} \\
\frac{\lambda W L}{\omega}=\frac{1}{p \cdot n} \cdot \frac{P}{p}=\frac{T}{p^{2}}
\end{array}
$$

Com base nas equações (3.62) e (3.70), tem-se que (DAVIES, 1963):

$$
\begin{array}{r}
F r=\frac{2 \sqrt{2}}{\pi \phi_{a c}} \cdot \frac{T}{p^{2}}=\frac{2 \sqrt{2} n^{0,325}}{\pi \text { cte } M T^{0,35}} \cdot \frac{T}{p^{2}} \\
\therefore F r=\text { cte } n^{0,325} \frac{T^{0,65}}{M p^{2}}
\end{array}
$$

\subsection{Apresentação resumida das principais equações mate- máticas que descrevem o comportamento da máquina}

De forma resumida, visando simplificar a compreensão dessas relações, a figura 24 apresenta a relação do fluxo por polo a partir da distribuição e penetração da corrente induzida no meio ferromagnético. Para tanto, observa-se que a partir dessa distribuição é possível calcular o campo magnético $H$, permitindo, assim, definir a densidade de campo magnético na superfície do cilindro $(\mathrm{y}=0)$. A partir do equacionamento da densidade de campo na região do entreferro e considerando a geometria do polo, define-se a relação do fluxo magnético por polo em função da corrente induzida $J_{z_{\max }}$ na região do entreferro. 


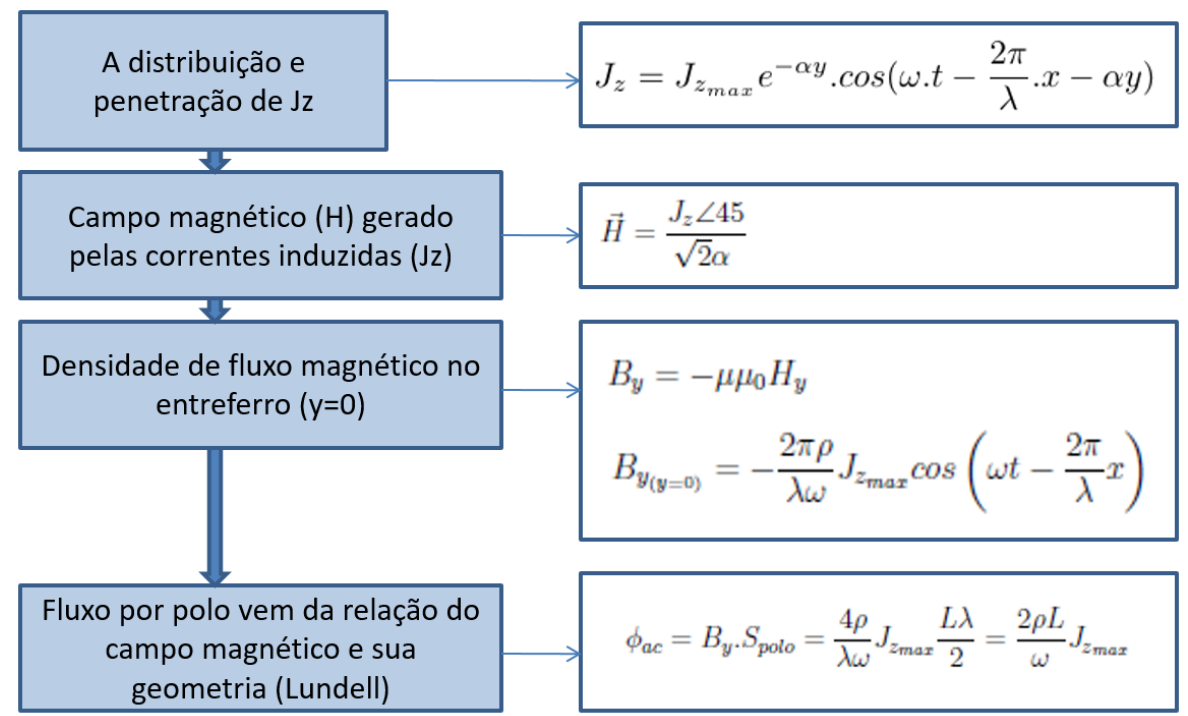

Figura 24 - Cálculo do fluxo por polo $\left(\phi_{a c}\right)$ a partir da equação das correntes induzidas $\left(J_{z}\right)$ no meio ferromagnético.

Uma vez conhecendo o comportamento das correntes que se propagam no cilindro é possível estipular a energia dissipada no material ferromagnético a partir da sua resistividade elétrica $(\rho)$. O diagrama apresentado pela figura 25 atualiza a equação que define o valor para o fluxo por polo $\left(\phi_{a c}\right)$, considerando agora as perdas no material em função da circulação da corrente.

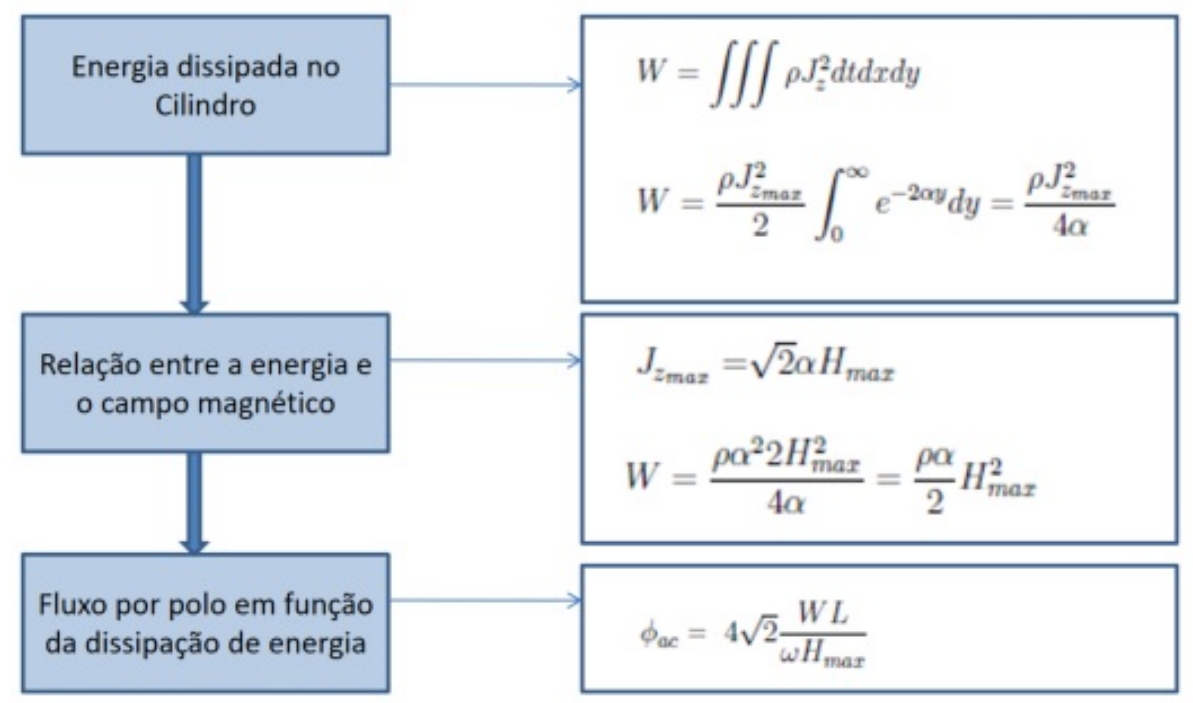

Figura 25 - Cálculo do fluxo por polo $\left(\phi_{a c}\right)$ em função da quantidade de energia dissipada $(W)$ no cilindro.

A grande contribuição de Davis foi adotar uma aproximação que expressasse o comportamento não linear dos materiais ferromagnéticos, principalmente no que se refere a saturação do meio. Assim, inicialmente, antes de aplicar essa aproximação, adotava-se 
3.10. Apresentação resumida das principais equações matemáticas que descrevem o comportamento da máquina

a permeabilidade constante $(\mu)$. Portanto, boa parte do desenvolvimento das equações adota essa premissa simplificadora. A figura 26 atualiza a equação que representa o fluxo magnético por polo, considerando no cálculo do campo magnético a não linearidade dos materiais ferromagnéticos.

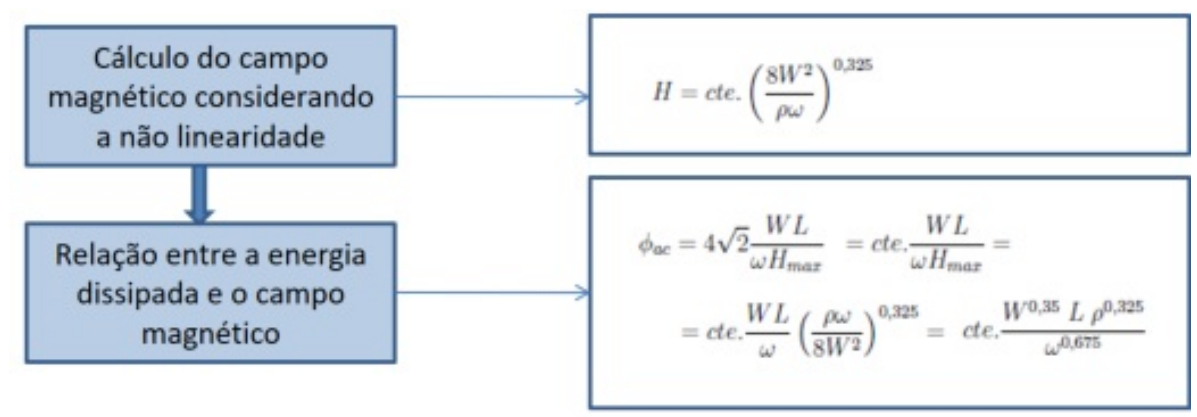

Figura 26 - Introdução da não linearidade dos materiais ferromagnéticos.

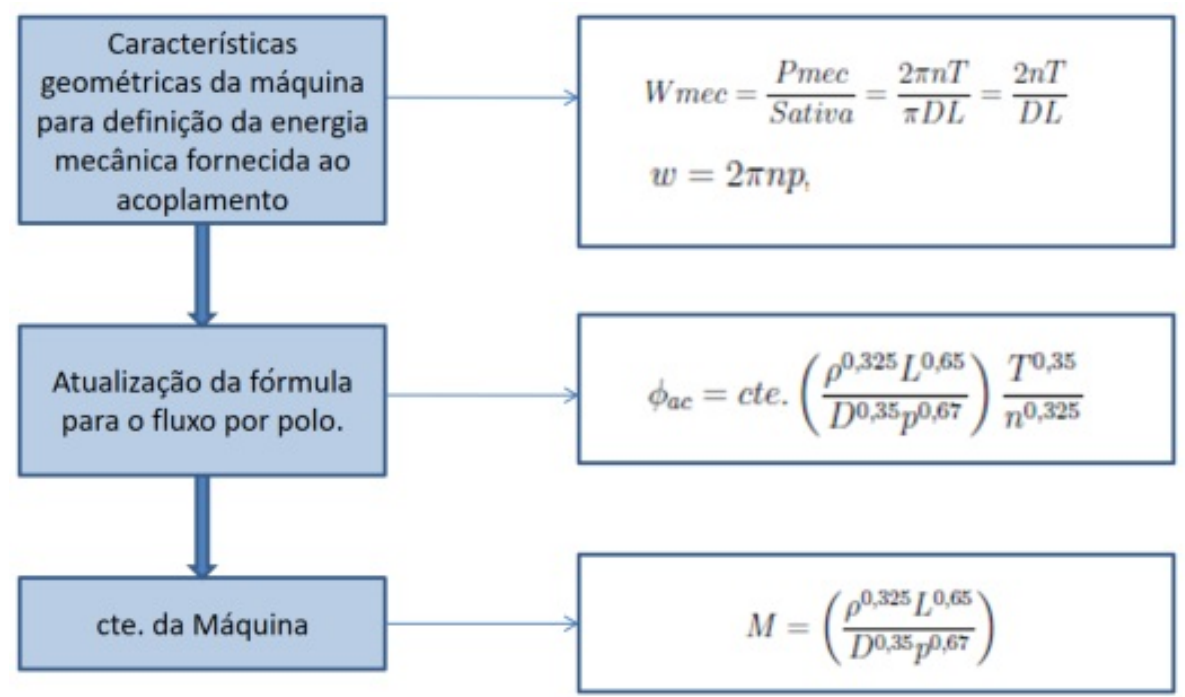

Figura 27 - Equação que define o fluxo magnético por polo $\phi_{a c}$.

Como a origem do funcionamento da máquina é a energia mecânica fornecida no eixo de entrada, quantifica-se a transferência de energia para o eixo de saída, igualando-se a dissipação de energia elétrica com a energia mecânica. A figura 27 apresenta essa relação entre o fluxo por polo e as características geométricas da máquina. Este equacionamento define a relação entre o torque desejado no eixo de saída com o fluxo magnético por polo, que deve ser gerado pelo eletroímã (bobina de campo anelar). A partir dessa relação obtém-se a constante da máquina $(M)$. Essa constante relaciona as variáveis físicas da máquina que são importantes como o diâmetro da área ativa $(D)$, o comprimento da área ativa $(L)$, a resistividade do material ferromagnético $(\rho)$ e o número de pares de polos $(p)$. 
Por fim, a figura 28 apresenta a relação entre o campo gerado pelas correntes induzidas $\left(H_{\max }\right)$ e a energia transferida pelo acoplamento magnético. Essa relação é constituída a partir do campo magnético estabelecido $\left(H_{\max }\right)$ em função das perdas $(W)$ e o fluxo magnético por polo. Em sua forma final, nota-se que a reação de armadura possui relação com as mesmas variáveis que definem o comportamento do fluxo magnético por polo. No decorrer deste capítulo esses tópicos serão apresentados com maiores detalhes.

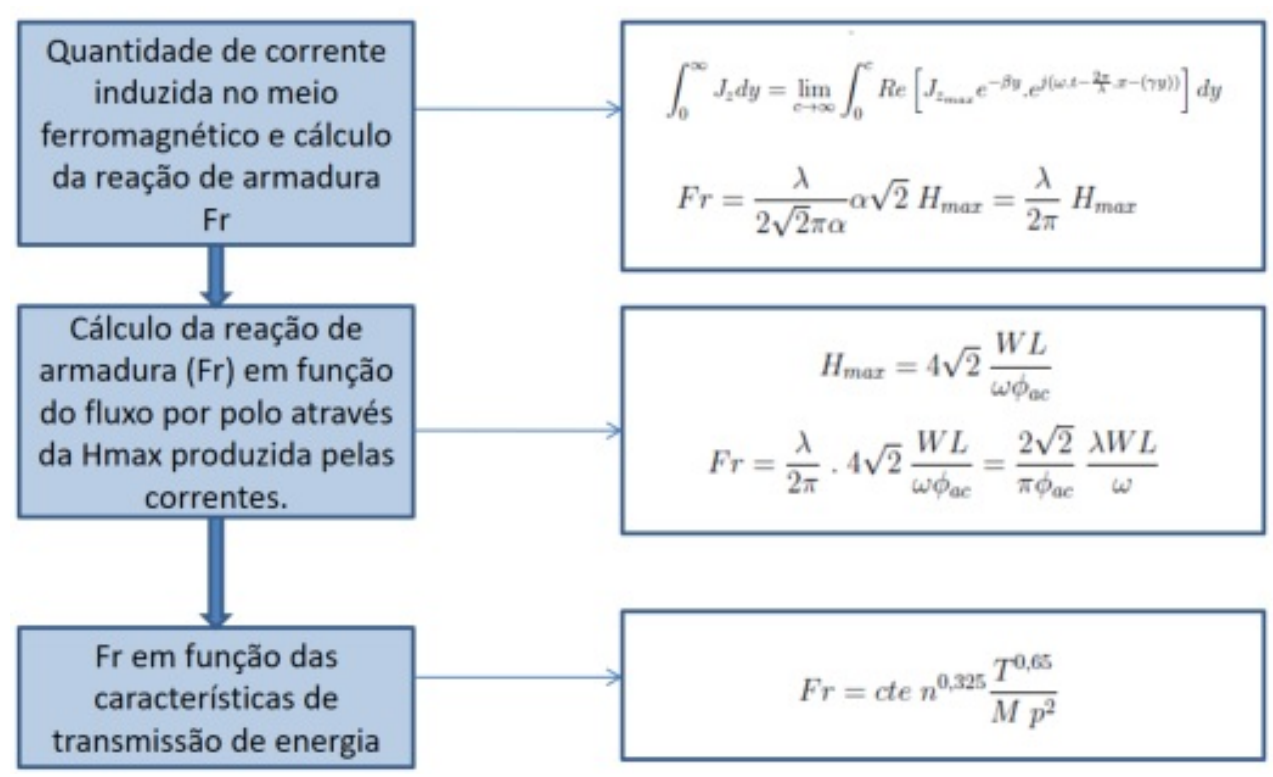

Figura 28 - Equação que define a reação de armadura Fr. 


\section{Concepção da bomba d'água de vazão variável com acoplamento magnético}

Conhecendo as equações fundamentais que descrevem o comportamento dos acoplamentos, seguiu-se então para a etapa de conceito. Levando-se em conta as principais características funcionais que o produto deve atender (desligamento, torque residual e ajuste de torque), partiu-se, então, para uma definição geométrica (BRONZERI et al., 2019).

O estudo mais recente encontrado sobre o tema apresenta uma topologia capaz de ajustar significativamente o torque transmitido, mas se propõe a posicionar o eletroímã onde a polia é montada. É um estudo interessante que pode servir de base para melhorias futuras. Tem diâmetro menor do que o proposto neste conceito, torque considerável gerado a partir de um eletroímã composto por 300 espiras e consumo máximo de 10, 0 A. A corrente elétrica é também utilizada para ajustar a potência transferida para o eixo de saída (LI et al., 2019).

Com o objetivo de estipular uma linha base para o projeto, optou-se por definir um conceito de máquina que permitisse a adaptação de um produto com comportamento já conhecido. A bomba escolhida como referência (benchmark) foi apresentada no capítulo 1 pela figura 3, item 5. Para comparar o desempenho dos dispositivos, os principais elementos foram mantidos, exceto a polia, que, apesar de ter seu diâmetro externo mantido, aumentou longitudinalmente para criar a região ativa da máquina. Desta forma, a construção do protótipo possibilitou agregar o acoplamento magnético dentro do espaço disponível, sendo totalmente envolvido pela polia.

\subsection{Definição da região ativa da máquina}

Um dos aspectos mais importantes durante a elaboração do conceito foi determinar onde seria formada a região ativa da máquina. Essa região é caracterizada pela propagação das correntes induzidas no material ferromagnético a partir da alternância do fluxo magnético imposto ao circuito.

O principal requisito na adaptação do produto corrente é não modificar o diâmetro externo da polia. Uma alteração nesse valor impossibilitaria a comparação entre as bombas, 
pois modificaria a relação de 1:1,47 existente entre a velocidade do motor de combustão interna e a velocidade de giro da polia. Em outras palavras, a relação do torque em função da velocidade da polia seria diferente. Essa alteração também inviabilizaria a substituição do produto corrente, pois exigiria a modificação do comprimento da correia.

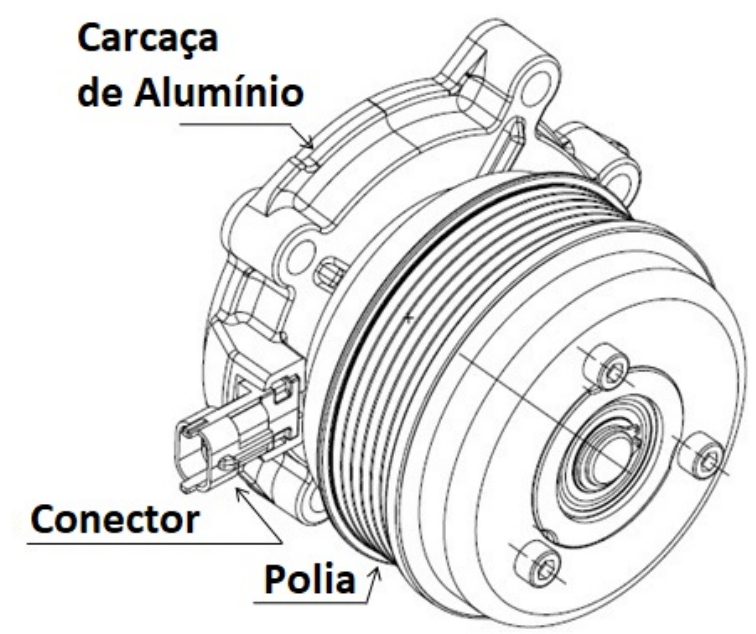

Figura 29 - Aspectos externos da bomba d'água de vazão variável.

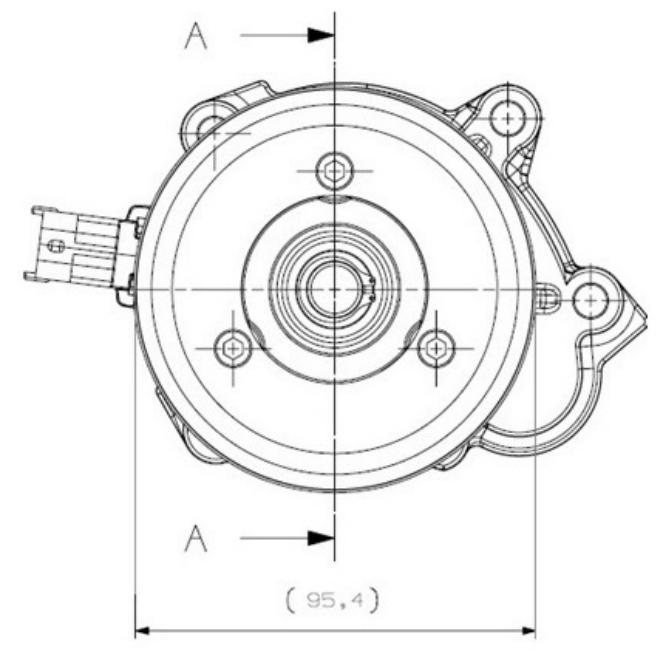

(a) A letra $A$ define o plano longitudinal vertical.

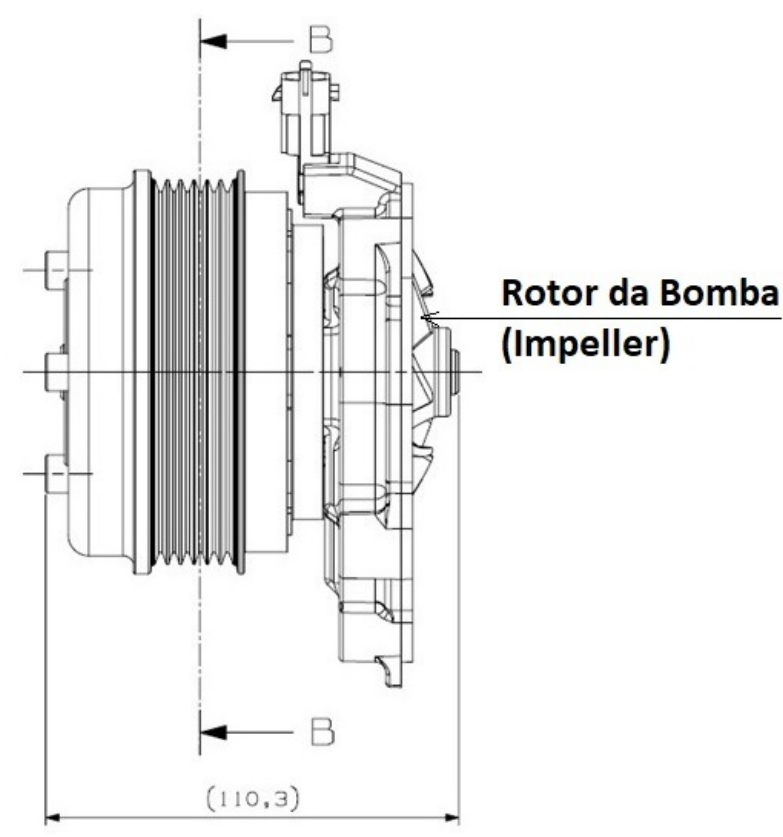

(b) A letra $B$ define o plano transversal vertical.

Figura 30 - Cortes usados para definição dos planos a partir da vista frontal e da vista lateral direita.

Outra característica que ajudou nessa definição é o fato da polia ser fabricada em aço SAE1020. Por ter um bom comportamento ferromagnético, boa espessura e ser um 
conjunto único, mostrou-se ideal para a propagação das correntes induzidas. Portanto, além da polia permitir a interface da bomba com a correia, neste novo conceito também compreende a região ativa da máquina. Essa definição equipara a polia ao cilindro. Cilindro foi o termo utilizado durante a etapa de modelamento matemático para referenciar o disco externo, conectado ao eixo de entrada, por onde as correntes induzidas se propagam e criam a região ativa da máquina.

A figura 29 apresenta os aspectos externos do dispositivo, onde evidencia-se o conector utilizado para fornecer corrente elétrica ao eletroímã, a carcaça de alumínio que permite a construção do dispositivo e sua fixação no bloco do motor, e a polia. A figura 30 define as vistas em corte que serão utilizadas. A figura 30a apresenta a linha de corte do plano longitudinal vertical a partir da vista frontal. Já a figura 30b apresenta a linha de corte do plano transversal vertical a partir da vista lateral direita.

\subsection{Características construtivas}

O dispositivo proposto é composto por oito pares de polos, sendo que, entre eles, foram posicionados ímãs de neodímio com o intuito de produzirem torque mesmo na ausência de corrente elétrica. Essa corrente é fornecida ao eletroímã (solenoide) por meio de um circuito eletrônico, cujo controle neste fornecimento visa ajustar o $\phi_{a c}$.

Para melhor explicar sua composição, a máquina foi dividida em três subconjuntos, conforme apresenta a figura 31, que são isolados mecanicamente. Os números foram devidamente posicionados para simplificar a identificação dos principais componentes de cada subconjunto. A tabela 3 , portanto, relaciona o número ao respectivo nome do componente.

Essa divisão tem como base os entreferros da máquina, sendo assim, do primeiro subconjunto para o segundo existe um entreferro de $0,25 \mathrm{~mm}$, assim como do segundo para o terceiro. Adotou-se esse valor para os entreferros por ser o menor espaçamento possível no processo de usinagem disponível. O espaço entre o primeiro e o segundo subconjunto é chamado de entreferro inferior. O espaço entre o segundo e o terceiro de entreferro superior. Este último é o entreferro entre os polos do acoplamento e a face interna da polia, que forma a região ativa da máquina. Nesta configuração, a única forma de movimentar o rotor de acoplamento é por magnetismo. Com a criação do entreferro inferior evita-se o uso de um coletor de anéis e escovas para alimentar a bobina que irá gerar o campo eletromagnético. 


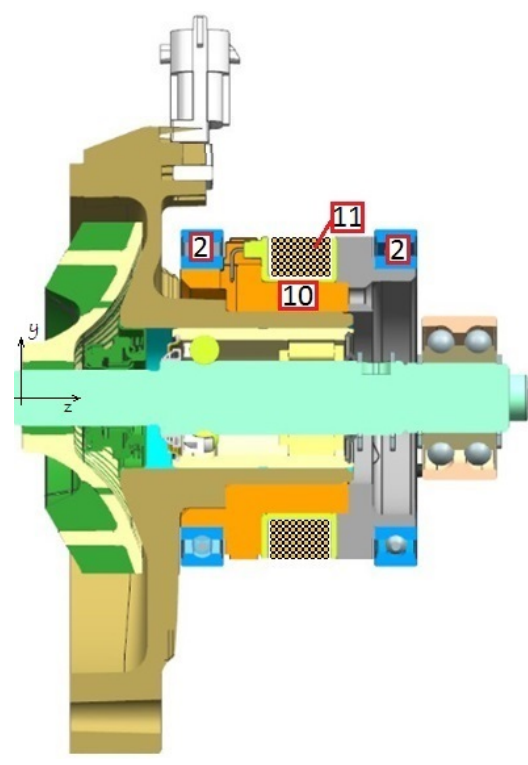

(a) $1^{\text {o }}$ subconjunto (eletroímã).

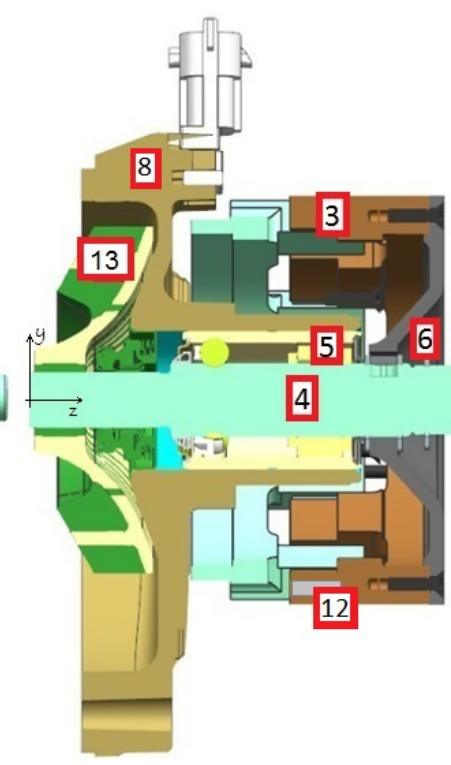

(b) $2^{\circ}$ subconjunto (rotor).

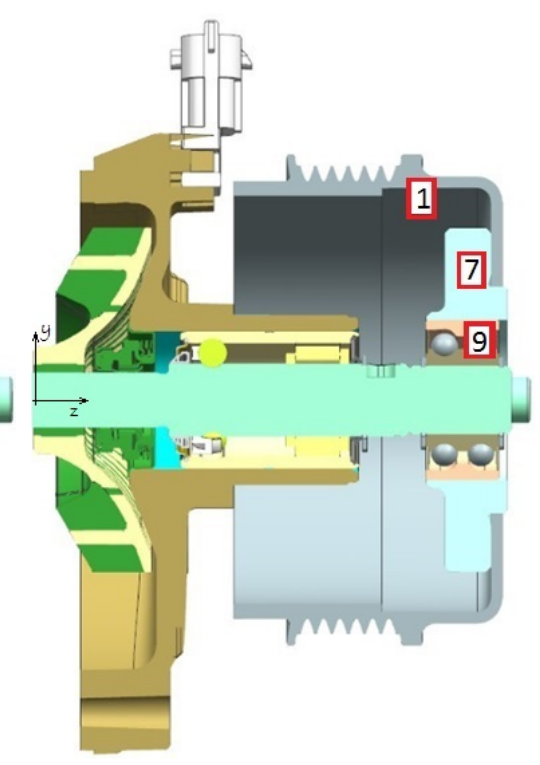

(c) $3^{\circ}$ subconjunto (polia ou cilindro).

Figura 31 - Divisão da máquina em três subconjuntos. O entreferro entre cada subconjunto é de $0,25 \mathrm{~mm}$.

Tabela 3 - Principais componentes da máquina e seus respectivos números.

\begin{tabular}{|l|l|l|l|l|l|}
\hline No. & Descrição & No. & Descrição & No. & Descrição \\
\hline 1 & Polia/cilindro & 6 & Peça de aço inoxidável & 11 & Eletroímã \\
\hline 2 & Rolamento & 7 & Flange & 12 & Ímã permanente \\
\hline 3 & Rotor & 8 & Carcaça & 13 & Rotor da bomba \\
\hline 4 & Eixo Principal & 9 & Rolamento secundário & & \\
\hline 5 & Rolamento & 10 & Base & & \\
\hline
\end{tabular}

O primeiro subconjunto é composto pelo eletroímã e por uma estrutura de aço ferromagnético denominada base, que deve ser prensada contra a carcaça de alumínio. $O$ eletroímã tem forma anular, colocado no meio da máquina, em torno da estrutura de aço. É um subconjunto fixo que aloja os rolamentos para interface com o rotor do acoplamento (eixo de saída) e é mostrado na figura 31a.

O segundo subconjunto, conforme mostrado pela figura $31 \mathrm{~b}$, é composto pelo rotor da bomba d'água, o eixo principal, o rolamento principal e o rotor do acoplamento. $\mathrm{O}$ movimento transferido do rotor do acoplamento para o rotor da bomba d'água é feito pela conexão mecânica entre a peça de aço inoxidável e o eixo principal. O rolamento principal permite que o eixo gire e é prensado contra a carcaça de alumínio, garantindo de forma adequada o alinhamento do eixo principal. 
O último subconjunto compreende a polia, a flange e um rolamento conectado ao eixo principal, isolando assim o movimento da polia. Este subconjunto é apresentado pela figura 31c.

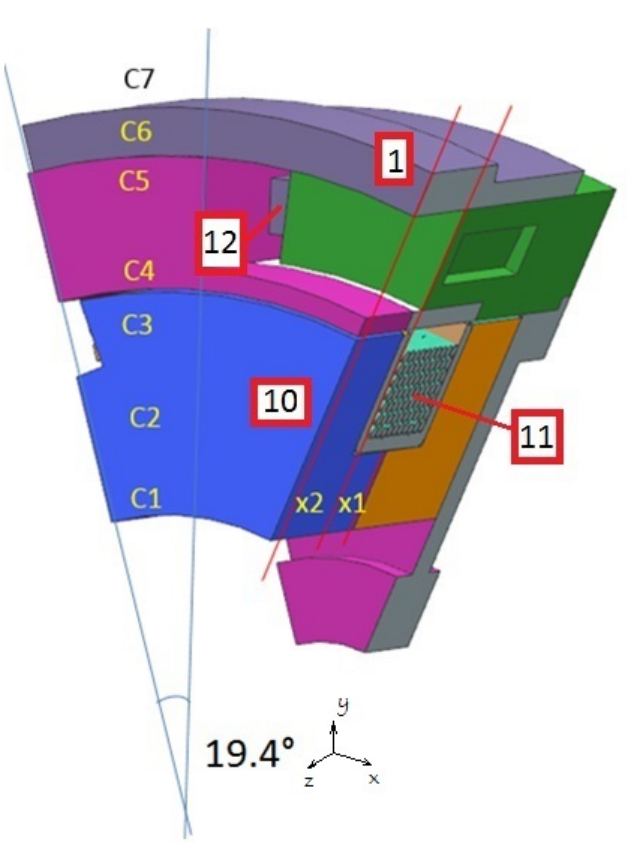

(a) Vista em perspectiva da máquina.

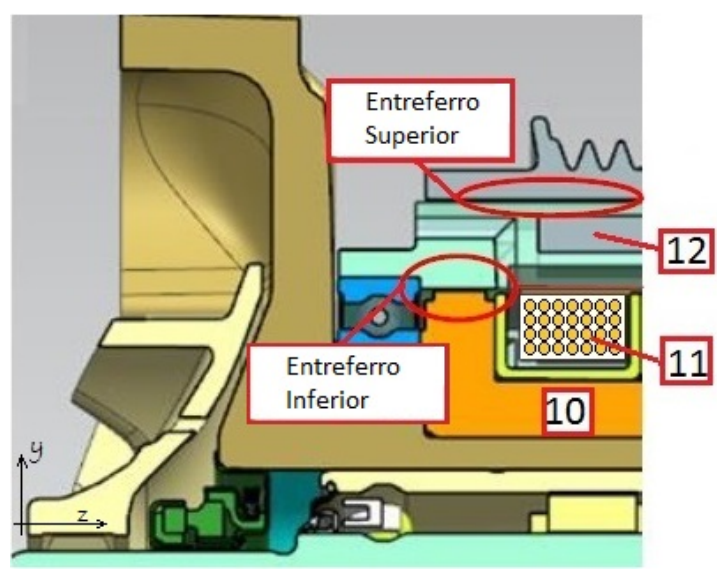

(b) Entreferro superior e inferior.

Figura 32 - Divisão da máquina em três subconjuntos. O entreferro entre cada subconjunto é de $0,25 \mathrm{~mm}$.

Apenas para melhor ilustrar o conceito, uma imagem que representa $45^{\circ}$ do plano transversal, resultando em uma vista em perspectiva de um par de polos, é apresentada pela figura 32a. A diferença entre o raio de $C 3$ e $C 4$ é de $0,25 \mathrm{~mm}$ e forma o entreferro inferior. O entreferro superior é formado pela diferença entre $C 5$ e $C 6$ de raio, também de 0,25 mm. Já a figura 32b indica com maior clareza onde se encontra o entreferro superior distância entre a região ativa presente na face interna da polia e o rotor do acoplamento - e o entreferro inferior. Por fim, a figura 33 apresenta o plano longitudinal, ilustrando a máquina em seu arranjo final com os três subconjuntos.

\subsection{Ativação da máquina}

A máquina é acionada quando a polia é colocada em movimento. A polia é conectada ao virabrequim do motor por uma correia, onde a força mecânica é transmitida para a bomba d'água. Supondo que a corrente elétrica máxima seja aplicada ao eletroímã (solenoide), a quantidade máxima de corrente é induzida na região ativa (face interna da polia) pelo fluxo 


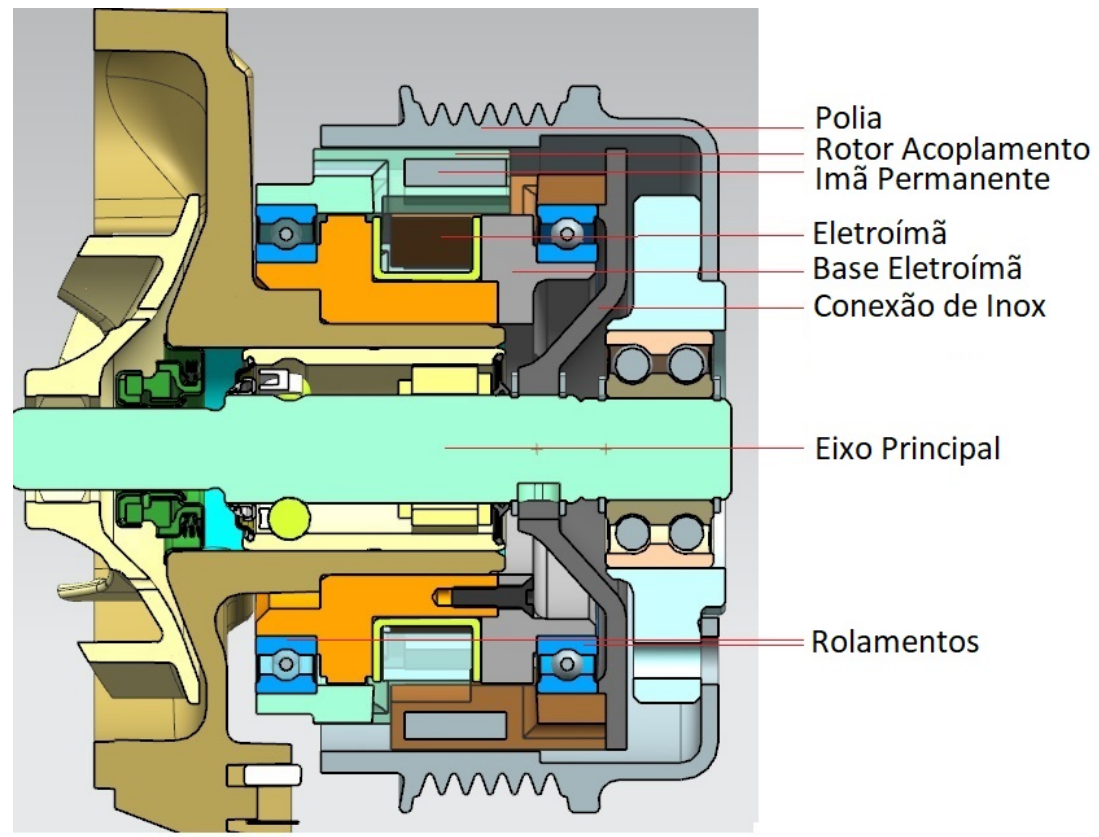

Figura 33 - Corte transversal a partir da visão lateral do modelo em três dimensões.

magnético que passa pelos polos do rotor $\left(\phi_{a c}\right)$.

Como efeito da indução das correntes de Foucault, o alinhamento das forças dos polos magnéticos e as correntes induzidas movem o subconjunto do rotor de acoplamento, que é conectado ao rotor da bomba d'água. A velocidade da polia é incontrolável, pois segue a rotação do motor (virabrequim). À medida que a velocidade do motor aumenta, a potência de entrada disponível aumenta proporcionalmente. Como este tipo de acoplamento é assíncrono, a velocidade do rotor da bomba d'água será sempre menor do que a velocidade da polia. Essa diferença entre a velocidade do eixo de saída e de entrada é a velocidade de escorregamento, e está relacionada à energia dissipada na região ativa.

\subsection{O rotor do acoplamento magnético}

O subconjunto do rotor de acoplamento é composto por 16 ímãs permanentes, além dos polos intercalados produzidos com material ferromagnético. Esse subconjunto é prensado contra dois rolamentos para o correto alinhamento e movimento adequado.

O rotor é conectado mecanicamente ao eixo principal pela peça de aço inoxidável onde, desta forma, o torque transferido eletromagneticamente é utilizado para movimentar o rotor da bomba d'água. A opção pela topologia Lundell (polos centralizados e intercalados) vem da afirmação de Davies (DAVIES, 1966), que, ao estudar um acoplamento indutivo e compará-lo ao da topologia Lundell, concluiu que este transferiu cerca de cinco vezes mais 


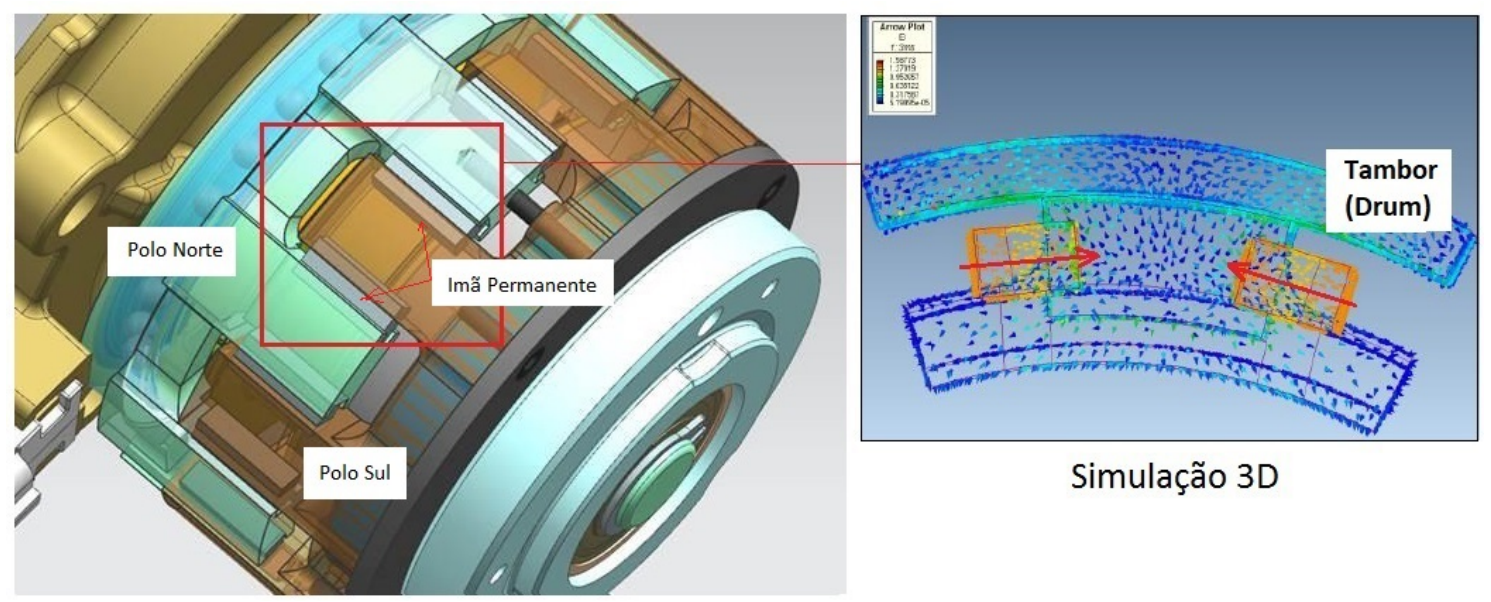

Figura 34 - Visão frontal de um polo e os ímãs permanentes.

torque. Essa capacidade em transferir mais energia vem da maior amplitude na excitação magnética por alternar entre os polos positivo e negativo de forma centralizada na região ativa.

Para um melhor entendimento, a figura 34 apresenta com maiores detalhes os componentes do rotor. A peça em verde representa o polo magnético norte, enquanto a peça marrom representa o polo magnético sul. Essa polarização é gerada pelo eletroímã presente no primeiro subconjunto. Portanto, os polos podem ser modificados, dependendo do sentido da corrente que passa pelo eletroímã. A figura também apresenta a polarização transversal exigida para os ímãs permanentes e destaca sua posição entre os polos magnéticos. O resultado de uma simulação feita em três dimensões evidencia a polarização dos ímãs e o fluxo magnético que circula no rotor.

\subsection{Cálculo da constante de máquina $M$}

A partir da definição geométrica foi possível então calcular a constante $M$, vide equação (3.62). O material utilizado foi o SAE1020, cuja resistividade $\rho$ é equivalente a $1,72.10^{-7}$ ohms. Os principais dados para o cálculo estão listados na tabela 4 , retirados da figura 35, que representa o polo magnético norte, também mostrado na figura 34.

Considerou-se, inicialmente, $L$ com 16 milímetros por conta do ímã utilizado e pela geometria centralizada dos polos. Este seria o valor que representa a interposição dos polos, onde ocorre a maior variação magnética. 

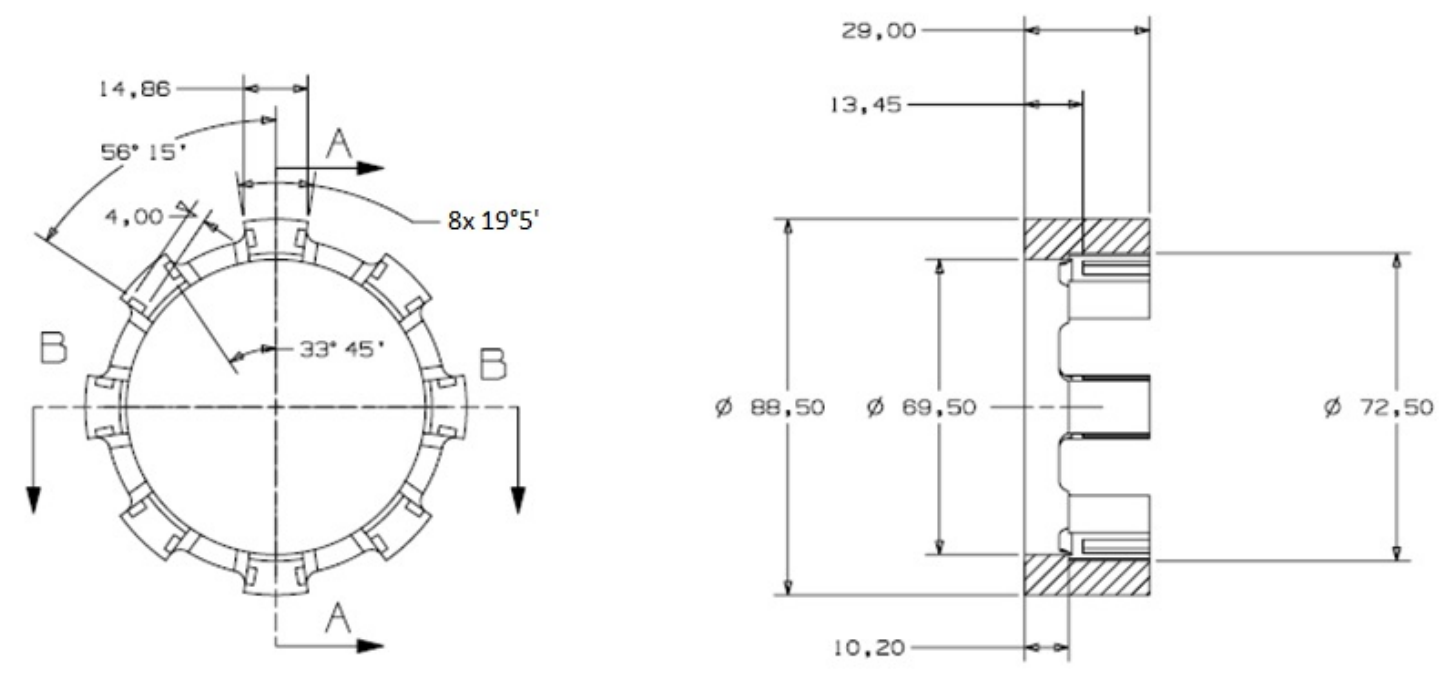

SECTION A-A

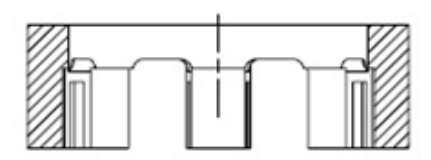

SECTION B-B

ULTINO NUMEO UTILIZZNO:
LST NEMGER USED:

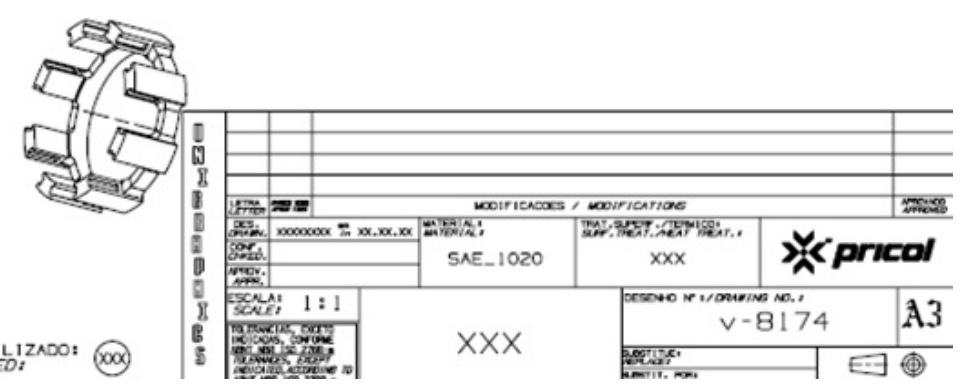

Figura 35 - Desenho com as dimensões de uma das peças do rotor do acoplamento.

Tabela 4 - Principais dados do dispositivo proposto e seus respectivos valores.

\begin{tabular}{|l|l|l|}
\hline Item & Valor & Unidade \\
\hline$D$ (diâmetro) & 88,50 & $\mathrm{~mm}$ \\
\hline$L$ (comprimento do polo) & 16,00 & $\mathrm{~mm}$ \\
\hline$\theta_{p}$ (segmento de arco de um polo) & 19,00 & graus \\
\hline$\rho$ (resistividade do SAE1020) & $1,72.10^{-7}$ & ohm \\
\hline$p$ (pares de polos) & 8 & $\mathrm{pares}$ \\
\hline$g$ (entreferro) & 0,25 & $\mathrm{~mm}$ \\
\hline$\mu_{0}$ (permeabilidade do vácuo) & $1,256.10^{-6}$ & $\mathrm{H} / \mathrm{m}$ \\
\hline
\end{tabular}

Sabendo-se que:

$$
M=\left(\frac{\rho^{0,325} L^{0,65}}{D^{0,35} p^{0,67}}\right)
$$

Tem-se que:

$$
M=\left[\frac{\left(1,2566 \cdot 10^{-6}\right)^{0,325} \cdot 0,016^{0,65}}{0,0885^{0,35} \cdot 8^{0,67}}\right]=2,47 \cdot 10^{-4}
$$




\subsection{Definição dos ímãs permanentes}

O ímã escolhido para o projeto foi o $\mathrm{N} 42 \mathrm{SH}$, com alto valor de $\mathrm{Br}$ e bom comportamento quando submetido a alta temperatura. A figura $36^{1}$ apresenta o segundo quadrante da curva de magnetização. Nota-se, por ela, o seu comportamento estendido para altas temperaturas. Desta curva obtém-se os principais dados operacionais do ímã, apresentados pela tabela 5 .

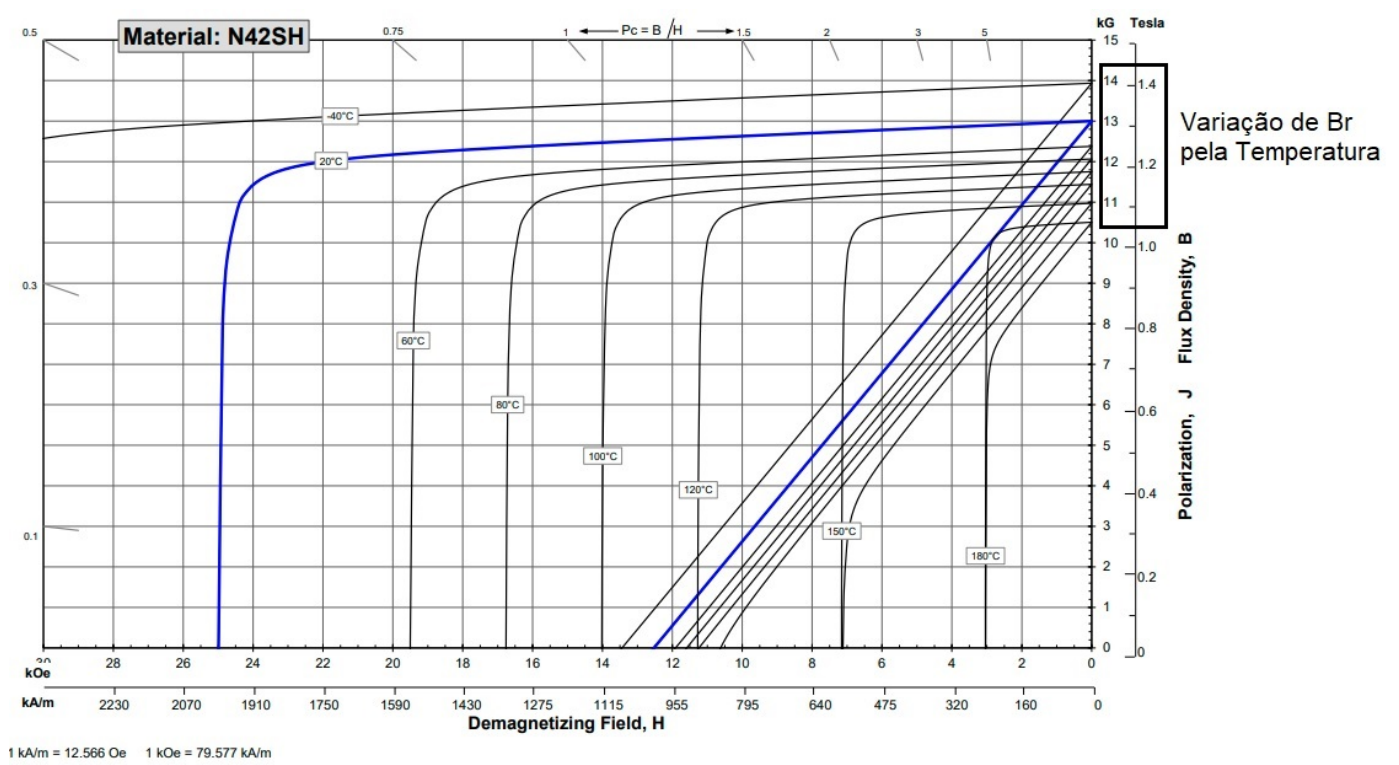

Figura 36 - Segundo quadrante da curva de magnetização.

Fonte: (Arnold Magnet Technologies)

Foi com base nesta escolha que foi definida a geometria dos polos e como fixar o ímã entre eles. A figura 37 apresenta as características dimensionais dos ímãs e como é feita sua polarização. Pode-se imaginar assim as linhas de campo no sentido horizontal e se propagando pelo ar, fechando o circuito entre os polos. Uma vez escolhido o ímã e com os seus dados levantados, o passo foi verificar se o ímã presente no software de simulação (Magnet, Infolytica) possuía um modelo compatível.

Tabela 5 - Dados característicos do ímã permanente (N42SH).

\begin{tabular}{|l|l|l|l|l|}
\hline Característica & Unidade & min. & nom. & max. \\
\hline$B r$ (Remanência) & $m T$ & 1280 & 1310 & 1340 \\
\hline$H_{c B}$ (Coercitividade) & $k A / m$ & 955 & 987 & 1019 \\
\hline$H_{c J}$ (Coercitividade intrínseca) & $k A / m$ & 1,592 & & \\
\hline$B H \max$ (Produto energético máximo) & $k J / m^{3}$ & 310 & 330 & 350 \\
\hline
\end{tabular}



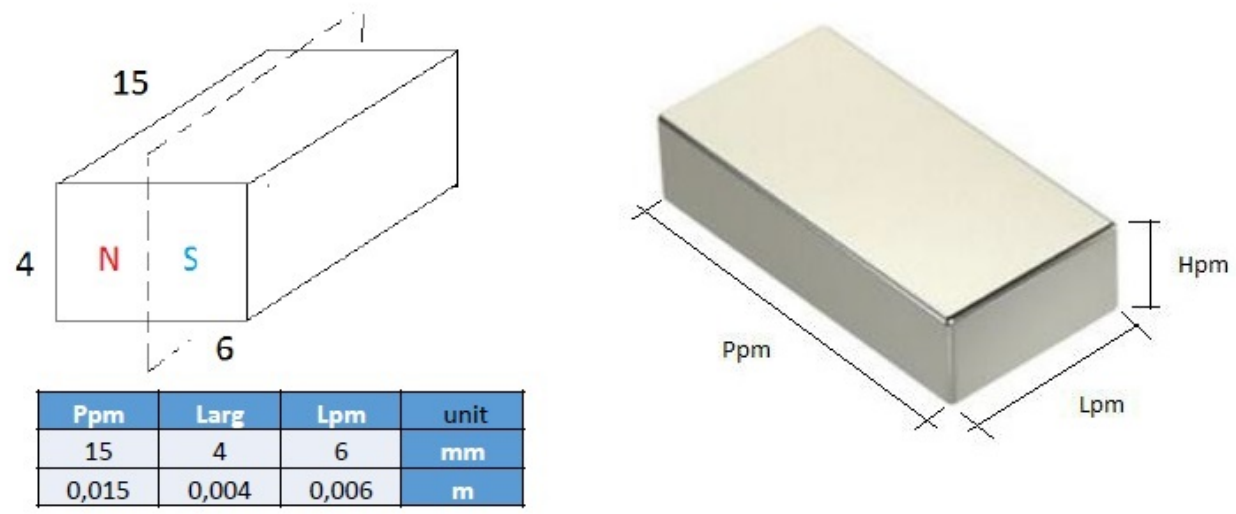

Figura 37 - Dimensional e polarização do ímã permanente.

Foram feitas simulações variando a temperatura em um circuito sem entreferro para comparação com o dados encontrados no manual. A figura 38 é o resultado da simulação com temperatura ambiente de $20^{\circ} \mathrm{C}$. Já a figura 39 apresenta o resultado da simulação para a temperatura ambiente de $150^{\circ} \mathrm{C}$.

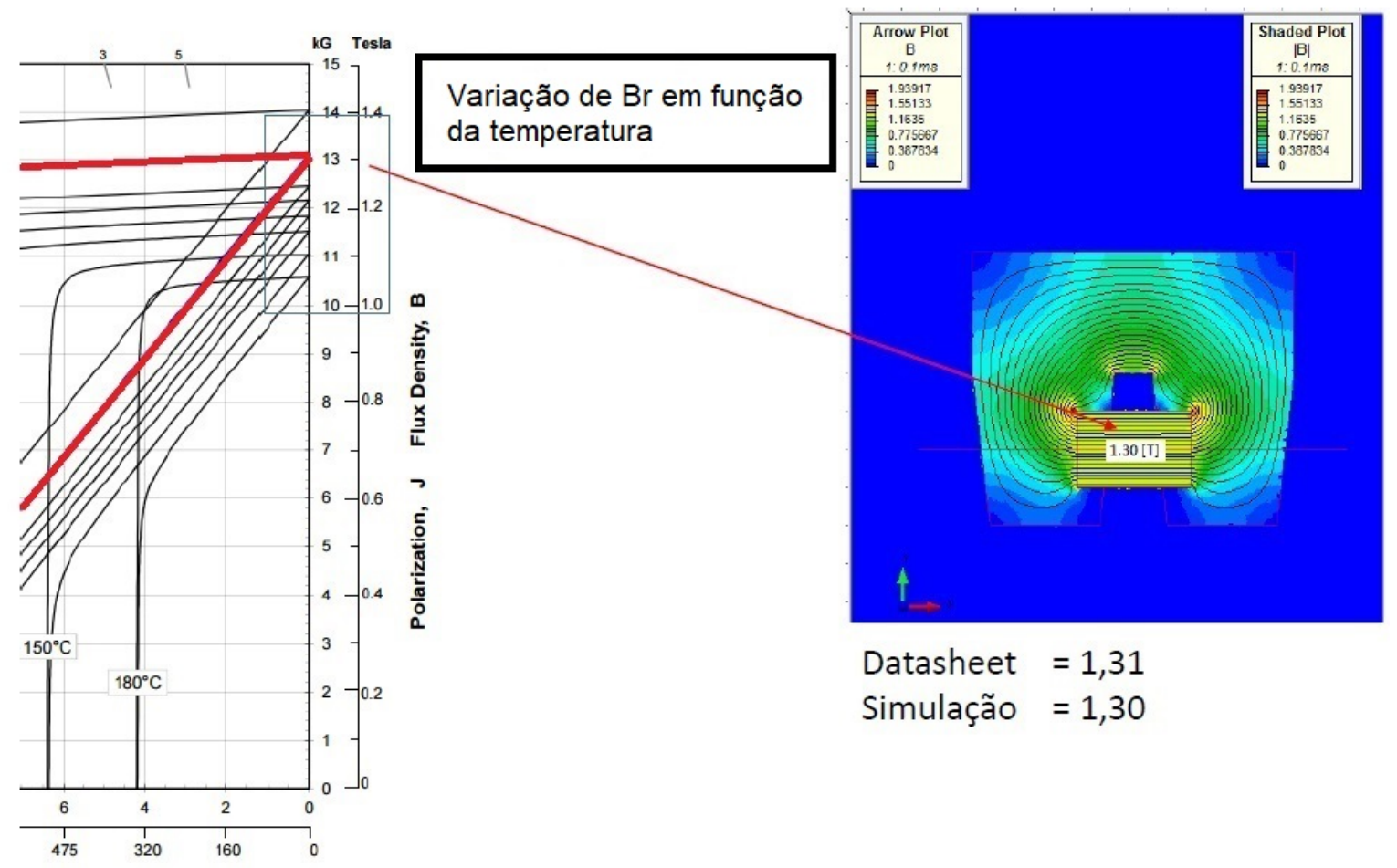

Figura 38 - Resultado da simulação com temperatura ambiente em $20^{\circ} \mathrm{C}$.

Ao comparar os resultados com temperatura ambiente em $150^{\circ} \mathrm{C}$, nota-se redução do fluxo magnético em aproximadamente $16 \%$. Outro ponto interessante é que os dois resultados da simulação apresentam valor inferior ao mostrado no manual. Essa pequena diferença é resultado da relutância do circuito criado com o aço SAE1020. 


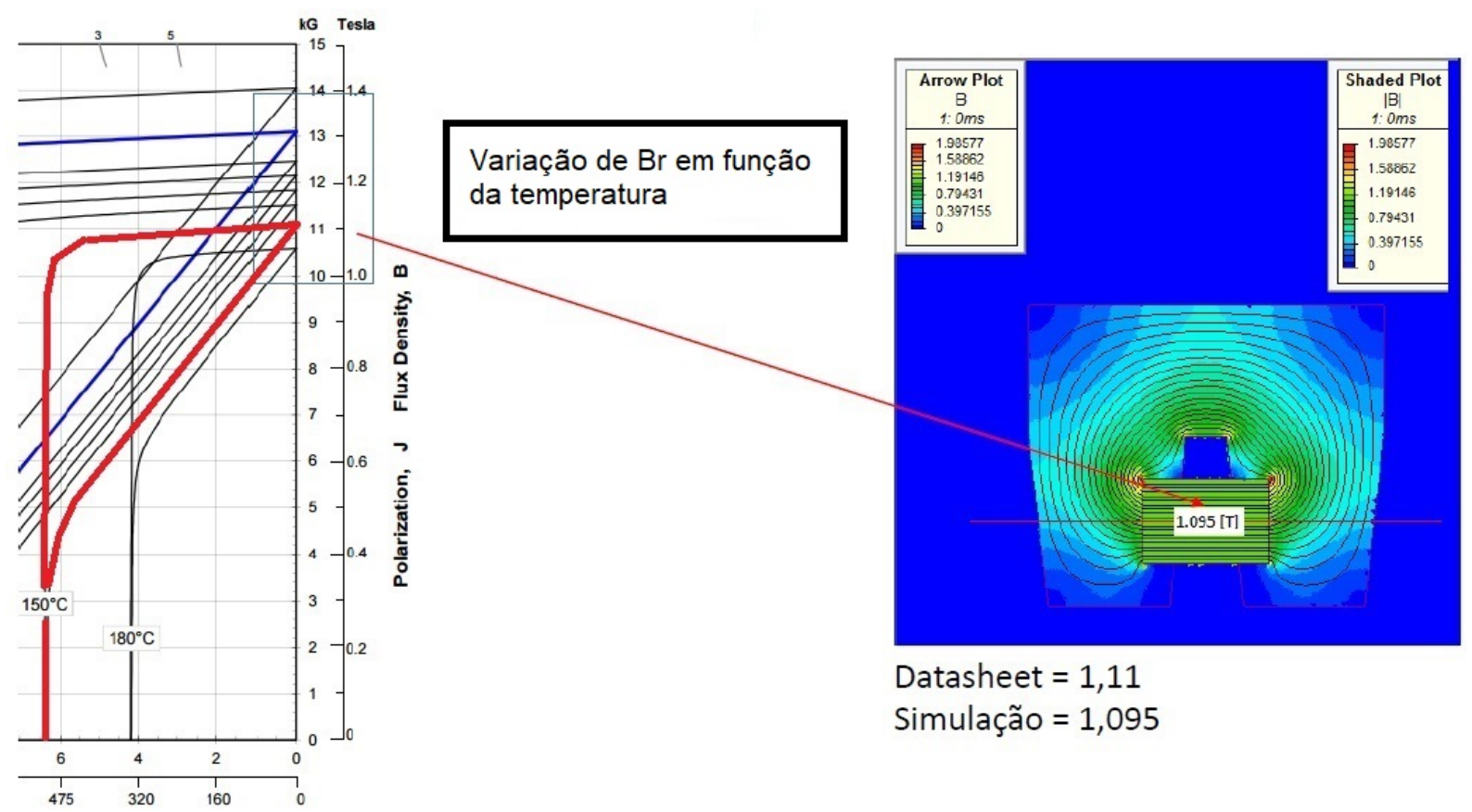

Figura 39 - Resultado da simulação com temperatura ambiente em $150^{\circ} \mathrm{C}$.

Estudando o caso com entreferro de 0,25 milímetros e utilizando o método apresentado no anexo A, $B g$ pôde ser calculado a partir da equação A.3:

$$
B g=\frac{1,31}{\left(1,12 \cdot 10^{-04}\right) /\left(6 \cdot 10^{-05}\right)}+1,056 \frac{0,5 \cdot 10^{-3}}{6 \cdot 10^{-3}}=0,66[T]
$$

Com isso chega-se ao valor do $\phi_{a c}$, onde:

$$
\begin{array}{r}
\phi_{a c}=\frac{B g}{S g}=7,51.10^{-05}[\mathrm{~Wb}] \\
B m=\frac{B g \cdot S g}{S p m}=1,25[\mathrm{~T}] \\
H m=\frac{B r-B o p}{\mu_{0} \mu_{r}}=44254[\mathrm{~A} / \mathrm{m}]
\end{array}
$$

Para ajustar o resultado com a relutância do circuito é necessário recalcular a força magneto motriz, considerando agora o $\phi$ de $7,51 \cdot 10^{-05}$. A tabela 6 é apresentada a seguir com os valores atualizados.

$$
H m=H c-\left(\frac{265,53}{0,006}\right)-\left(\frac{34,37}{0,006}\right)=937017[\mathrm{~A} / \mathrm{m}]
$$

Sendo $\mu_{r}=1,056$ e conhecendo $H m$, tem-se que:

$$
B m=937017 . \mu_{0} \mu_{r}=1,24[T]
$$




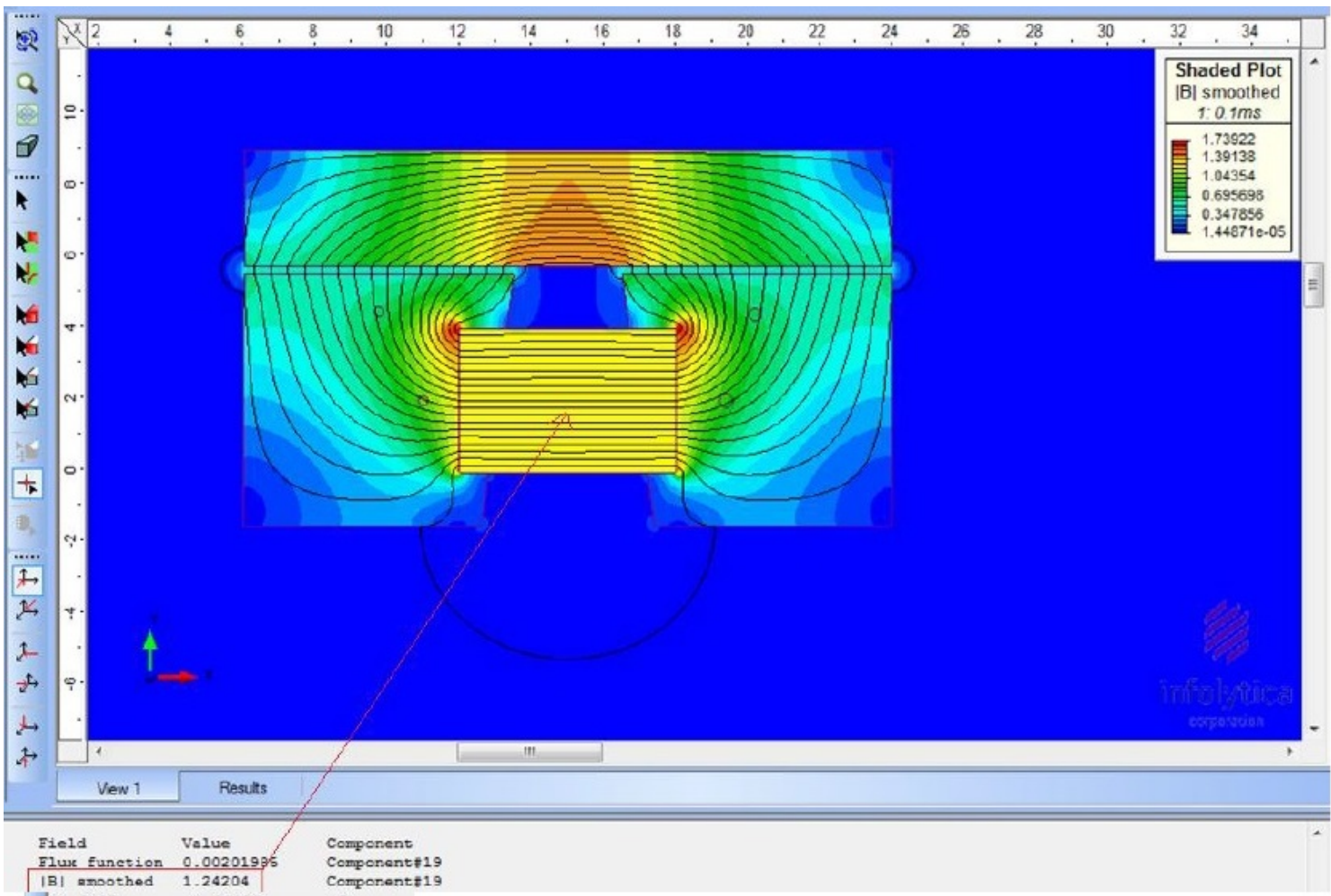

Figura 40 - Simulação por elementos finitos usando o software Magnet.

Tabela 6 - Variáveis para cálculo de Bg.

\begin{tabular}{|l|l|l|l|l|l|l|l|}
\hline Rx. & $A\left(m^{2}\right)$ & $L(m)$ & $\phi(W b)$ & $B(T)$ & $\Re(A t / W b)$ & $H(A t / m)$ & $\varepsilon=H . L$ \\
\hline 1 & $1,05 \mathrm{E}-04$ & $2,25 \mathrm{E}-03$ & $7,51 \mathrm{E}-05$ & $7,49 \mathrm{E}-01$ & & $3,65 \mathrm{E}+02$ & $8,21 \mathrm{E}-01$ \\
\hline 2 & $1,16 \mathrm{E}-04$ & $3,60 \mathrm{E}-03$ & $7,51 \mathrm{E}-05$ & $6,80 \mathrm{E}-01$ & & $3,20 \mathrm{E}+02$ & $1,15 \mathrm{E}+00$ \\
\hline 3 & $1,16 \mathrm{E}-04$ & $3,60 \mathrm{E}-03$ & $7,51 \mathrm{E}-05$ & $6,80 \mathrm{E}-01$ & & $3,20 \mathrm{E}+02$ & $1,15 \mathrm{E}+00$ \\
\hline 4 & $4,80 \mathrm{E}-05$ & $1,05 \mathrm{E}-02$ & $7,51 \mathrm{E}-05$ & $1,64 \mathrm{E}+00$ & & $2,80 \mathrm{E}+03$ & $2,94 \mathrm{E}+01$ \\
\hline 5 & $1,16 \mathrm{E}-04$ & $3,60 \mathrm{E}-03$ & $7,51 \mathrm{E}-05$ & $6,80 \mathrm{E}-01$ & & $3,20 \mathrm{E}+02$ & $1,15 \mathrm{E}+00$ \\
\hline 6 & $1,16 \mathrm{E}-04$ & $3,60 \mathrm{E}-03$ & $7,51 \mathrm{E}-05$ & $6,80 \mathrm{E}-01$ & & $3,20 \mathrm{E}+02$ & $1,15 \mathrm{E}+00$ \\
\hline 7 & $1,05 \mathrm{E}-04$ & $2,25 \mathrm{E}-03$ & $7,51 \mathrm{E}-05$ & $7,49 \mathrm{E}-01$ & & $3,65 \mathrm{E}+02$ & $8,21 \mathrm{E}-01$ \\
\hline $\mathrm{g}$ & $1,13 \mathrm{E}-04$ & $2,50 \mathrm{E}-04$ & $7,51 \mathrm{E}-05$ & $6,50 \mathrm{E}-01$ & $1,77 \mathrm{E}+06$ & $5,31 \mathrm{E}+05$ & $1,33 \mathrm{E}+02$ \\
\hline $\mathrm{g}$ & $1,13 \mathrm{E}-04$ & $2,50 \mathrm{E}-04$ & $7,51 \mathrm{E}-05$ & $6,50 \mathrm{E}-01$ & $1,77 \mathrm{E}+06$ & $5,31 \mathrm{E}+05$ & $1,33 \mathrm{E}+02$ \\
\hline
\end{tabular}

A comprovação vem pela simulação por elementos finitos, apresentada pela figura 40. O mais importante nesta etapa do estudo é comprovar que os modelos para simulação por elementos finitos dos principais componentes que serão utilizados estão de acordo com o esperado.

\subsection{Definição do ponto de operação}

Para definir o ponto de operação do dispositivo, que servirá como base para os cálculos, voltemos ao cálculo do fluxo por polo, vide equação 3.62, onde:

$$
\phi_{a c}=\text { cte. } M \frac{T^{0,35}}{n^{0,325}}
$$


Sendo $M$ uma constante e seu valor conhecido, as variáveis de entrada a serem estudadas passam a ser o torque $T$ e o escorregamento $n$. Por definição, escolheu-se que 400 rpm seria um escorregamento razoável para a máxima vazão. Assim, conhecendo a curva característica da bomba d'água, conforme apresentadas pelas figuras 4a e 4b, pôde-se estimar o torque desejado, baseando-se na máxima velocidade.

É importante destacar que o fluxo calculado, resultado do escorregamento e torque, já sofre redução por conta da reação de armadura, vide equação 3.71. Para melhor estudar esse efeito, algumas simulações foram realizadas e o valor do fluxo por polo calculado. Com isso foi possível estimar a redução efetiva. Essa estimativa é importante para o dimensionamento do circuito magnético, uma vez que este é feito para um fluxo estático. Assim, calcular o fluxo por polo necessário para um escorregamento de $400 \mathrm{rpm}$, conhecer a redução pela reação de armadura e efetuando-ser essa correção, torna-se fundamental para projetos com essa configuração de máquina.

Além da definição do escorregamento mínimo, e considerando as limitações físicas do projeto, pôde-se definir o volume ocupado pelo eletroímã. Lembrando que este componente encontra-se no primeiro subconjunto, cercado pela base ferromagnética do dispositivo. Para garantir seu isolamento, um componente de plástico com espessura de 1,2 $\mathrm{mm}$ foi projetado para acomodá-lo. Alguns estudos preliminares foram realizados a fim de maximizar a relação ampere-espira para a área disponível, concluindo que a melhor opção seria adotar o fio AWG23. Considerando o diâmetro nominal da seção de cobre $\mathrm{F}_{c}$ igual a $0,574 \mathrm{~mm}$ e adotando uma densidade de corrente $J$ em torno de $8,5 \mathrm{~A} / \mathrm{mm}^{2}$, obtém-se a corrente nominal de 2, $20 \mathrm{~A}$, como apresenta a equação 4.1 .

$$
i_{\text {nom }}=\pi \cdot\left(\frac{F_{c}}{2}\right)^{2} \cdot J=\pi \cdot\left(\frac{0,574}{2}\right)^{2} \cdot(8,5)=2,20(A)
$$

\subsection{Modos de operação}

A máquina foi projetada com o objetivo de fornecer controle do fluxo e, em caso de falha, operar com o campo magnético gerado pelos ímãs como forma de segurança. A partir das características construtivas do dispositivo, três modos de operação foram elaborados em função do sentido imposto à corrente aplicada no eletroímã.

Os modos de operação visão: ajustar a vazão da bomba d'água em qualquer valor 
até o limite imposto pela máxima transmissão de torque considerando a corrente elétrica no sentido positivo; desligar a bomba d'água aplicando corrente elétrica no sentido negativo ou proteger o motor de combustão a partir do torque residual em caso de pane que impossibilite o fornecimento de corrente elétrica.

No caso do modo de operação que visa ajustar a vazão, esse comportamento tem como base o ajuste da corrente elétrica no sentido positivo, podendo variar de zero até o limite de corrente. $O$ valor da corrente reflete no valor do torque transmitido e, consequentemente, no valor da vazão imposta ao sistema de refrigeração.

O primeiro modo a ser apresentado com mais detalhes é justamente o que aplica corrente positiva no eletroímã. Desta forma, o fluxo magnético na região ativa passa a ser controlado de forma a aumentar a transmissão do torque. A figura 41a ilustra a relação entre o fluxo magnético gerado pelo eletroímã $\left(\phi_{s o l}\right)$ e o fluxo gerado pelos ímãs permanentes $\left(\phi_{\text {mag }}\right)$.

No canto superior esquerdo da figura é possível observar o resultado da simulação 3D feita para um par de polos, onde mantiveram-se visíveis apenas os ímãs permanentes e o cilindro. É possível ver o módulo de densidade de fluxo magnético $|B|$, em torno de 1, 2 T na face interna do cilindro. Nesta configuração os campos são adicionados na região ativa da máquina $\left(\phi_{s o l}+\phi_{m a g}\right)$. Como consequência, o resultado da simulação mostra a face interna do cilindro quase completamente verde (em uma faixa entre 0,9 T a 1,3 T), indicando uma alta densidade de campo.

Mudando o sentido da corrente elétrica, observa-se o comportamento oposto, onde as forças magnetomotrizes do lado inferior são aumentadas e o magnetismo gerado pelos ímãs permanentes flui através dele. Neste momento a transmissão de torque é desligada, parando o movimento do impulsor. Este modo é mostrado pela figura $41 \mathrm{~b}$, onde pode ser visto que a face interna do cilindro é completamente azul, o que significa abaixo de $0,1 \mathrm{~T}$.

O terceiro e último modo de operação ocorre com a ausência de corrente elétrica no eletroímã. $O$ fluxo magnético gerado pelos ímãs permanentes $\left(\phi_{\text {mag }}\right)$ é dividido entre o circuito magnético superior e o inferior. Com esta configuração, estima-se que metade do fluxo magnético permaneça induzindo corrente em uma região ativa e transferindo potência pelo torque residual, uma vez que os entreferros superior e inferior são iguais. Na figura 41c observa-se uma maior concentração de fluxo magnético (em verde) na região dos ímãs e ausência de corrente parasita no centro (em azul). Comparativamente, seria uma situação intermediária entre o resultado apresentado nos dois modos anteriores. 


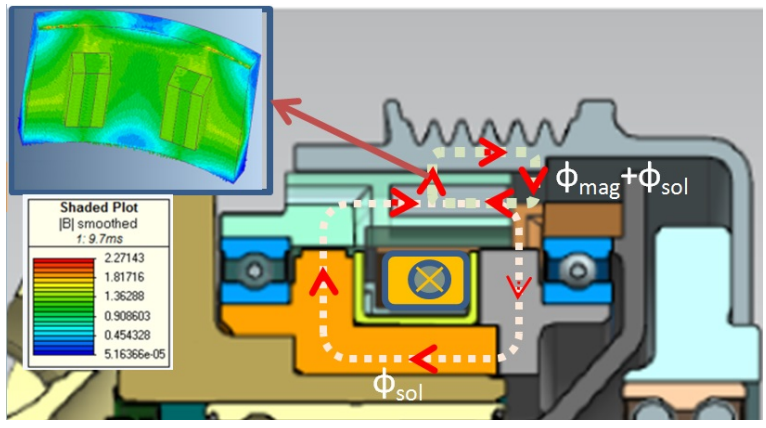

(a) Corrente no sentido positivo aplicada no eletroímã. A soma dos fluxos magnéticos $\left(\phi_{m a g}+\phi_{s o l}\right)$ é direcionada para a região ativa.

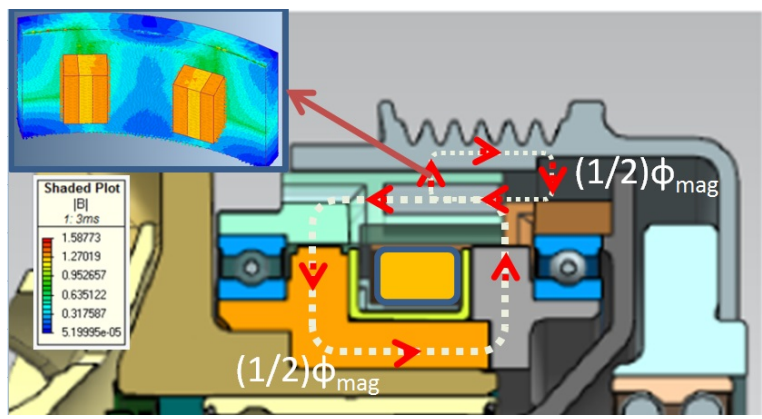

(c) Ausência de corrente elétrica. $\bigcirc \phi_{\text {mag }}$ divide-se entre os dois circuitos magnéticos. Como o entreferro superior é equivalente ao entreferro inferior, estima-se que metade do fluxo magnético é direcionado para a base do eletroímã, enquanto o valor restante é direcionado para a região ativa, através da superfície dos polos magnéticos do rotor do acoplamento.

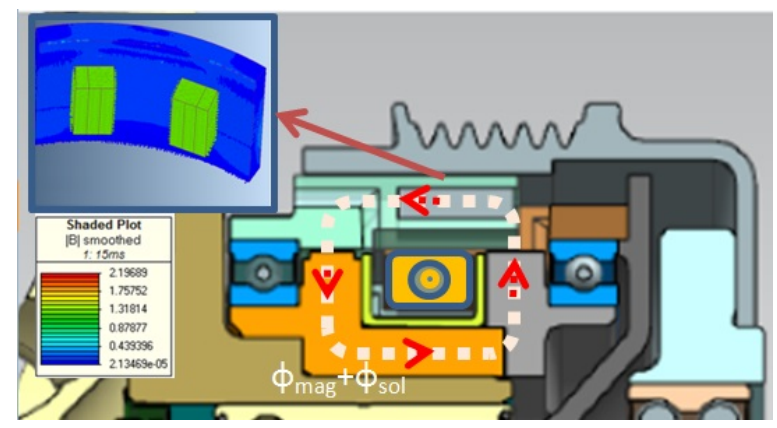

(b) Corrente no sentido negativo aplicada no eletroímã e ausência de fluxo na região ativa.

Figura 41 - Plano longitudinal superior da máquina ilustrando os caminhos percorridos pelo fluxo magnético nos três modos de operação.

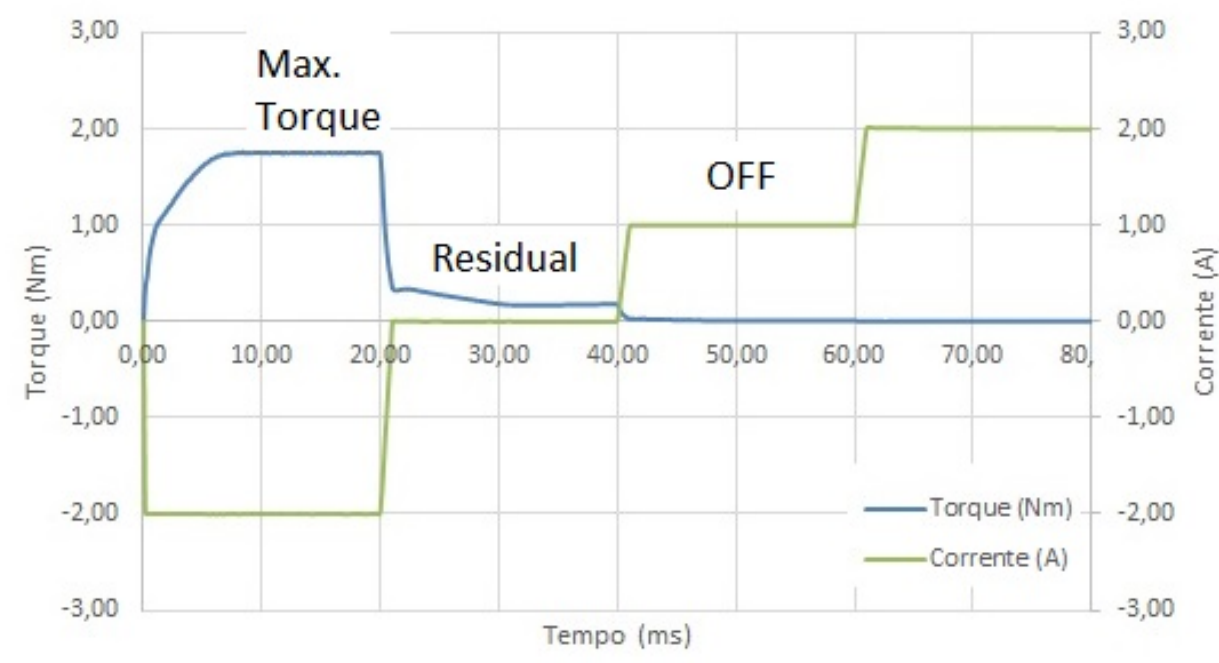

Figura 42 - Modos de operação: torque e corrente em função do tempo. 
Apenas para reforçar o conceito, a figura 42 apresenta um gráfico feito a partir dos dados obtidos de uma simulação, tema do próximo capítulo. Nele, destaca-se o torque residual, quando há ausência de corrente elétrica no eletroímã. Apesar do valor baixo, existe algum torque sendo transferido. Equilibrar esses valores é o desafio dos estudos em andamento. 


\section{Simulação por elementos finitos em}

\section{duas dimensões}

Uma vez criado o conceito para o dispositivo e tendo em mãos as fórmulas que modelam seu comportamento, utilizou-se uma ferramenta para simulação por elementos finitos para levantamento dos principais dados comportamentais da máquina, para que, posteriormente, os resultados possam ser validados com os dados de desempenho do protótipo. Desta forma, um conjunto de ferramentas validadas será construído e auxiliará no desenvolvimento de novos projetos.

Dada a complexidade do dispositivo, algumas simplificações foram necessárias durante a criação do modelo em duas dimensões. A primeira delas relaciona-se aos polos e aos ímãs. Lembrando que, como a maior parcela de torque gerado pelo acoplamento está na região de interposição dos polos, definiu-se a profundidade do modelo em 16 milímetros. A figura 43 demonstra essa concentração de fluxo a partir de uma simulação 3D.

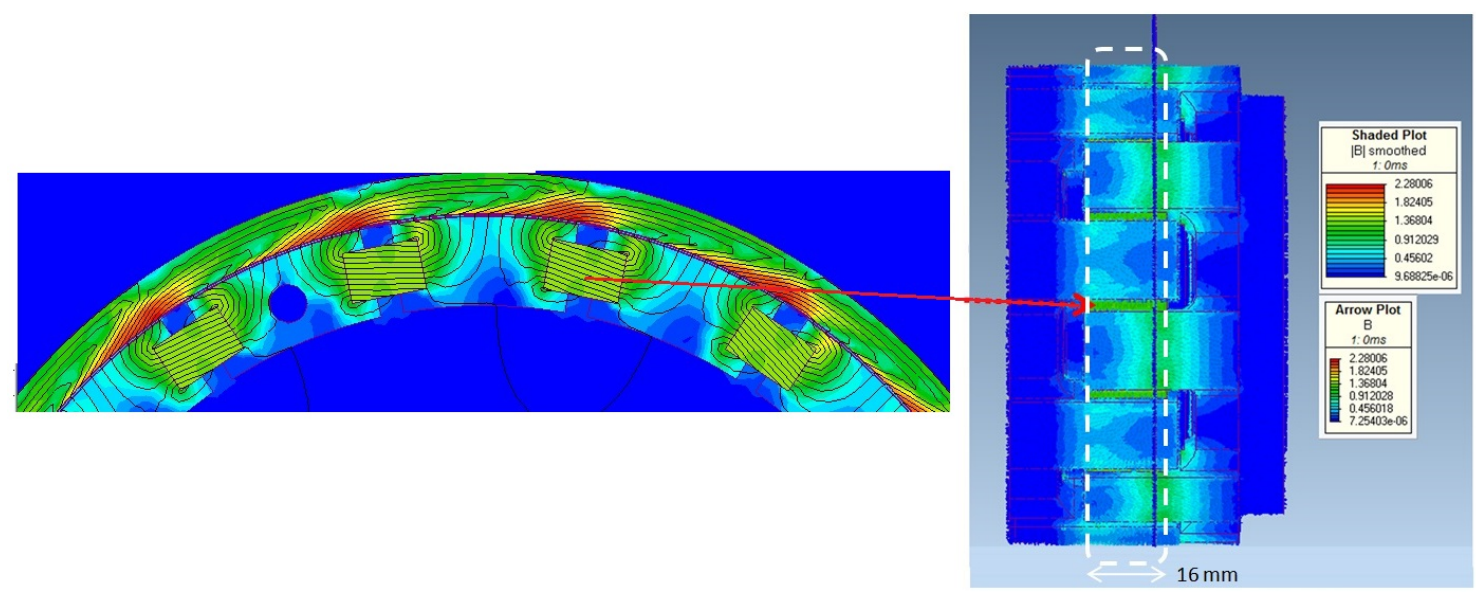

Figura 43 - Modelo 3D indicando a concentração do campo magnético na região onde os ímãs estão posicionados. Vista transversal utilizada como referência para o posicionamento.

\subsection{Definição do modelo em duas dimensões}

Inspirando-se no modelo em três dimensões apresentado pela figura 34, onde simulou-se apenas um polo magnético conectado à dois ímãs, criou-se um modelo para todo o conjunto conforme ilustração apresentada pela figura 44 . 

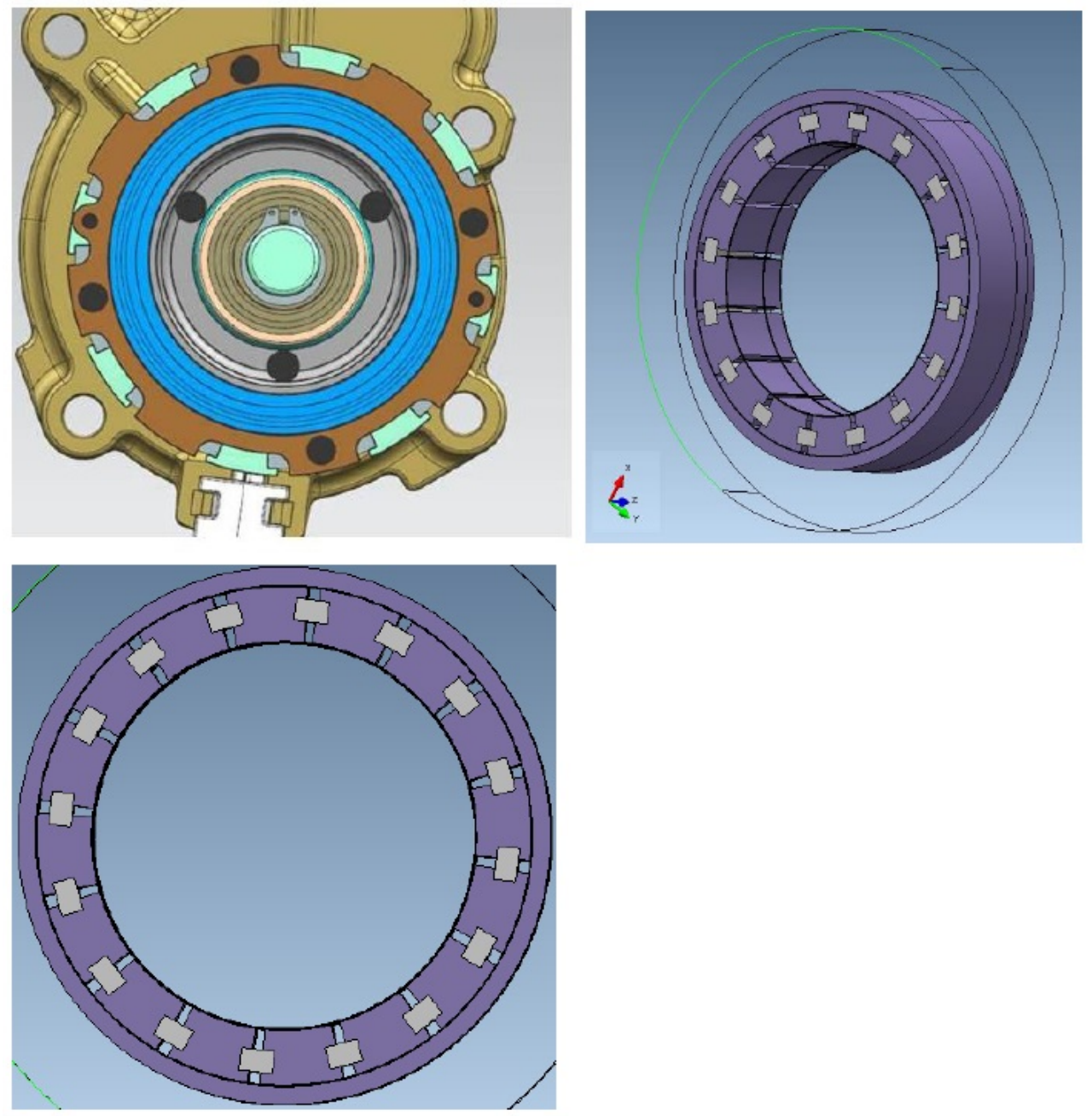

Figura 44 - Modelo 2D da simplificação proposta.

A primeira imagem (parte superior e lado esquerdo) é a visão frontal do dispositivo quando retirada a polia. Pode-se ver nela os ímãs e polos. Exportando o desenho em duas dimensões desta imagem e mantendo apenas os polos magnéticos, os ímãs e adicionando o disco que representa a polia (com espessura de 3 milímetros), chega-se no desenho apresentado pela segunda imagem (parte inferior e lado esquerdo). A terceira imagem (parte superior e lado direito) é uma vista em perspectiva.

Uma vez definida a geometria básica, buscou-se então polarizar os ímãs. Esta, por sua vez, é representada por uma seta vermelha, cujo sentido indicado informa a configuração dos polos magnéticos. Trata-se de uma configuração vetorial, sendo, portanto, diferente para cada ímã. A figura 45 mostra esta polarização para quatro ímãs posicionados na parte superior do modelo.

A figura 46 é o resultado de uma simulação. Nela, pode-se ver o circuito magnético criado por cada ímã, passando pela área ativa e o disco externo (cilindro), que está em 
movimento. Nota-se também saturação em algumas regiões em vermelho.

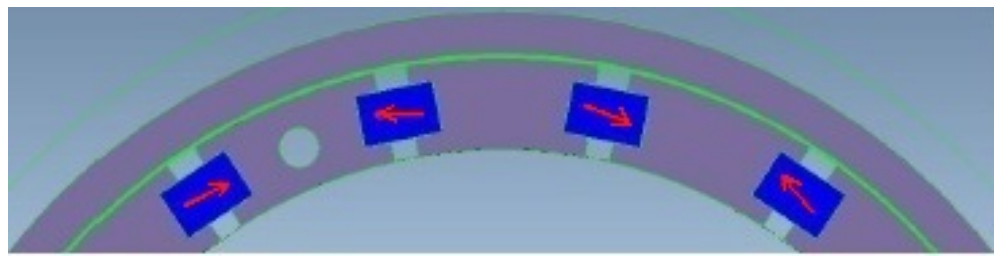

Figura 45 - Polarização dos ímãs permanentes.

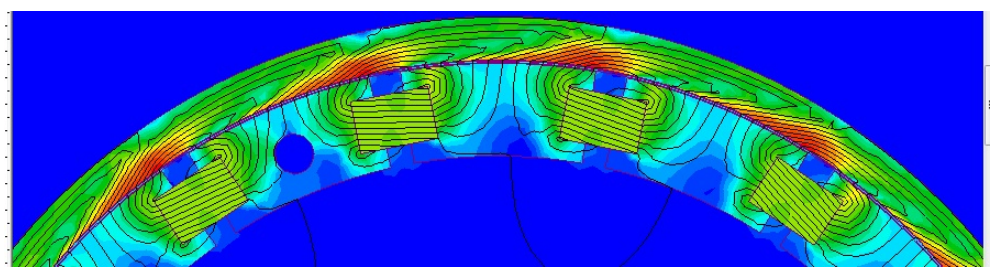

Figura 46 - Resultado da simulação 2D e as respectivas linhas de campo.

Outra simplificação possível para esse modelo foi manter o rotor do acoplamento estacionário. Com isso cria-se apenas uma região de movimento (polia), o que facilita o processamento matemático para os elementos finitos executado pelo simulador. Isto significa que a velocidade imposta na região ativa representa o escorregamento em si.

Definido o circuito magnético dos polos (representados o mais próximo da realidade possível), por fim, definiu-se como simular o eletroímã. Com sua configuração anelar e localizado no centro do dispositivo, a opção encontrada foi dividi-lo na mesma quantidade dos polos, buscando assim uma equivalência magnética. Esta opção baseou-se no artigo publicado por Ostovic (OSTOVIC et al., 1999), que estudou o circuito magnético de um alternador automotivo; uma máquina similar à proposta neste trabalho. A figura 47 apresenta o circuito magnético completo. Importante salientar que este circuito não representará as relutâncias reais do dispositivo e servirá para validar o cálculo e sua funcionalidade magnética apenas no que se refere ao torque em função do fluxo por polo.

A figura 47, além de apresentar o circuito magnético, também mostra o circuito elétrico aplicado utilizado para a simulação. Composto por uma fonte de corrente, os eletroímãs são conectados em série, mantendo assim a relação ampere-espira equivalente ao eletroímã anelar. Nesta configuração, o número de espiras de cada eletroímã deve ser o número total de espiras do eletroímã anelar, dividido pela quantidade de pares de polos. A utilização de uma fonte de corrente ajuda a diminuir o tempo de simulação, uma vez que não precisamos esperar a corrente estabilizar ao aplicar tensão. 

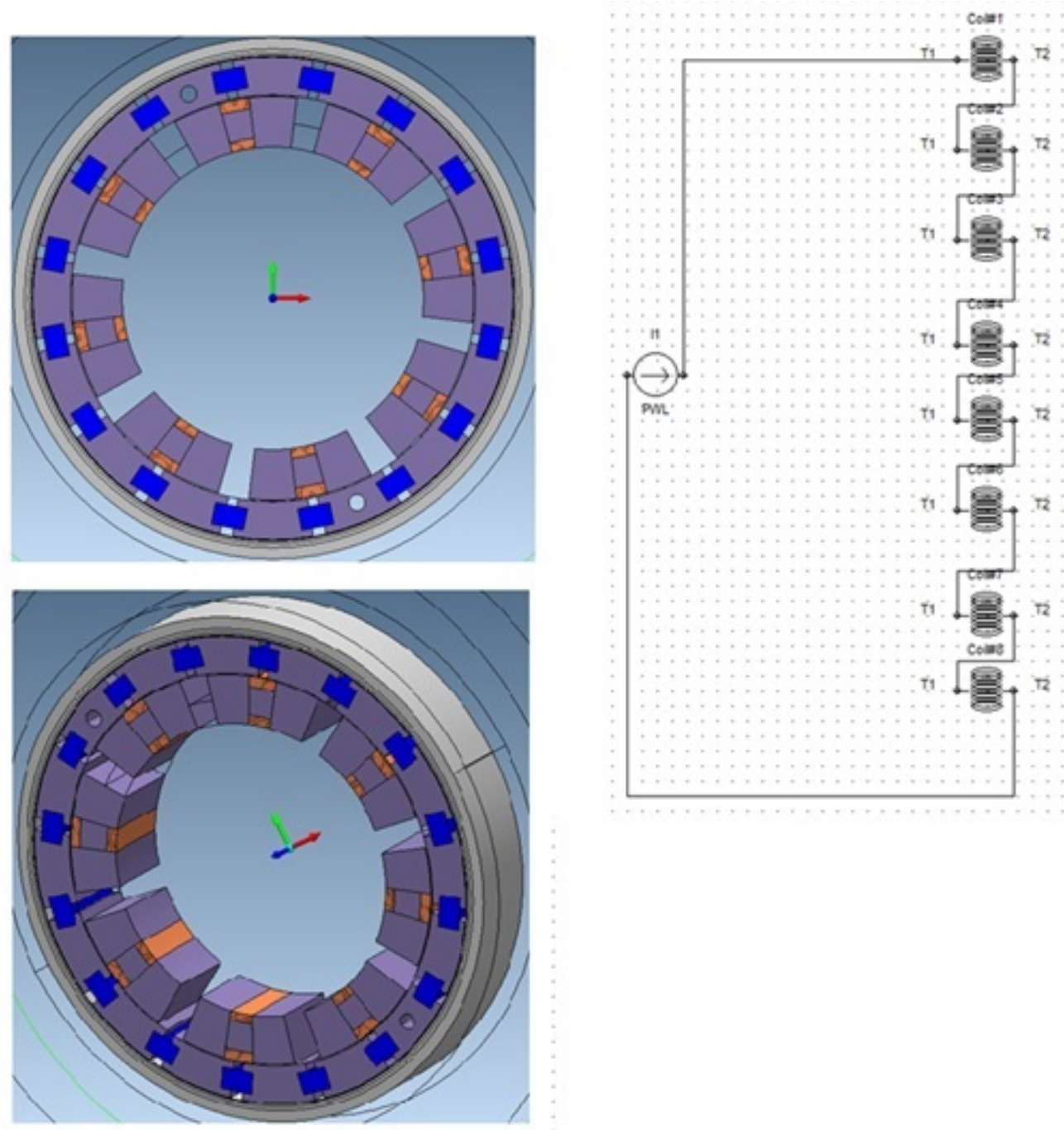

Figura 47 - Circuito elétrico utilizado nas simulações por elementos finitos.

\subsection{Comparação entre as simulações e os cálculos matemáti-} cos para o $\phi_{a c}$ e $J_{m}$

Para comparar o modelo em duas dimensões com os cálculos matemáticos, fixou-se o escorregamento em $400 \mathrm{rpm}$ e variou-se o torque partindo de 0 até $4 \mathrm{Nm}$. Além disso, testou-se a metodologia variando o material da região ativa, aplicando aço SAE1020 e aço puro (Ingot), utilizando os dados apresentados por Davies (DAVIES et al., 1975). Assim, na tabela 7 são listadas as principais variáveis de entrada para o cálculo.

Para obter o valor do fluxo por polo, integra-se o valor densidade de fluxo (B) ao longo da região que deseja-se calcular o fluxo magnético. Neste caso, integra-se a densidade de fluxo que passa através da face de um polo magnético do rotor do acoplamento, na região do entreferro. 
Tabela 7 - Principais dados do dispositivo proposto e seus respectivos valores.

\begin{tabular}{|l|l|l|}
\hline Item & Valor & Unidade \\
\hline$D$ (diâmetro) & 0.089 & $\mathrm{~m}$ \\
\hline$L$ (comprimento do polo) & 0.026 & $\mathrm{~m}$ \\
\hline$\rho_{S A E}$ (resistividade SAE1020 para $\left.20^{\circ} C\right)$ & $1,72.10^{-7}$ & $\Omega . \mathrm{m}$ \\
\hline$\rho_{\text {Ingor }}$ (resistividade aço puro) & $1,12.10^{-7}$ & $\Omega . \mathrm{m}$ \\
\hline$p$ (pares de polos) & 8 & Pares \\
\hline$n$ (escorregamento) & 6.67 & $\mathrm{rps}$ \\
\hline$l g$ (entreferro entre os polos e área ativa) & $0,25.10^{-3}$ & $\mathrm{~m}$ \\
\hline EspMag (espessura do ímã) & $4.10^{-3}$ & $\mathrm{~m}$ \\
\hline
\end{tabular}

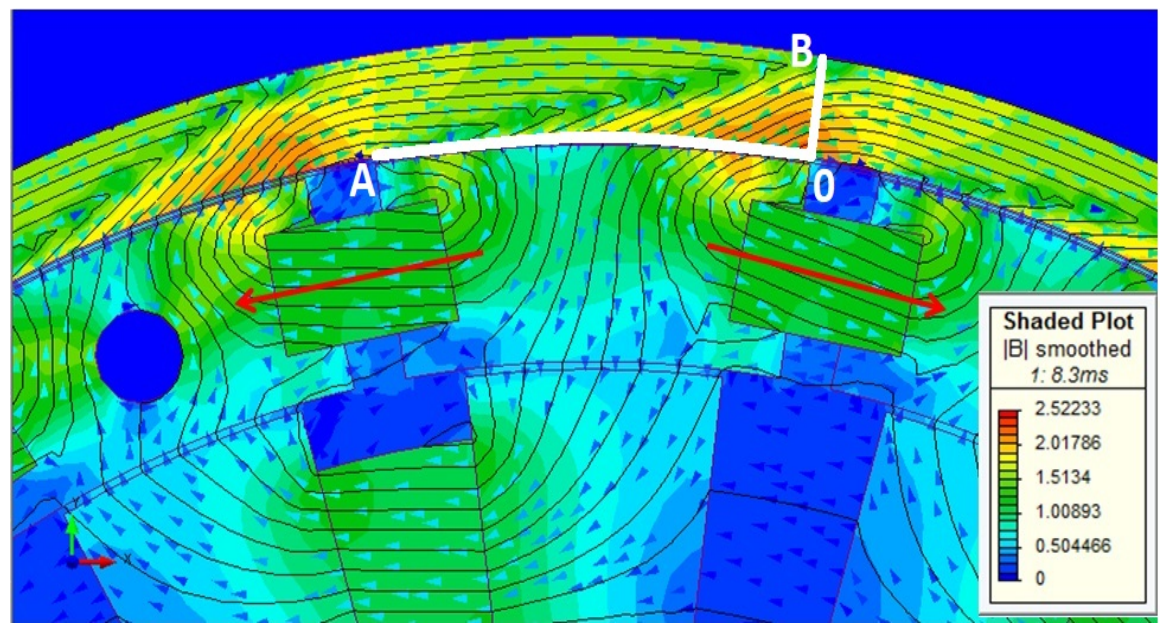

Figura 48 - Resultado da simulação por elementos finitos apresentando o fluxo magnético resultante em função da polarização dos ímãs permanentes.

A figura 48 evidencia o resultado da simulação, destacando as linhas que representam o fluxo magnético, bem como a face do polo em estudo. Com esse valor e sendo $\phi=B A$, é possível estimar $\phi_{a c}$. A simulação é transitória no tempo e a velocidade da polia é imposta a fim de produzir um escorregamento conhecido, conforme mencionado anteriormente. O tempo adotado para cada simulação foi de 8,3ms; tempo necessário para o acomodamento do torque produzido pelo escorregamento. No início da simulação o torque é nulo e aumenta ao longo do tempo. A figura 49 mostra esse comportamento em função do fluxo por polo para o aço SAE1020.

Como o torque é resultado da interação do campo magnético gerado pelas correntes induzidas e do fluxo magnético presente nos polos, simulamos quatro valores de indução ajustando-se a corrente elétrica consumida pelos eletroímãs.

Para comparação entre o resultado do cálculo e da simulação, o fluxo magnético foi medido a partir da integral da superfície de um polo, conforme mencionado anteriormente. Os resultados são apresentados pela figura 50. As tabelas 8 e 9 apresentam os valores com maiores detalhes e seus respectivos percentuais. 


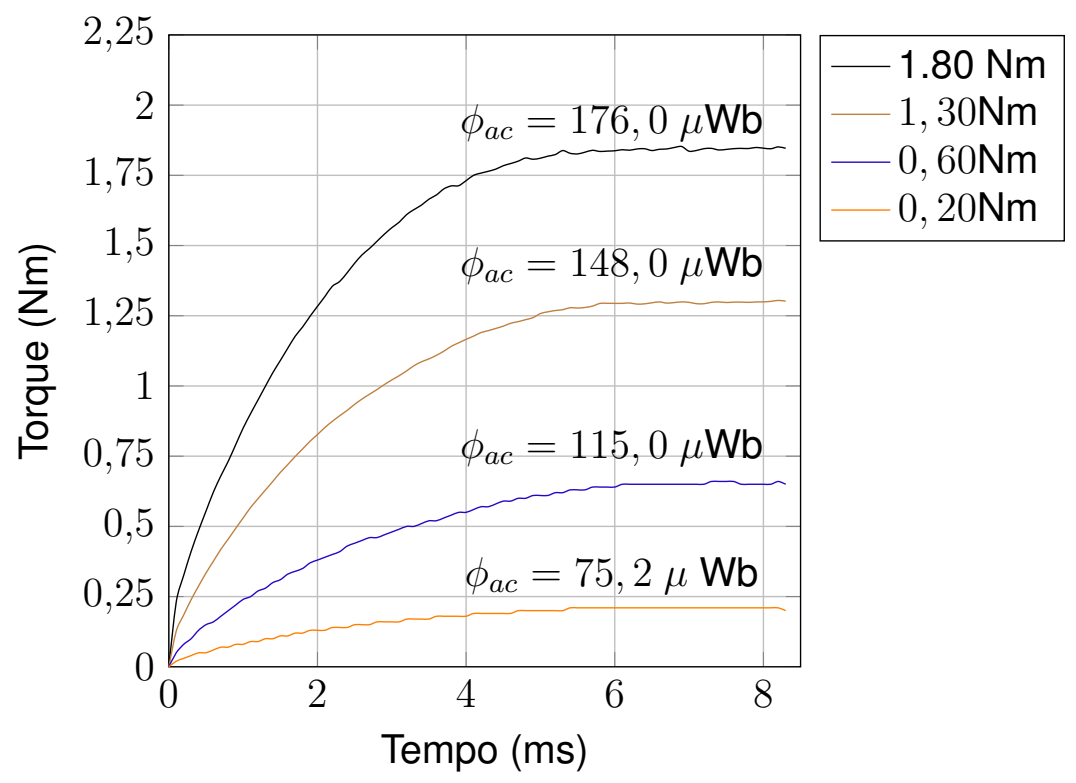

Figura 49 - Simulação dinâmica relacionando torque e fluxo magnético por polo com velocidade de 400 rpm.

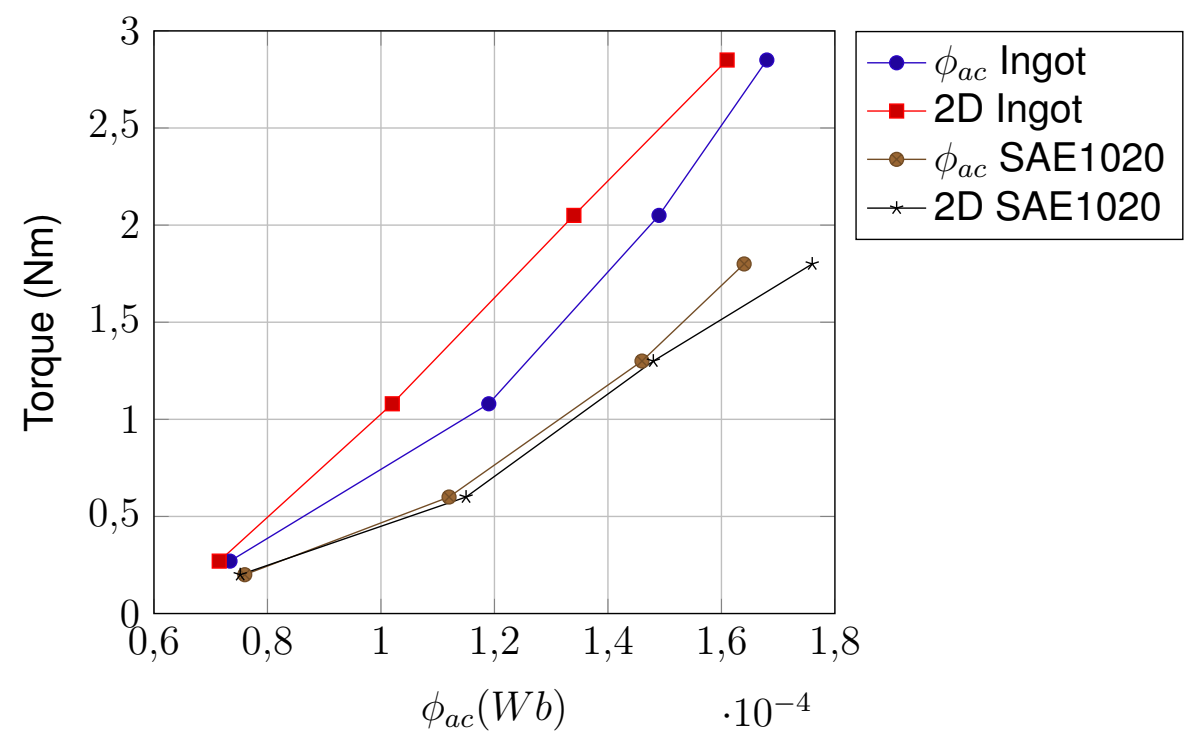

Figura 50 - Comparativo com base no torque simulado versus analítico em função do fluxo por polo.

Outro estudo foi feito para as correntes induzidas. Neste caso, considerou-se o valor máximo ( $J_{m}$ está na origem "0") para a corrente induzida e os cálculos foram feitos a partir da equação 3.48. A figura 51 apresenta o resultado da simulação e como os valores das correntes induzidas foram medidos. No trecho que vai da origem (0) até a face externa da polia $(J)$ ocorre a penetração das correntes no aço. Da origem até o fim da superfície do polo em estudo $(A)$ mediu-se a corrente na região ativa, o mais próximo possível do entreferro. A figura 52 apresenta os resultados. As tabelas 10 e 11 apresentam esses 
valores com maiores detalhes e seus respectivos percentuais.

Tabela 8 - Diferença percentual do fluxo por polo $\left(\phi_{a c}\right)$ para o aço puro.

\begin{tabular}{|l|l|l|l|}
\hline Torque Simulação $(\mathrm{Nm})$ & $\phi_{a c}$ Ingot - Eq. 3.62 $(\mathrm{Wb})$ & $2 \mathrm{D}$ Model $(\mathrm{Wb})$ & Dif $(\%)$ \\
\hline 0,27 & $7,34.10^{-5}$ & $7,15.10^{-5}$ & 2,70 \\
\hline 1,08 & $1,19.10^{-4}$ & $1,02.10^{-4}$ & 16,95 \\
\hline 2,05 & $1,49.10^{-4}$ & $1,34.10^{-4}$ & 11,44 \\
\hline 2,85 & $1,68.10^{-4}$ & $1,61.10^{-4}$ & 4,05 \\
\hline
\end{tabular}

Tabela 9 - Diferença percentual do fluxo por polo $\left(\phi_{a c}\right)$ para o aço SAE1020.

\begin{tabular}{|l|l|l|l|}
\hline Torque Simulação $(\mathrm{Nm})$ & $\phi_{a c}$ SAE1020 - Eq. 3.62 $(\mathrm{Wb})$ & 2D Model $(\mathrm{Wb})$ & Diff $(\%)$ \\
\hline 0,20 & $7,60.10^{-5}$ & $7,52.10^{-5}$ & 1,06 \\
\hline 0,60 & $1,12 \cdot 10^{-4}$ & $1,15.10^{-4}$ & 3,20 \\
\hline 1,30 & $1,46.10^{-4}$ & $1,48.10^{-4}$ & 1,14 \\
\hline 1,80 & $1,64.10^{-4}$ & $1,76.10^{-4}$ & 7,33 \\
\hline
\end{tabular}

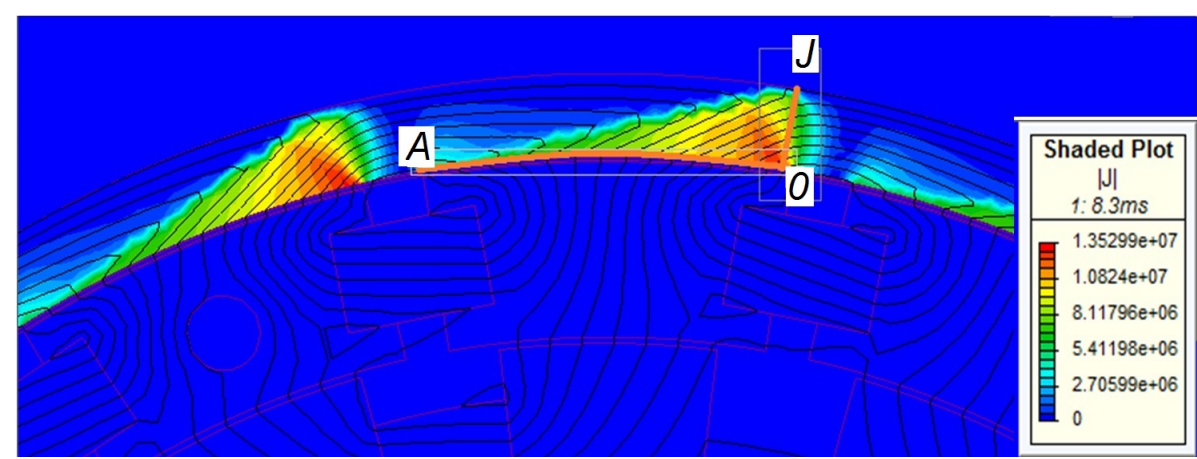

Figura 51 - Resultado da simulação para o modelo 2D mostrando as correntes induzidas na superfície interna do cilindro (0-A) e sua profundidade de penetração (0-J).

Pela simulação é possível observar que as correntes chegam a penetrar totalmente pelos 3 milímetros de espessura especificado para a polia. Ainda é difícil falar se as diferenças entre o simulado e o cálculo matemático são significativas. A comparação para o $\phi_{a c}$ foi considerada satisfatória.

Tabela 10 - Diferença percentual da corrente induzida $(\mathrm{Jm})$ para o aço puro.

\begin{tabular}{|l|l|l|l|}
\hline Torque Simulação $(\mathrm{Nm})$ & $J m$ Ingot - Eq. 3.48 $\left(\mathrm{A} / \mathrm{m}^{2}\right)$ & 2D Model $\left(\mathrm{A} / m^{2}\right)$ & Dif $(\%)$ \\
\hline 0,27 & $6,87.10^{+6}$ & $9,00.10^{+6}$ & 31,09 \\
\hline 1,08 & $1,12.10^{+7}$ & $1,45.10^{+7}$ & 30,01 \\
\hline 2,05 & $1,40.10^{+7}$ & $1,90.10^{+7}$ & 36,08 \\
\hline 2,85 & $1,57.10^{+7}$ & $2,10.10^{+7}$ & 34,07 \\
\hline
\end{tabular}




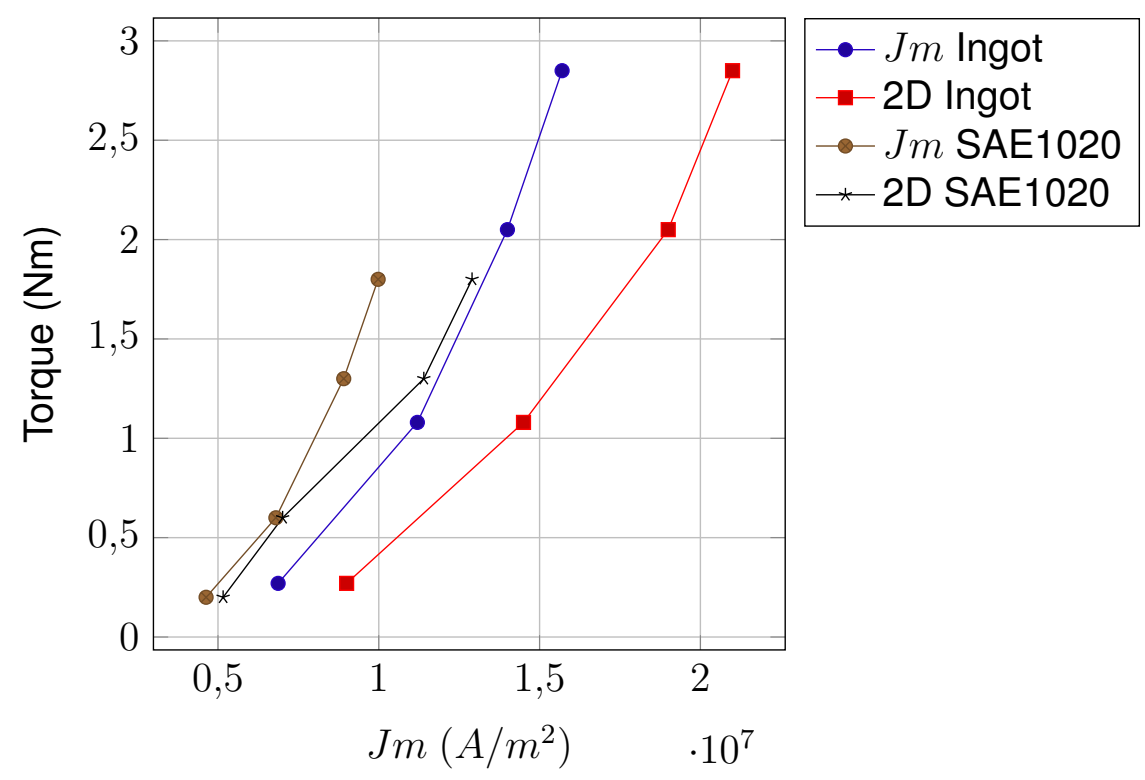

Figura 52 - Comparativo com base no torque simulado versus analítico em função da densidade de corrente.

Tabela 11 - Diferença percentual da corrente induzida $(\mathrm{Jm})$ para o aço SAE1020.

\begin{tabular}{|l|l|l|l|}
\hline Torque Simulação $(\mathrm{Nm})$ & $J m$ SAE1020 - Eq.3.48 $\left(\mathrm{A} / \mathrm{m}^{2}\right)$ & 2D Model $\left(\mathrm{A} / \mathrm{m}^{2}\right)$ & Diff $(\%)$ \\
\hline 0,20 & $4,63.10^{+6}$ & $5,16.10^{+6}$ & 11,52 \\
\hline 0,60 & $6,80.10^{+6}$ & $7,01.10^{+6}$ & 3,21 \\
\hline 1,30 & $8,91.10^{+6}$ & $1,14.10^{+7}$ & 27,96 \\
\hline 1,80 & $9,98.10^{+6}$ & $1,29.10^{+7}$ & 29,21 \\
\hline
\end{tabular}

\subsection{Fator para correção do fluxo por polo necessário com escorregamento nulo}

Conforme já estudado, o torque produzido pelo acoplamento magnético está relacionado com a velocidade de escorregamento (diferença de velocidade entre a polia e o rotor) e a quantidade de corrente induzida pela alternância do fluxo magnético. Com a existência desta corrente, ocorre a reação de armadura. Essa reação causa uma diminuição do fluxo magnético nos polos.

Considerando, portanto, que o valor do fluxo encontrado a partir do equacionamento já contempla essa perda e que o cálculo estrutural da máquina deve basear-se no fluxo estático, tem-se a necessidade de corrigir este valor calculado para o escorregamento nulo. É conhecendo este valor que será possível otimizar o dimensionamento dos demais componentes do circuito magnético.

Existem métodos para estimar essa correção, mas dada a semelhança alcançada com o modelo em duas dimensões, tal estimativa pôde ser feita obtendo-se o valor do fluxo 
magnético no início da simulação. A figura 53 mostra o resultado dinâmico para o ponto de maior torque, conforme apresentado anteriormente na figura 49, e a comparação será feita entre a origem e o último instante simulado. O fluxo magnético será obtido a partir da densidade $(B)$ na região ativa.

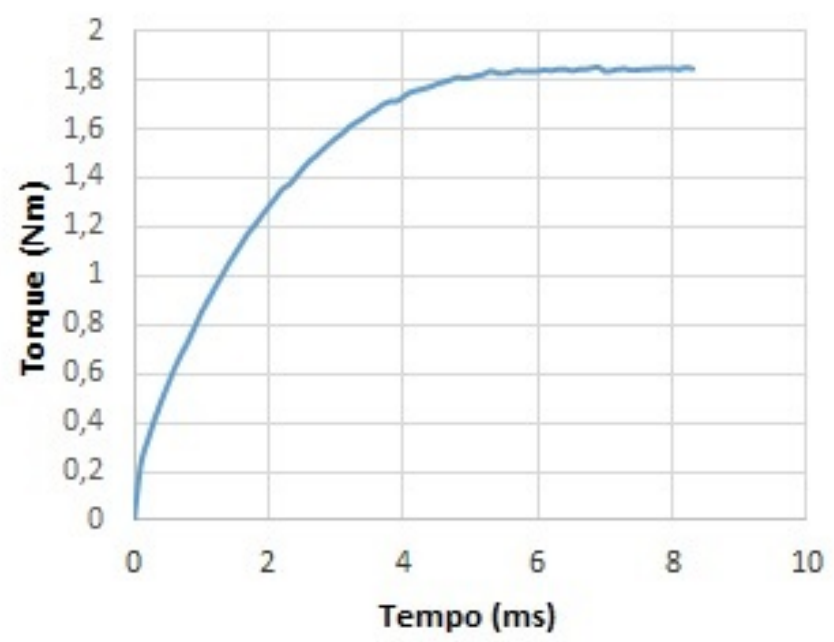

Figura 53 - Comportamento do torque em função do tempo.

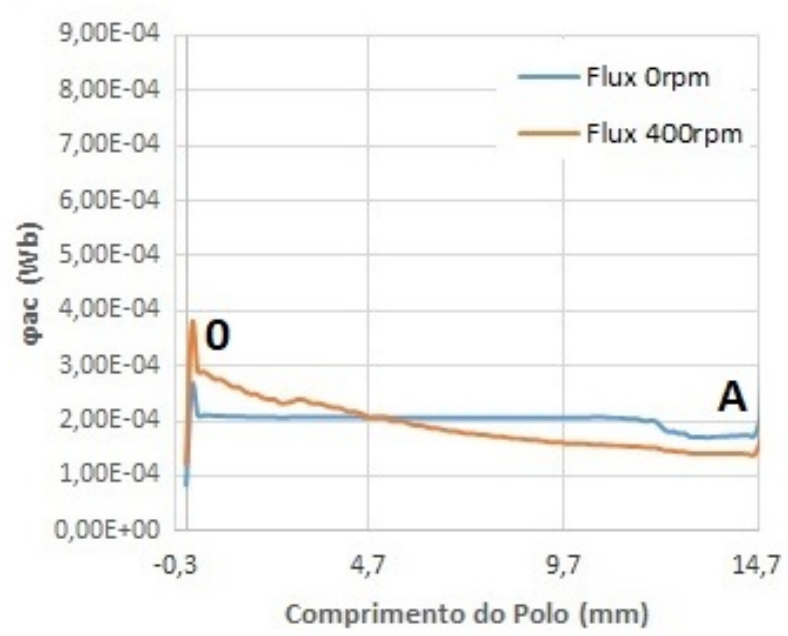

Figura 54 - Comportamento do fluxo magnético na superfície interna do cilindro com origem 0 indicada pela figura 48.

Sendo $\phi_{a c}=B . S$, onde $S$ representa a área do polo, obtém-se o gráfico apresentado pela figura 54 do fluxo em função do comprimento do polo. Nota-se que, com velocidade nula, praticamente a distribuição do fluxo é constante no polo. Impondo escorregamento de 400 rpm, tem-se o efeito da reação de armadura. Aplicando a integral chega-se nos valores de $2,06.10^{-4} \mathrm{~Wb}(0 \mathrm{rpm})$ e $1,76.10^{-4} \mathrm{~Wb}$ (400 rpm). Neste caso, o decréscimo é de aproximadamente $17 \%$ no valor do $\phi_{a c}$ com escorregamento de $400 \mathrm{rpm}$. A variação do 
fluxo $\phi_{a c}$ entre o ponto de origem 0 e o ponto $A$ está relacionada com o comportamento da densidade de fluxo magnético $(B)$ em função do movimento do cilindro ao simular o escorregamento. Esse comportamento é observado no resultado obtido através da simulação por elementos finitos e apresentado figura 48. Importante ressaltar que o ponto A delimita a região ativa em função do comprimento de um polo magnético.

A obtenção do valor para o fluxo magnético (estático) por polo permite equacionar a máquina adequadamente, definindo o número de ampere-espira necessário para atingir o torque exigido pelo projeto. Isso porque o fluxo gerado a partir do eletroímã sofre perdas em função das relutâncias dos materiais. Essas perdas devem ser contabilizadas para que se garanta a transmissão de torque em função do escorregamento. 


\section{Construção do protótipo da bomba}

\section{d'água de vazão variável e testes de va-} lidação

Este capítulo traz informações sobre a construção do protótipo visando a validação do conceito e do ferramental teórico construído anteriormente. O dispositivo foi montando utilizando ímãs com comportamento conhecido e seu desempenho foi medido aplicando as correntes de 2.23 e 4.0 A no eletroímã. Nos testes estáticos sete pontos de operação foram registrados para cada nível de corrente aplicado. As variáveis registradas foram: velocidade da polia, escorregamento, corrente consumida, pressão do sistema e o torque transmitido. Com base nas medições, novas simulações foram efetuadas e, por fim, os resultados foram então confrontados. O teste dinâmico evidenciou a controlabilidade do dispositivo, bem como o seu comportamento com a transmissão do torque residual (BRONZERI; CHABU, 2021).

\subsection{A montagem}

Com o propósito de validar o conceito e o modelo simplificado em duas dimensões, um protótipo para o dispositivo proposto, apresentado no capítulo 4, foi construído em aço SAE1020. A figura 55 apresenta o dispositivo detalhadamente, destacando o posicionamento dos seus principais componentes. A tabela 12 traz a definição de cada componente.

A figura 55 apresenta duas imagens. A primeira é a vista de um plano a partir de um corte longitudinal do dispositivo, onde apresenta a maioria de seus componentes internos e sua estrutura mecânica formada pelos rolamentos. A segunda, uma vista de um plano a partir de um corte tangencial, evidencia a localização dos ímãs permanentes e dois furos (19) que servem como guia e trava mecânica ao mesmo tempo. A figura 56 apresenta esses componentes já confeccionados e prontos para a etapa de montagem. Na área reservada para o eletroímã, foi possível bobinar 370 espiras, com resistência aproximada de 4,9 ohms.

A figura 57 apresenta fotos do dispositivo já com o eletroímã e a medição feita para confirmar o valor da resistência. Teoricamente, considerando fio AWG23 e o volume 
disponível para o eletroíma, uma quantidade de 286 espiras foi estimada. Esta estimativa leva em conta a espessura do cobre, a isolação escolhida e a geometria disponível.
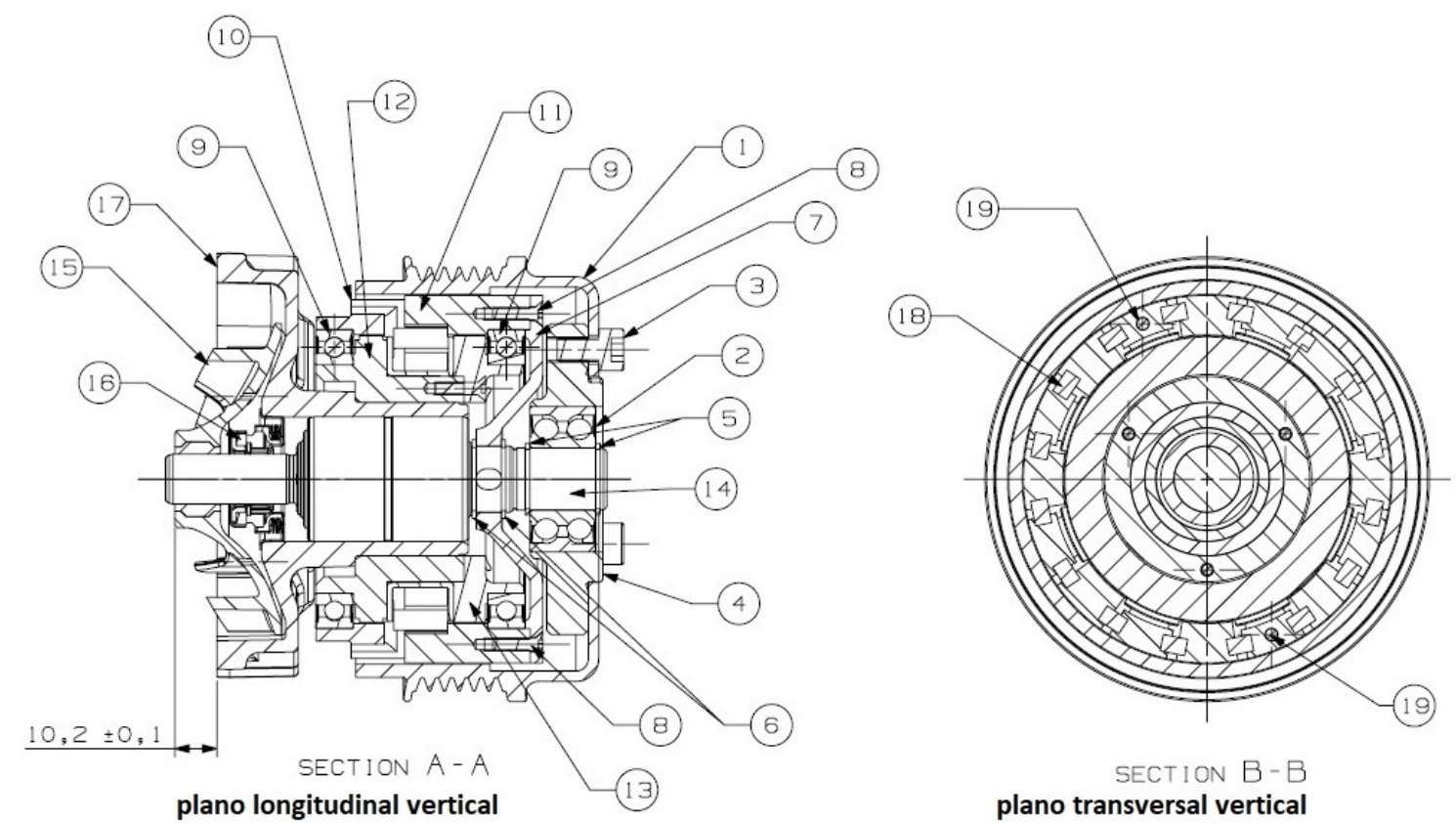

Figura 55 - Plano longitudinal e transversal destacando o posicionamento dos componentes da máquina.

Tabela 12 - Tabela descrevendo os principais componentes destacados pela figura 55.

\begin{tabular}{|l|l|l|l|}
\hline Item & Descrição & Item & Descrição \\
\hline 1 & Polia & 11 & Rotor \\
\hline 2 & Rolamento & 12 & Suporte do eletroímã (base) \\
\hline 3 & Parafuso M6x12 & 13 & Suporte do eletroímã (base) \\
\hline 4 & Flange & 14 & Rolamento \\
\hline 5 & Retentor $\phi 15$ & 15 & Rotor da bomba \\
\hline 6 & Retentor $\phi 13$ & 16 & Selo mecânico \\
\hline 7 & Conexão & 17 & Carcaça de alumínio \\
\hline 8 & Parafuso M3x12 & 18 & ímãs \\
\hline 9 & Rolamento & 19 & Pino guia \\
\hline 10 & Rotor & & \\
\hline
\end{tabular}

Tabela 13 - Característica da bobina e do fio AWG23.

\begin{tabular}{|l|l|l|}
\hline Item & Valor & Unidade \\
\hline Din (diâmetro interno da bobina) & 52,10 & $\mathrm{~mm}$ \\
\hline Dex (diâmetro externo da bobina) & 68,51 & $\mathrm{~mm}$ \\
\hline Cin (comprimento interno da bobina) & 13,60 & $\mathrm{~mm}$ \\
\hline Fcobre (diâmetro nominal AWG23) & 0,574 & $\mathrm{~mm}$ \\
\hline Fnom (diâmetro nominal com isolação) & 0,625 & $\mathrm{~mm}$ \\
\hline res (resistência elétrica) & 0,067 & $\Omega / m$ \\
\hline
\end{tabular}

Considerando o diâmetro a partir da espessura do carretel e com base nos dados apresentados pela tabela 13, o número de espiras para uma fileira no sentido radial pode 
ser definido como:

$$
\begin{array}{r}
N c=\left[\frac{(\text { Dex }- \text { Din }) / 2}{\text { Fnom }}\right] \approx 13 \\
N f=\left[\frac{\text { Cin }}{\text { Fnom }}\right] \approx 22 \\
N t=N c . N f=286[\text { espiras }]
\end{array}
$$

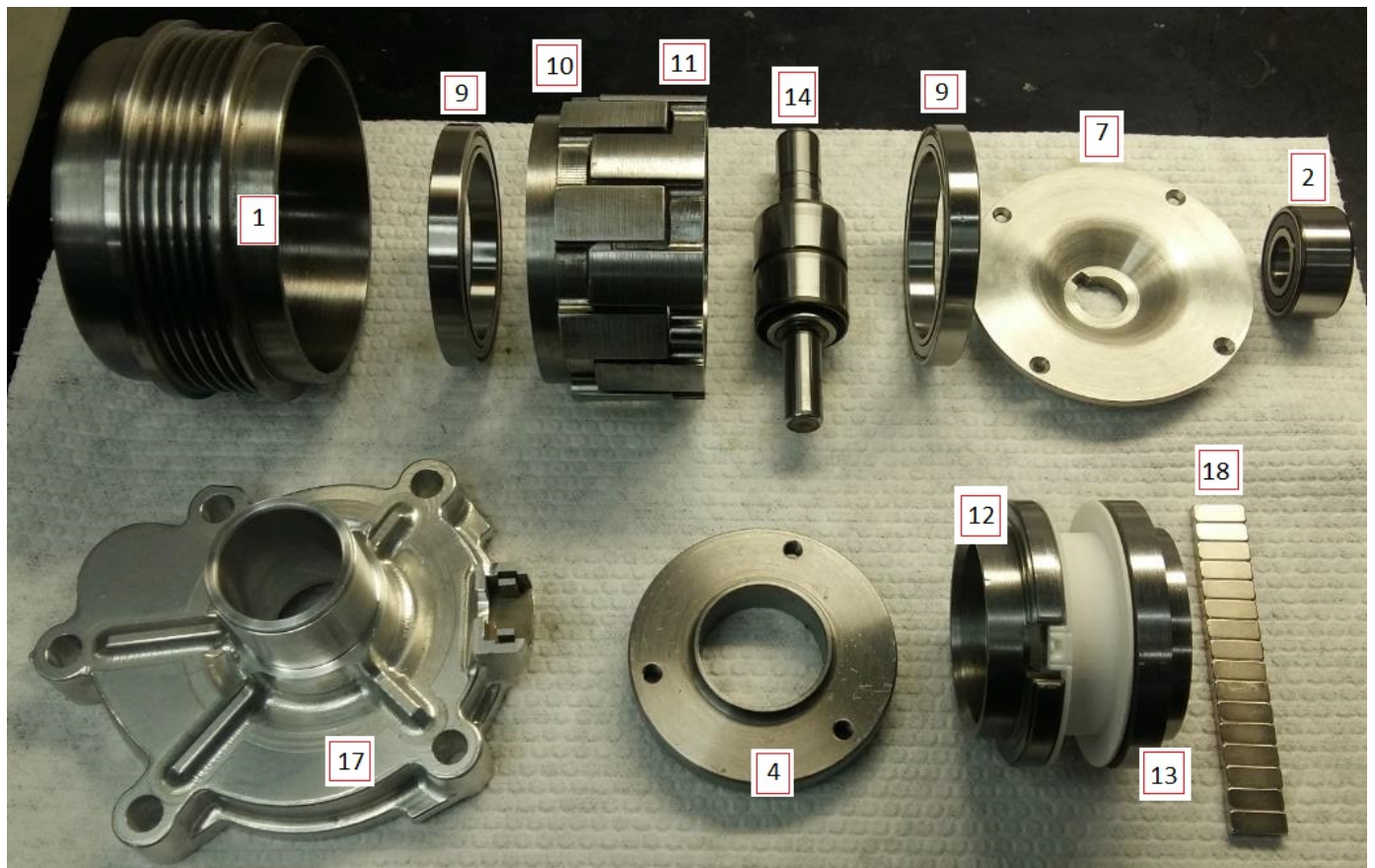

Figura 56 - Componentes confeccionados e prontos para a montagem.

A resistência pode então ser calculada a partir do comprimento estimado do eletroímã, uma vez que a resistividade em função do comprimento é conhecida:

$$
\begin{array}{r}
C=(N c \operatorname{Din} \pi) \cdot\left(\frac{N c^{3} \pi}{2} \text { Fnom }\right) \cdot N f=53,5[\mathrm{~m}] \\
\therefore R=(53,5) \cdot(0,067)=3,56[\Omega]
\end{array}
$$

Sendo 13 volts (DC) a tensão máxima aplicada em veículos automotivos:

$$
\begin{gathered}
I=12 / 3,56=3,65[A] \\
\mathfrak{F} m m=N I=I . N t=3,65.286=1043[A t]
\end{gathered}
$$



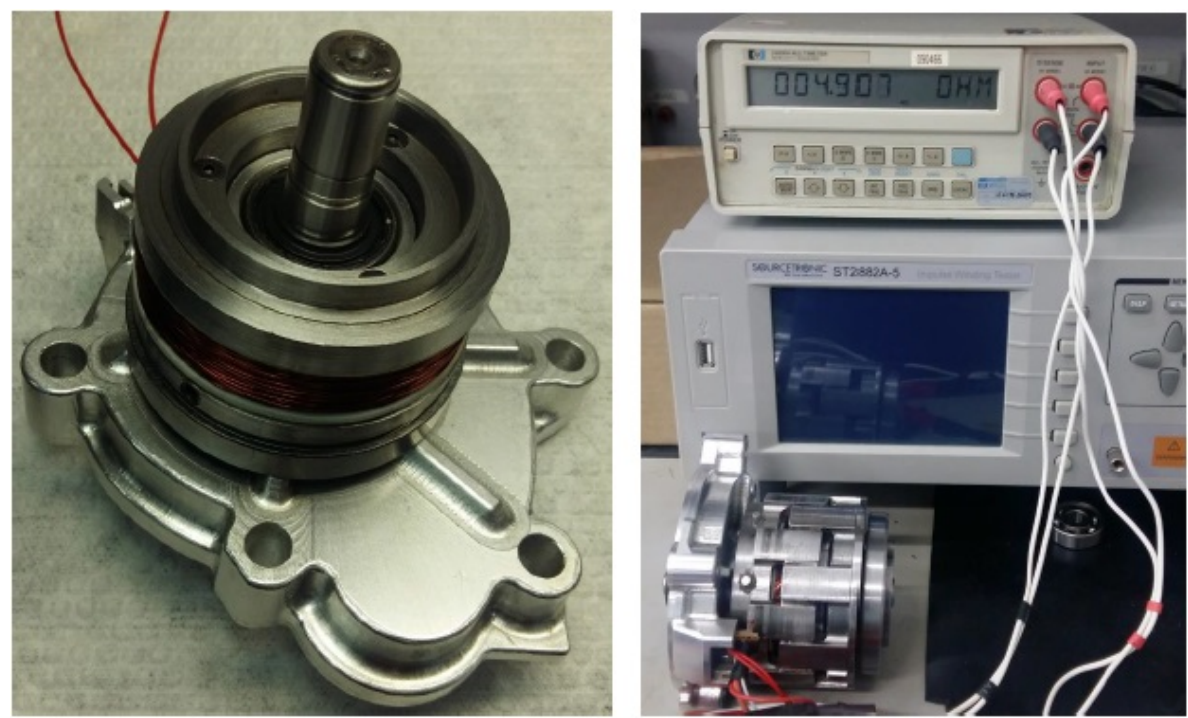

Figura 57 - Montagem parcial e posicionamento do eletroímã e leitura da resistência (4 fios).

Tabela 14 - Comparativo entre o número de voltas teórico e o obtido durante a montagem do protótipo.

\begin{tabular}{|l|l|}
\hline Item & Número de Voltas \\
\hline Estimativa matemática & 286 \\
\hline Protótipo após montagem & 370 \\
\hline Modelo 2D & 360 \\
\hline Protótipo após ajuste & 360 \\
\hline Por par de polo (8 pares ) & 45 \\
\hline
\end{tabular}

Dadas as estimativas e o valor real atingido no bobinamento do eletroímã, a quantidade de espiras de cada bobina do modelo em duas dimensões pôde ser definida. Como a capacidade real é superior do que apresentado pelo cálculo, foi possível construir uma bobina com 370 espiras. Para que cada bobina do simulador tenha um número exato de espiras, optou-se pelo valor de 360 espiras. A tabela 14 apresenta os valores obtidos em cada etapa do processo de desenvolvimento e o ajuste final do protótipo para igualar o número de espiras total do simulador, criando assim um solenoide com resistência de $4,9 \Omega$.

O próximo item que exige cuidados na montagem compreende o subconjunto do rotor do acoplamento, onde os ímãs são posicionados. Para garantir que os 16 ímãs utilizados na montagem apresentassem as características necessárias, algumas medições foram feitas seguindo método apresentado no anexo B.

A montagem do dispositivo possui, basicamente, oito etapas, como ilustra a figura 58. Seguindo a nomenclatura formalizada pela tabela 12, a montagem em si inicia-se prensando o rolamento (14) à carcaça de alumínio (17). Com o eixo posicionado, prensa-se 
o rotor da bomba d'água (15). Esses subconjunto define a primeira etapa. Na segunda etapa, posiciona-se o suporte do eletroímã (12). Na terceira, posiciona-se o eletroímã (representado na figura pelo carretel). Em seguida, vide etapa quatro, o rotor do acoplamento (10) é posicionado e junto a ele os ímãs são fixados. Na etapa cinco posiciona-se o outro rotor (11). Finalizando a montagem interna, na sexta etapa posiciona-se a peça feita de inox (7), que conecta o rotor magnético ao eixo da bomba. Por fim, posiciona-se a polia (sétima etapa), e na oitava etapa fixa-se a polia à flange (4) com três parafusos, garantindo assim o seu alinhamento. Para finalizar, a figura 59 coloca o modelo do dispositivo feito em três dimensões ao lado do subconjunto já montado, evidenciando mais uma vez o posicionamento dos ímãs permanentes.
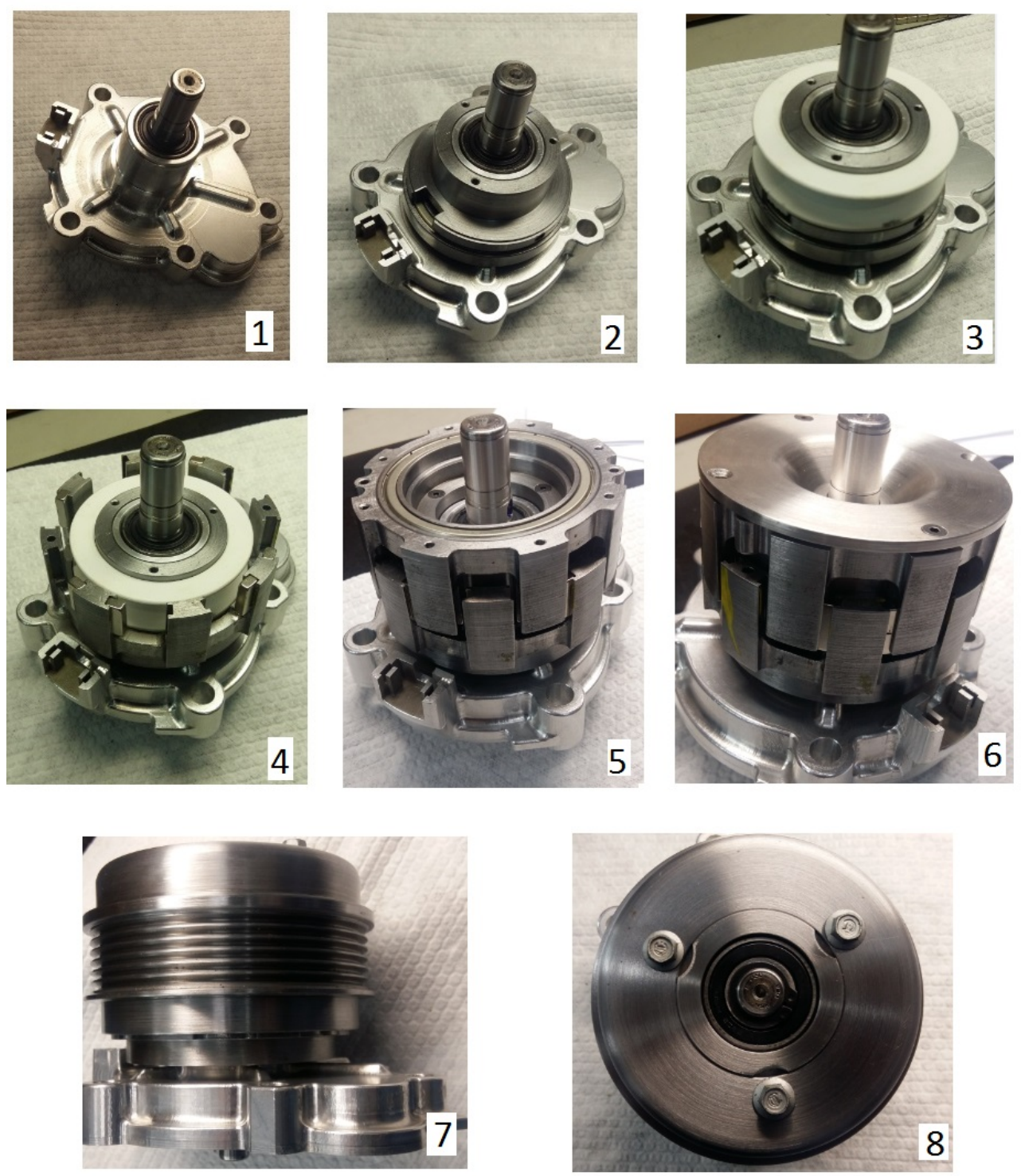

Figura 58 - Método de montagem do protótipo. 
Para permitir a medição do escorregamento, um sensor magnético (efeito hall) com saída digital foi fixado na carcaça do dispositivo. No rotor, dois pequenos ímãs foram colados com um certo distanciamento que permitisse a identificação de uma rotação completa, vide figura 60 .
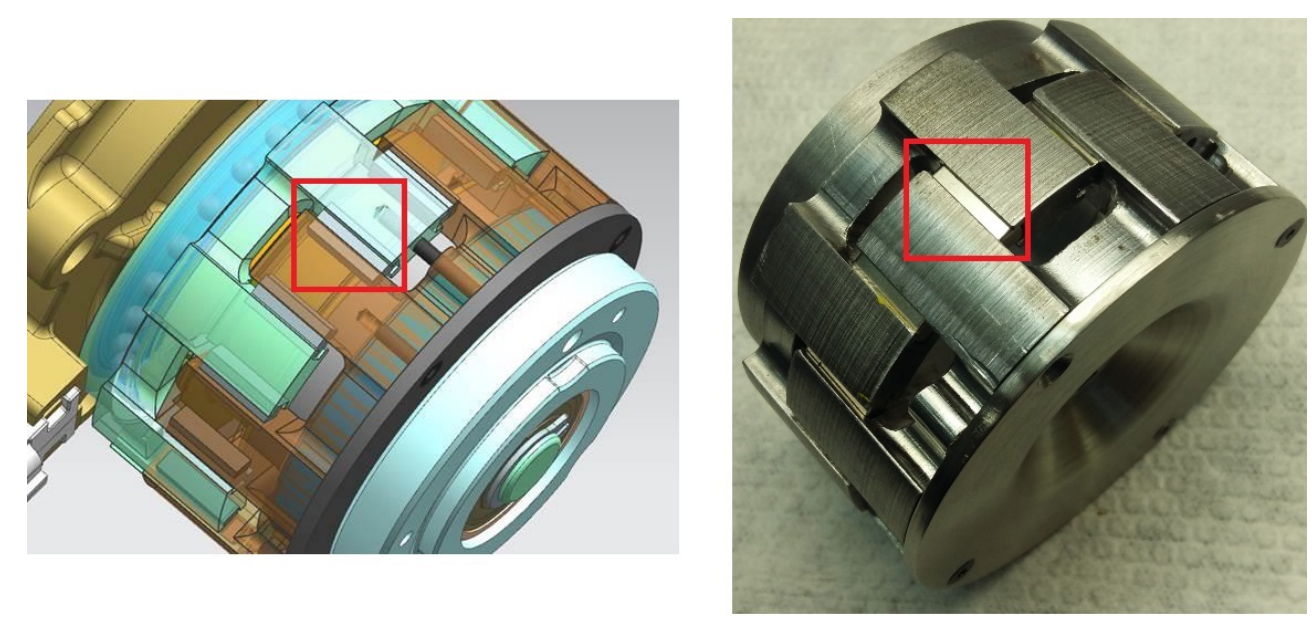

Figura 59 - Subconjunto com o rotor, polos magnéticos e ímãs permanentes em destaque.

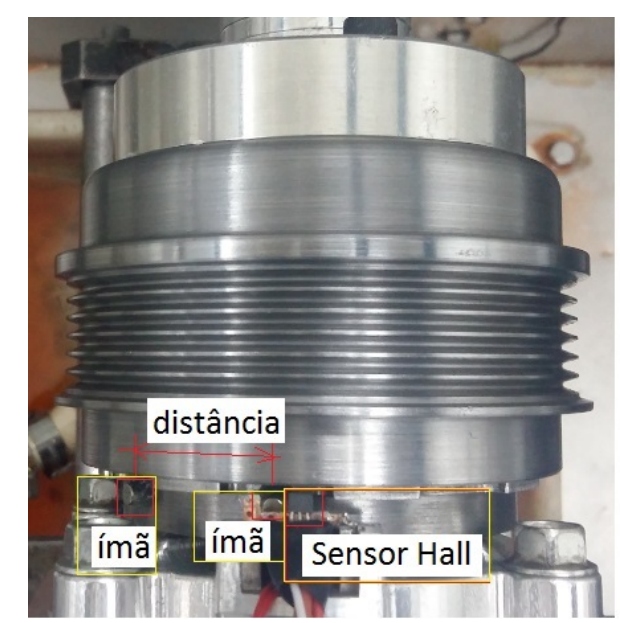

Figura 60 - Posicionamento dos ímãs e sensor hall para medir o escorregamento.

\subsection{Equipamento para teste de desempenho}

O equipamento disponível para testar o protótipo é o mesmo utilizado para levantamento das curvas de desempenho das bombas d'água, capaz, assim, de medir o torque transferido, o fluxo do fluído arrefecedor, simular a velocidade de entrada, medir temperatura e variações de pressão. O controle é feito por um programa específico elaborado no Labview que registra todas as variáveis, seguindo as especificações da ISO 9906:2012 (ISO, 2012). 
O torque é medido através de um transdutor, modelo T34ST, fabricado pela empresa alemã Hottinger Baldwin Messtechnik (HBM), conforme apresenta a figura 61.

Seu principal componente é um motor de corrente alternada acionado por um inversor de frequência ajustável conforme a necessidade do teste. Uma foto retirada do equipamento durante os testes com uma bomba d'água convencional é apresentada pela figura 62. Portanto, o equipamento simula o circuito especificado para o veículo, impondo restrições e demais itens necessários para avaliar a desempenho.

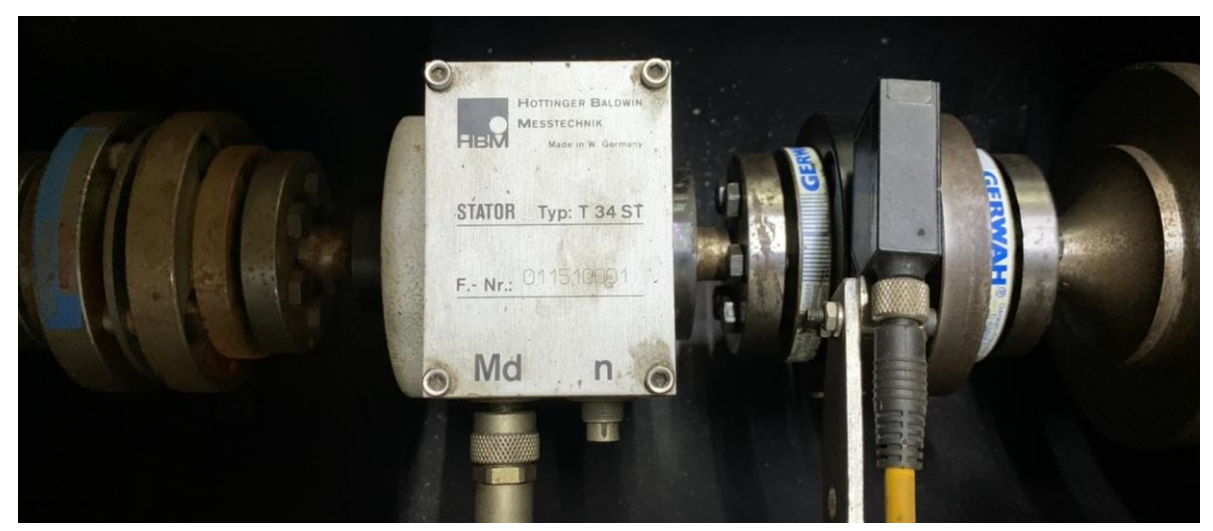

Figura 61 - Transdutor de torque modelo T34ST.

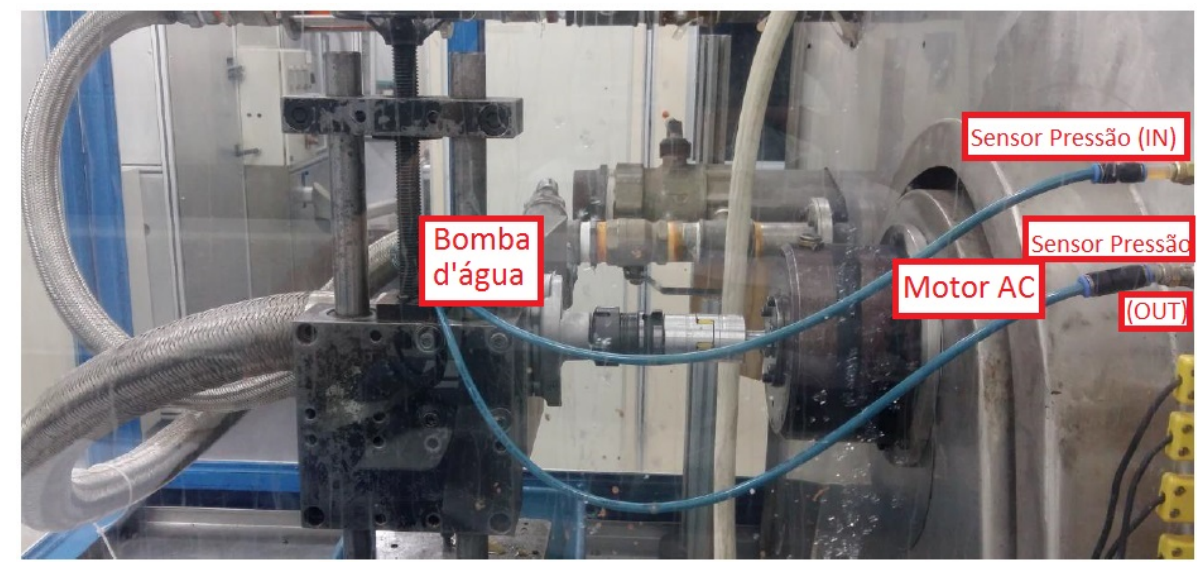

Figura 62 - Teste de desempenho de bombas d'água.

A foto do sistema já com a bomba variável é apresentada na figura 63. Para viabilizar a conexão do protótipo no dispositivo, eliminou-se a conexão por correia. Uma adaptação foi desenvolvida visando conectar o acoplamento diretamente ao eixo do motor de corrente alternada. A figura 64 apresenta esta adaptação. 


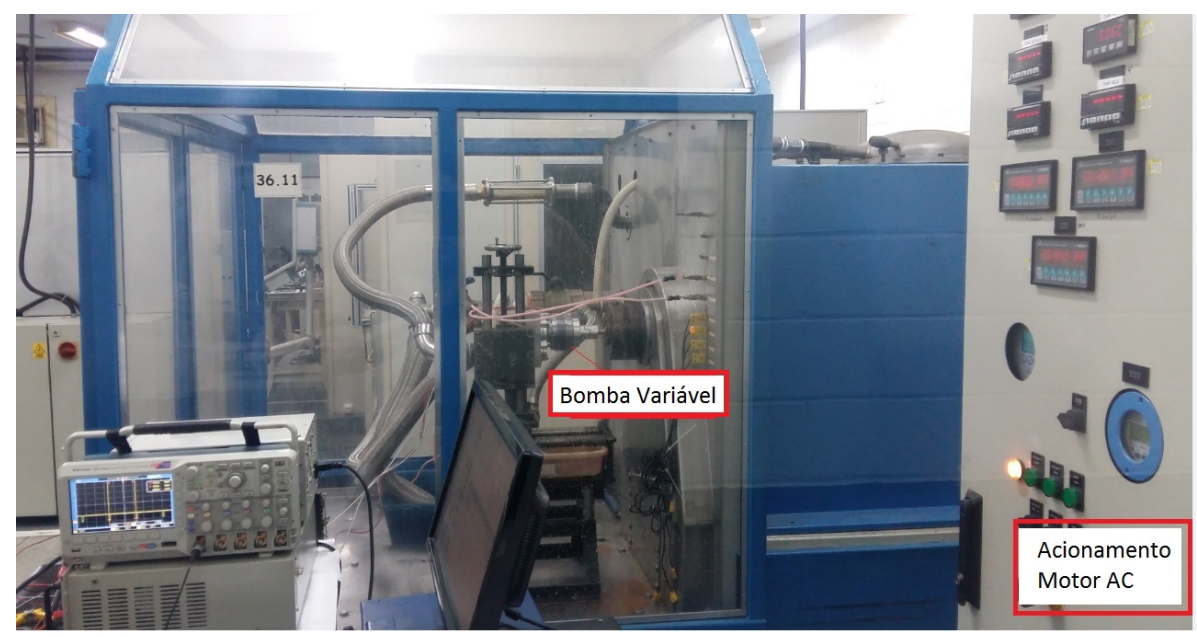

Figura 63 - Bomba variável conectada ao equipamento para teste.

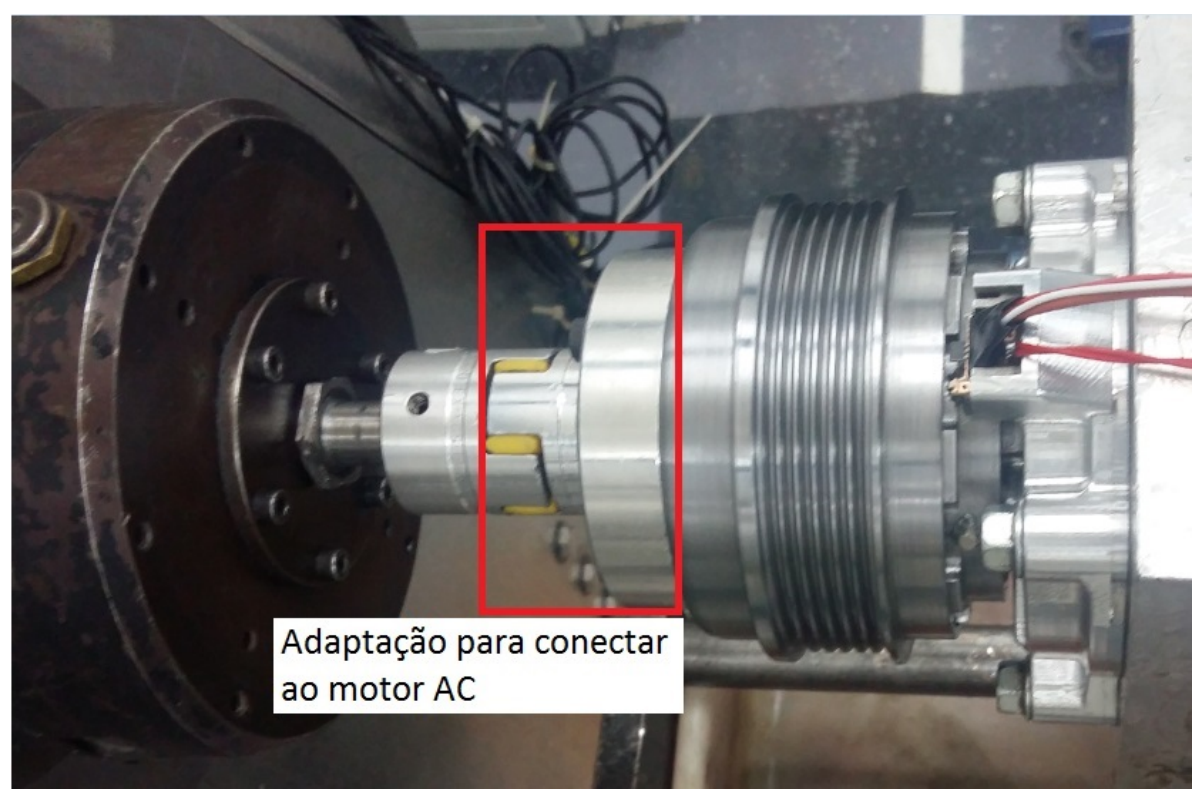

Figura 64 - Bomba variável conectada ao equipamento para teste.

\subsection{Desempenho hidráulico}

O primeiro teste feito com o protótipo teve como objetivo levantar o seu desempenho hidráulico. Para isso, uma pequena adaptação foi feita conectando a polia ao segundo subconjunto (rotor do acoplamento). Desta forma, a energia mecânica é transferida por meio dessa adaptação, sem escorregamento.

Variando a velocidade da polia, que neste caso é a mesma do rotor, foram coletados o torque transferido para a bomba e a vazão resultante. Esse resultado foi então comparado aos dados nominais já conhecidos para este rotor. A figura 65 apresenta o resultado para torque e a figura 66 o resultado para a vazão. Nota-se bom comportamento para ambas as variáveis, tornando-se possível avançar nos estudos com o acoplamento. Apenas na vazão 


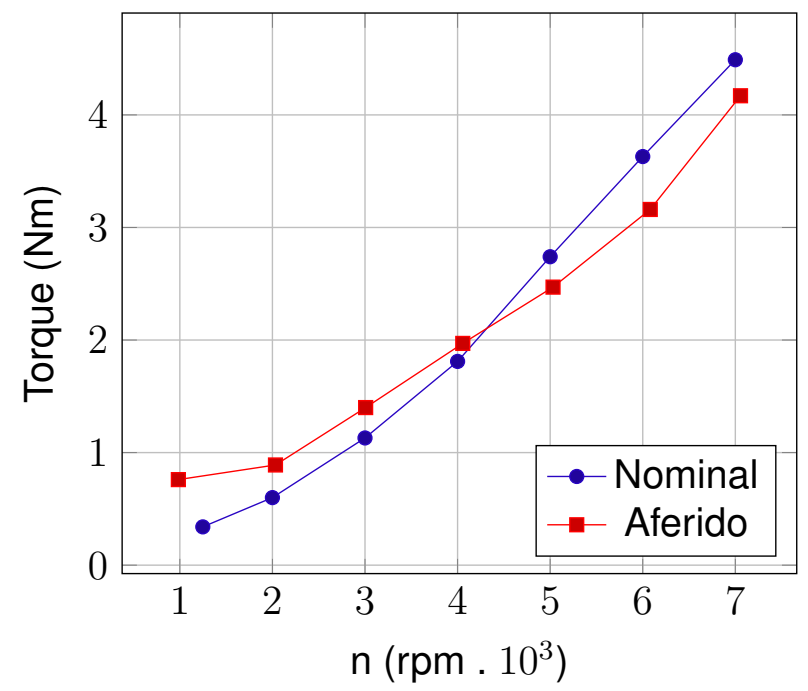

Figura 65 - Característica do torque em função da velocidade.

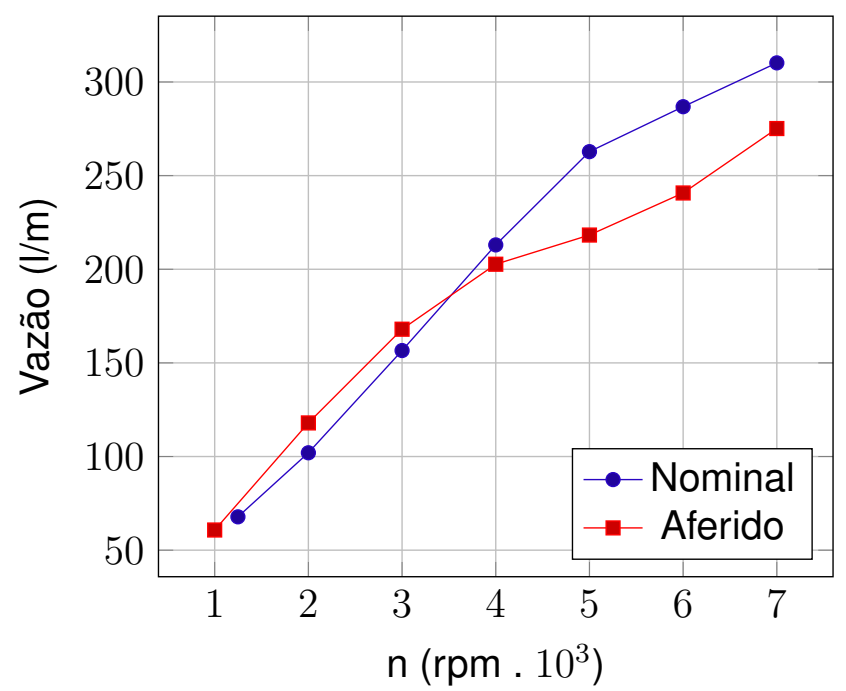

Figura 66 - Característica da vazão em função da velocidade.

acima de $4000 \mathrm{rpm}$ nota-se queda de desempenho de forma acentuada, praticamente 50 Ipm a menos nessa faixa do que o valor nominal da bomba original.

\subsection{Testes de desempenho e comparação com o modelo para simulação em duas dimensões}

Após remover o pino que conecta o rotor da bomba à polia, o segundo grupo de testes foi executado com dois valores de corrente elétrica $(2,23$ e 4, $00 \mathrm{~A})$. Para cada corrente aplicada, sete etapas foram executadas e para cada uma delas o torque e escorregamento foram registrados após estabilizar.

Como é mais simples ajustar o escorregamento no modelo simulado, primeiramente 
efetuou-se o teste com o dispositivo para as correntes mencionadas. O objetivo do teste é fixar a corrente consumida pelo eletroímã, variar a rotação da polia e conferir tanto o escorregamento quanto o torque transferido. Com esse levantamento novas simulações com essas condições foram feitas a fim de comparar os resultados.

As tabelas 15 e 16 apresentam os resultados. Os dados de entrada são a velocidade da polia e a corrente consumida. Os resultados são o torque transferido $\left(\mathrm{T}_{\text {РROTO }}\right)$, o intervalo entre pulsos informados pelo sensor hall (posteriormente transformado em rotação) e o escorregamento, que é a diferença entre a rotação da polia e a rotação do rotor do acoplamento.

Tabela 15 - Resultado do teste para corrente de $4 \mathrm{~A}$ e temperatura ambiente de $25^{\circ} \mathrm{C}$.

\begin{tabular}{|l|l|l|l|l|l|}
\hline $\begin{array}{l}\mathrm{T}_{\text {PROTO }} \\
{[\mathrm{N} . \mathrm{m}]}\end{array}$ & $\begin{array}{l}\text { Polia } \\
{[\mathrm{rpm}]}\end{array}$ & $\begin{array}{l}\text { Sensor } \\
\text { Hall }[\mathrm{ms}]\end{array}$ & $\begin{array}{l}\text { Freq. Rotor } \\
{[\mathrm{Hz}]}\end{array}$ & $\begin{array}{l}\text { Velocidade Ro- } \\
\text { tor }[\mathrm{rpm}]\end{array}$ & $\begin{array}{l}\text { Escorregamento } \\
{[\mathrm{rpm}]}\end{array}$ \\
\hline 1,99 & 7051 & 17,80 & 56,17 & 3370 & 3680 \\
\hline 1,60 & 6076 & 20,00 & 50,00 & 3000 & 3076 \\
\hline 1,32 & 5027 & 22,20 & 45,04 & 2702 & 2324 \\
\hline 1,17 & 4053 & 25,40 & 39,37 & 2362 & 1691 \\
\hline 1,00 & 3005 & 31,00 & 32,25 & 1935 & 1070 \\
\hline 0,68 & 2032 & 41,90 & 23,86 & 1431 & 600 \\
\hline 0,47 & 984 & 74,30 & 13,45 & 807 & 176 \\
\hline
\end{tabular}

Tabela 16 - Resultado do teste para corrente de $2.23 \mathrm{~A}$ e temperatura ambiente de $25^{\circ} \mathrm{C}$.

\begin{tabular}{|l|l|l|l|l|l|}
\hline $\begin{array}{l}\mathrm{T}_{P R O T O} \\
{[\mathrm{~N} . \mathrm{m}]}\end{array}$ & $\begin{array}{l}\text { Polia } \\
{[\mathrm{rpm}]}\end{array}$ & $\begin{array}{l}\text { Sensor } \\
\text { Hall }[\mathrm{ms}]\end{array}$ & $\begin{array}{l}\text { Freq. Rotor } \\
{[\mathrm{Hz}]}\end{array}$ & $\begin{array}{l}\text { Velocidade Ro- } \\
\text { tor }[\mathrm{rpm}]\end{array}$ & $\begin{array}{l}\text { Escorregamento } \\
{[\mathrm{rpm}]}\end{array}$ \\
\hline 1,53 & 7052 & 22,60 & 44,24 & 2654 & 4397 \\
\hline 1,21 & 6077 & 24,60 & 40,65 & 2439 & 3638 \\
\hline 1,05 & 5028 & 26,20 & 38,16 & 2290 & 2738 \\
\hline 0,90 & 4054 & 29,90 & 33,44 & 2006 & 2047 \\
\hline 0,74 & 3005 & 35,50 & 28,16 & 1690 & 1315 \\
\hline 0,37 & 2032 & 47,90 & 20,87 & 1252 & 779 \\
\hline 0,42 & 984 & 87,10 & 11,48 & 688 & 295 \\
\hline
\end{tabular}

Obtidos os valores para o escorregamento, novas simulações foram feitas com as mesmas condições. Para cada valor obtido, uma simulação (transitória) foi executada. Após 10 milissegundos, o valor para o torque foi registrado $\left(\mathrm{T}_{F E A}\right)$, tempo suficiente para estabilizá-lo.

Os resultados da simulação são apresentados pelas figuras 67 e 68 . À esquerda de cada uma delas tem-se o resultado para simulação dinâmica para cada valor de escorregamento. À direita, os valores para o torque $\left(\mathrm{T}_{F E A}\right)$ obtidos após 10 milissegundos em função da velocidade de escorregamento, conforme apresentado pelas tabelas 15 e 16 . A 
compilação dos resultados coletados $\left(\mathrm{T}_{\text {PROTO}}\right)$ e simulados $\left(\mathrm{T}_{F E A}\right)$ é apresenta pela figura 69.
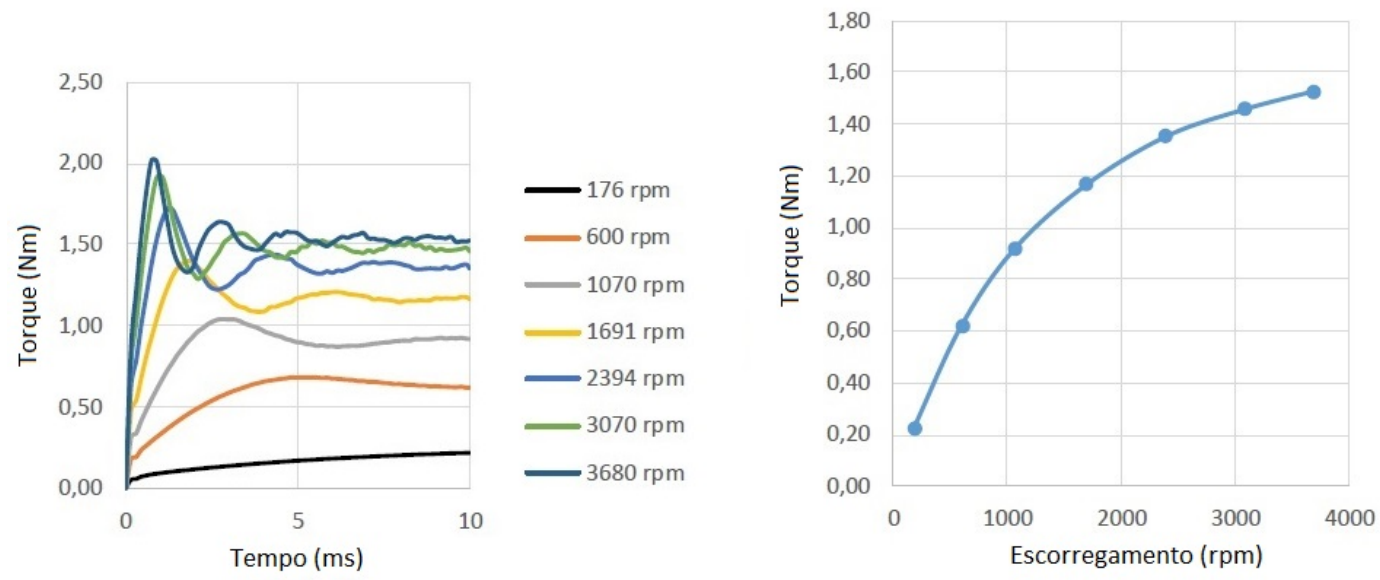

Figura 67 - Torque $\left(\mathrm{T}_{F E A}\right)$ obtido com corrente elétrica de 2,23 A.
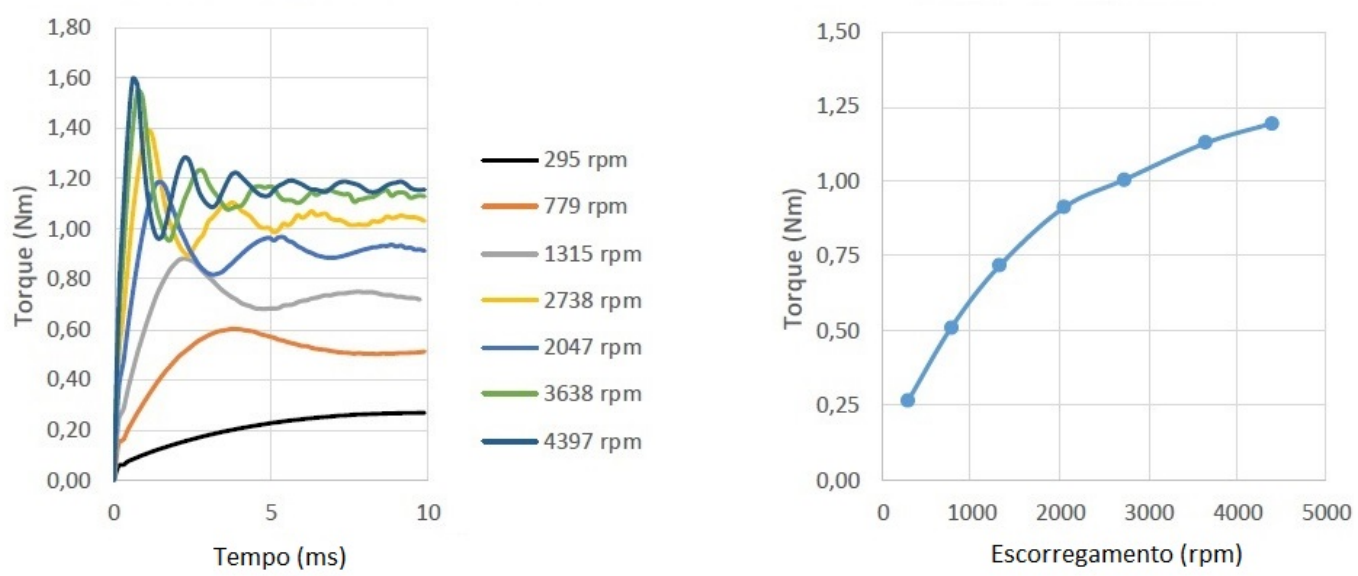

Figura 68 - Torque $\left(\mathrm{T}_{F E A}\right)$ obtido com corrente elétrica de 4,0 A.

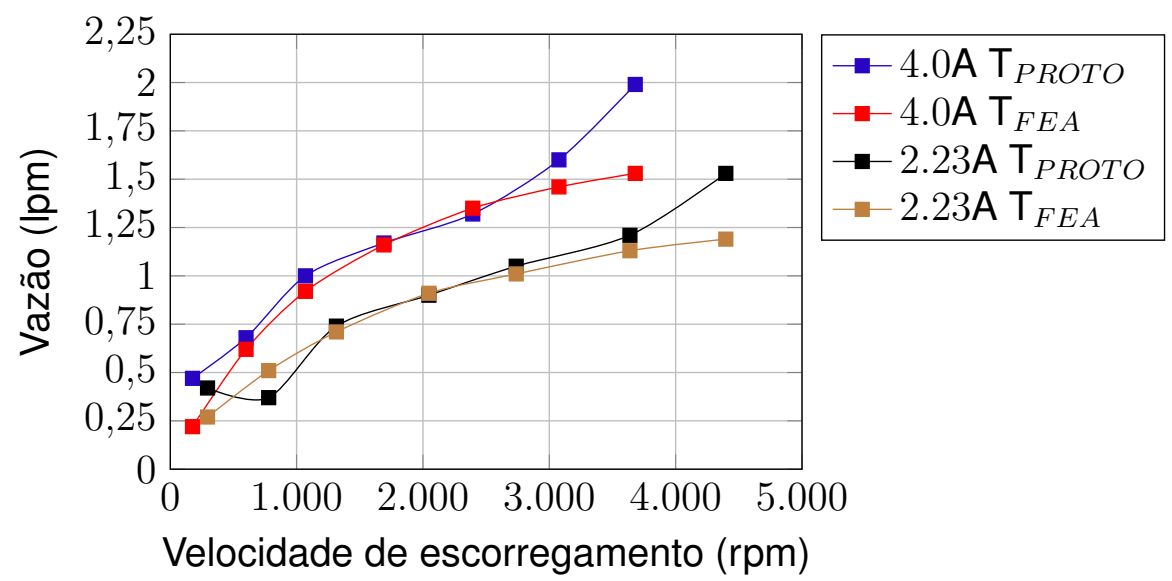

Figura 69 - Comparação entre torque do protótipo $\left(\mathrm{T}_{P R O T O}\right)$ e o simulado $\left(\mathrm{T}_{F E A}\right)$ em função da velocidade de escorregamento. 
O comparativo mostra que, com o modelo simplificado, obteve-se certa previsibilidade. A partir de 6000 rpm o resultado simulado apresenta comportamento diferente, como se indicasse saturação - ou acomodação - diferentemente do resultado prático que apresentou aumento na produção de torque. O escorregamento para essa rotação está em 3638 rpm para 2, $23 \mathrm{~A}$ e $3076 \mathrm{rpm}$ para 4, $0 \mathrm{~A}$.

\subsection{Comparação com os dados nominais da bomba d'água} original.

A figura 70a mostra os resultados e também duas curvas de torque para referência, que representam a vazão máxima (Máx. Torque) e mínima (Min. Torque) exigida pela aplicação. Isso permite ter uma melhor visão de quão longe está o torque transmitido pelo acoplamento da necessidade de máxima vazão em função da velocidade da polia. O fluxo atingido pelo fluido refrigerante é apresentado pela figura $70 \mathrm{~b}$, onde o fluxo produzido pelo torque residual foi omitido devido ao valor muito baixo registrado.

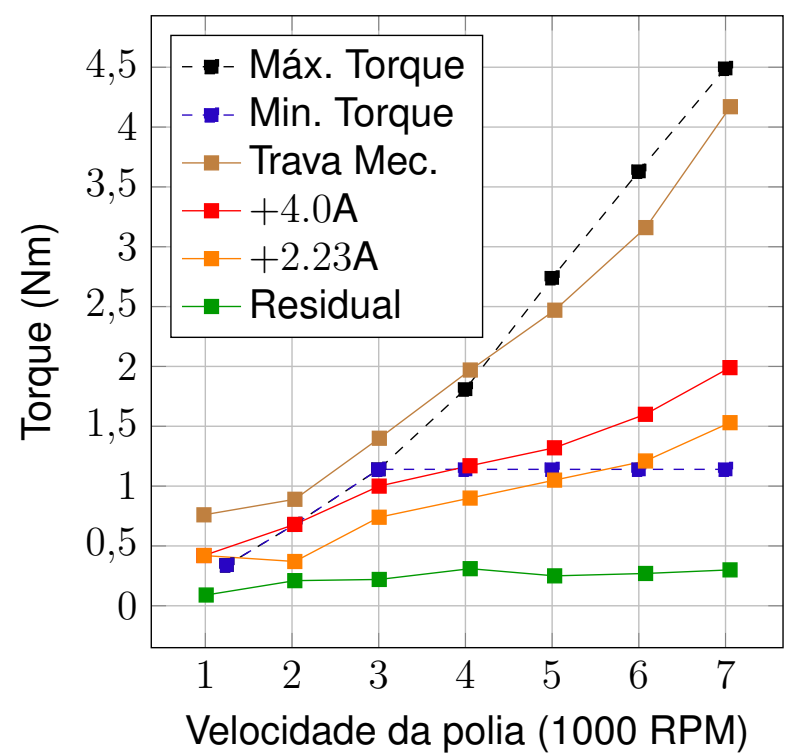

(a) Torque em função da velocidade de entrada.

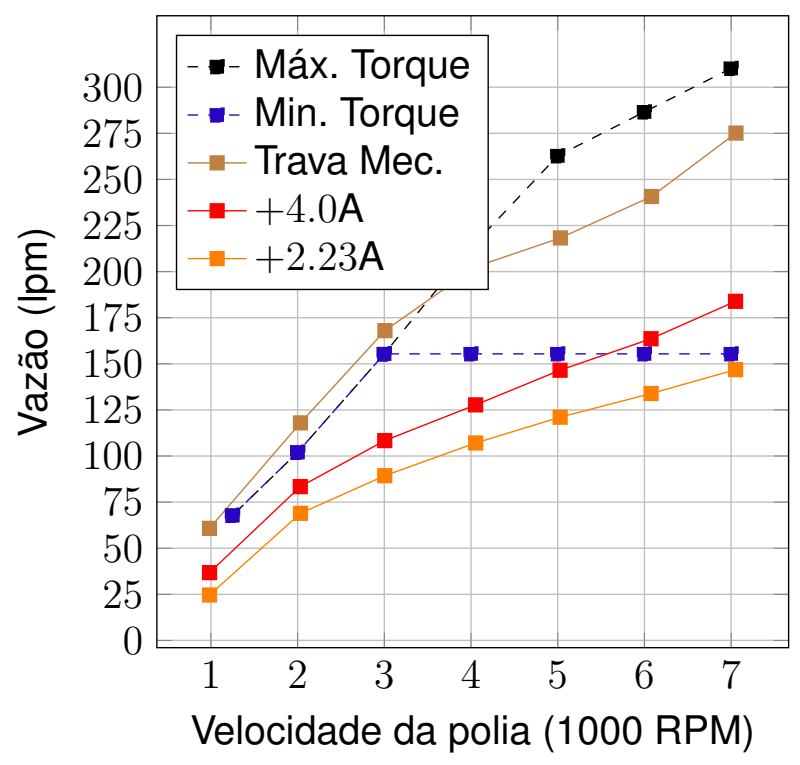

(b) Vazão do fluido refrigerante em função da velocidade de entrada.

Figura 70 - Comparação dos resultados com a bomba d'água variável contra os valores nominais da bomba d'água mecânica e a bomba com o pino de travamento, com o fluido refrigerante a $25^{\circ} \mathrm{C}$.

A figura 71a apresenta o comportamento da eficiência do dispositivo, mostrando a percentagem relativa de torque e vazão alcançada com base na energia disponível (protótipo 
com o pino de travamento) em função da velocidade da polia. A figura $71 \mathrm{~b}$ mostra a relação entre o comportamento nominal e a bomba com o pino de travamento. Nota-se que, por volta de 4000 rpm, o desempenho apresentado pela bomba com o acoplamento é inferior ao desempenho nominal, chegando a apresentar aproximadamente $18 \%$ menos vazão a $5000 \mathrm{rpm}$. Esse resultado mostra que uma parte do baixo desempenho do ponto de vista da vazão está relacionado com a construção do protótipo, mais especificamente com a eficiência do rotor da bomba utilizado.

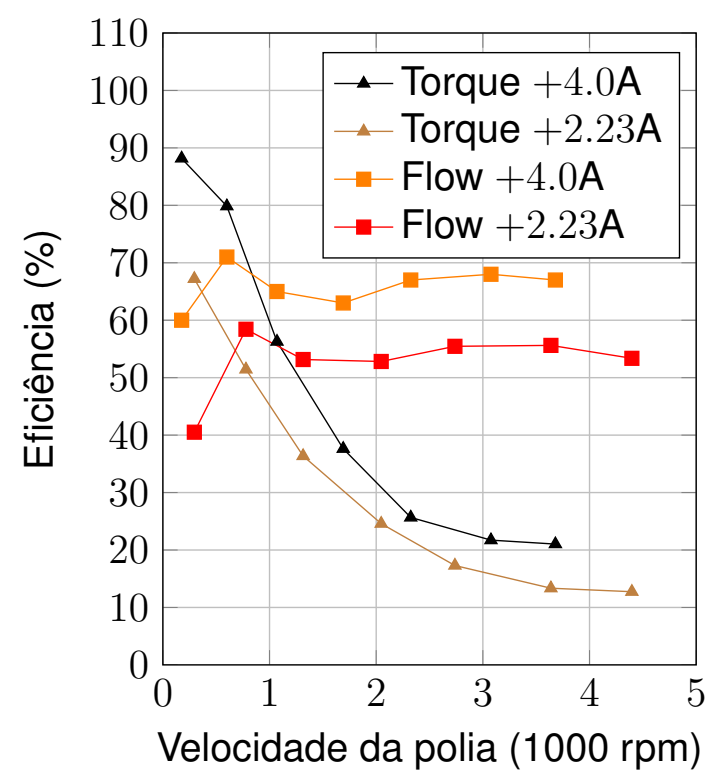

(a) Relação entre a energia máxima disponível (bomba com o pino de travamento) e a energia entregue pelo acoplamento magnético, em função da velocidade de entrada.

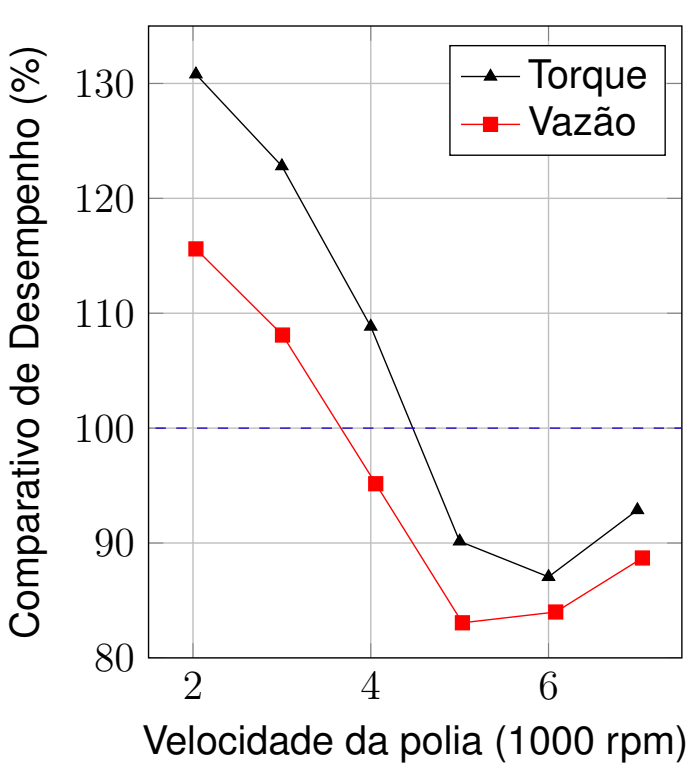

(b) Desempenho hidráulico. Relação entre a curva nominal e a energia transferida pelo acoplamento travado.

Figura 71 - Eficiência do acoplamento da bomba de vazão variável em função da velocidade de entrada, com o fluido refrigerante a $25^{\circ} \mathrm{C}$.

Por fim, falta analisar o resultado do torque residual gerado pelos ímãs na ausência de corrente elétrica. A figura 42, apresentada na seção 4.8, traz o comportamento dinâmico esperado obtido por simulação. O torque residual nela informado atinge valores em torno de $0,3 \mathrm{Nm}$. Já a figura 72 apresenta com maiores detalhes os dados plotados do torque residual na figura $70 a$.

O resultado evidencia um ponto importante de melhoria na configuração da máquina. O baixo valor observado mostra que a relação entre os entreferros pode ser revista e otimizada. Não há a necessidade de obter uma vazão nula para considerar o equipamento desligado, tão pouco foi necessário inverter a polaridade da corrente consumida pelo 
eletroímã para efetuar o desligamento. Existe, portanto, bastante desperdício de energia magnética nesta etapa funcional.

Como proposta para melhoria deste comportamento, o aumento do entreferro inferior deve ser avaliado. Esse incremento na relutância faria com que boa parte do campo magnético gerado pelos ímãs permanentes fosse direcionado para a região ativa. No ciclo de desligamento o objetivo é utilizar toda a energia disponível para atrair o campo magnético gerado pelos ímãs permanentes. Da forma como está configurada a máquina atual, a inversão de fato garante a transferência de torque nula, porém pode-se considerar 20 l/min como um valor mínimo razoável.

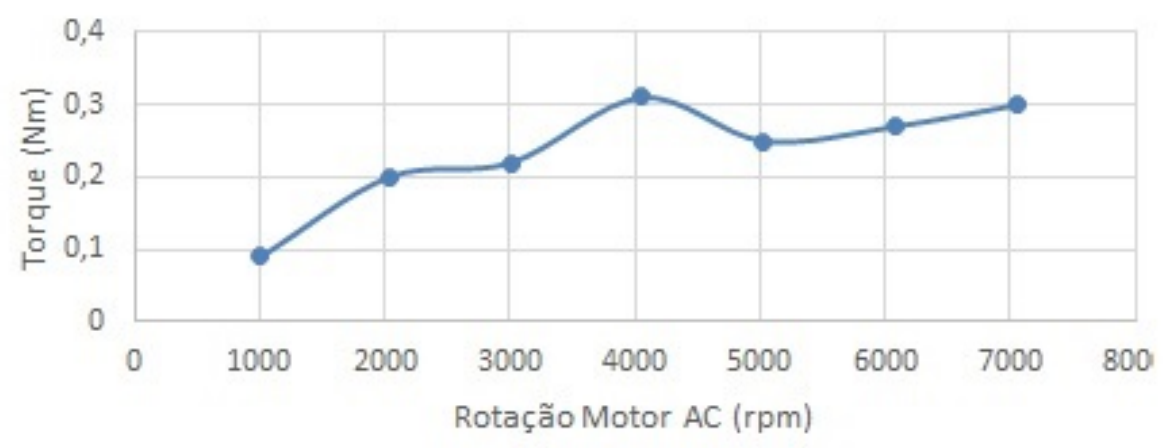

Figura 72 - Torque residual gerado apenas pelos ímãs permanentes.

\subsection{Características relevantes à dissipação térmica}

Em estudos que envolvem temperatura, uma característica interessante das bombas d'água está relacionada à variação do consumo de potência em função da viscosidade do fluido. Por outro lado, sabendo que as correntes de Foucault são dependentes da resistência elétrica do meio em que se propagam, a elevação da temperatura também afeta o desempenho da máquina.

Para quantificar as perdas, definiu-se que a variável a ser monitorada seria a vazão. Todas as perdas por variação da viscosidade, resistência do meio e diminuição no consumo de potência refletem no valor transferido de torque. Outro ponto de interesse é a temperatura dissipada pelo aço que envolve a polia e a temperatura interna do dispositivo. Para esta última, usou-se a variação da resistência elétrica da bobina para calcular a temperatura interna. Esse valor é importante para determinar as caraterísticas da isolação do fio utilizado no eletroímã. 
Submetendo o dispositivo ao teste em seu ponto de máximo torque, os dados foram registrados até que houvesse acomodação da vazão. Os dados coletados foram: vazão, diferencial de pressão, corrente consumida, torque e temperatura final na polia. A figura 73 é uma foto feita com o posicionamento de dois sensores de temperatura ao final do testes.

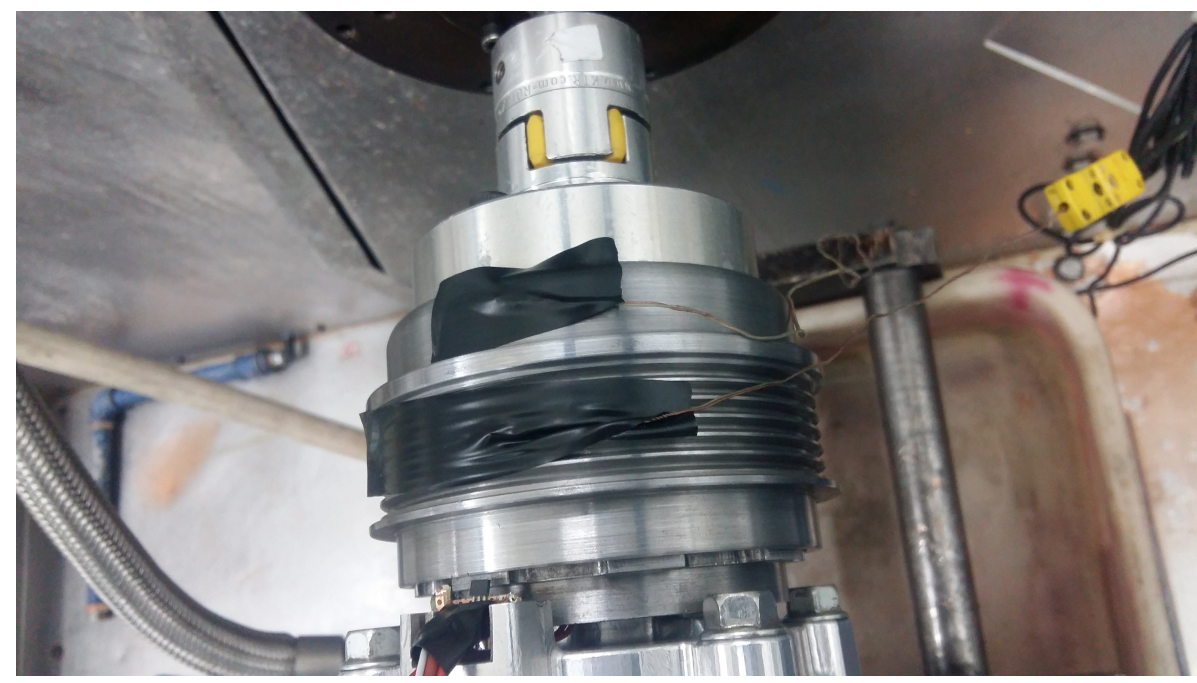

Figura 73 - Posicionamento dos sensores de temperatura.

Registrando-se a temperatura ambiente no início dos testes, a temperatura final no eletroímã pôde ser estimada pela relação apresentada na equação 6.1, onde $\alpha$ representa o coeficiente de temperatura do cobre $\left(3,9.10^{-3}\right), R(T)$ o valor da resistência no final do teste à temperatura $T$ e $R\left(T_{0}\right)$ o valor da resistência no início à temperatura $T_{0}$.

$$
T-T_{0}=\frac{1}{R\left(T_{0}\right)} \cdot \frac{R(T)-R\left(T_{0}\right)}{\alpha}
$$

Tabela 17 - Estimativa da temperatura do eletroímã para uma tensão aplicada de 13,2 volts e fluido com temperatura de $32^{\circ} \mathrm{C}$.

\begin{tabular}{|l|l|l|l|l|l|l|}
\hline Tempo (Min) & Corrente $(\mathrm{A})$ & Vazão $(\mathrm{l} / \mathrm{m})$ & Torque $(\mathrm{Nm})$ & Resistência $(\Omega)$ & $T_{0}\left({ }^{\circ} \mathrm{C}\right)$ & $T\left({ }^{\circ} \mathrm{C}\right)$ \\
\hline 1 & 2,11 & 150,55 & 1,46 & 6,26 & 32,00 & 32,00 \\
\hline 2 & 2,02 & 139,74 & 1,17 & 6,53 & 32,00 & 42,94 \\
\hline 3 & 1,95 & 137,42 & 1,12 & 6,77 & 32,00 & 51,44 \\
\hline 4 & 1,91 & 135,27 & 1,05 & 6,91 & 32,00 & 56,30 \\
\hline 5 & 1,88 & 134,28 & 1,03 & 7,02 & 32,00 & 59,95 \\
\hline 6 & 1,86 & 132,12 & 1,01 & 7,10 & 32,00 & 62,38 \\
\hline 7 & 1,85 & 131,77 & 1,01 & 7,14 & 32,00 & 63,60 \\
\hline 8 & 1,83 & 125,75 & 0,98 & 7,21 & 32,00 & 66,03 \\
\hline 9 & 1,82 & 125,06 & 0,99 & 7,25 & 32,00 & 67,24 \\
\hline 10 & 1,81 & 127,98 & 0,98 & 7,29 & 32,00 & 68,46 \\
\hline 11 & 1,81 & 131,46 & 0,98 & 7,29 & 32,00 & 68,46 \\
\hline 12 & 1,80 & 131,30 & 0,98 & 7,33 & 32,00 & 69,67 \\
\hline 13 & 1,80 & 131,48 & 0,94 & 7,33 & 32,00 & 69,67 \\
\hline
\end{tabular}

O primeiro teste feito foi sob temperatura ambiente de $32^{\circ} \mathrm{C}$ e velocidade de entrada constante em 7000 rpm. Conforme mostra a tabela 17, o teste durou cerca de 13 minutos, 
com um registro a cada minuto. Dada a diminuição da corrente em função do acréscimo da resistência, estimou-se a temperatura no eletroímã em aproximadamente $70^{\circ} \mathrm{C}$. A diminuição da vazão foi da ordem de $13 \%$, torque $36 \%$ e a temperatura na polia no final do teste foi registrada em $108^{\circ} \mathrm{C}$. Portanto, a diferença de temperatura entre o eletroímã e a polia foi de aproximadamente $38^{\circ} \mathrm{C}$.

Tabela 18 - Estimativa da temperatura do eletroímã para uma tensão aplicada de 13,2 volts e fluido com temperatura de $90^{\circ} \mathrm{C}$.

\begin{tabular}{|l|l|l|l|l|l|l|}
\hline Tempo (Min) & Corrente $(\mathrm{A})$ & Vazão $(\mathrm{L} / \mathrm{m})$ & Torque $(\mathrm{Nm})$ & Resistência $(\Omega)$ & $T_{0}\left({ }^{\circ} \mathrm{C}\right)$ & $T\left({ }^{\circ} \mathrm{C}\right)$ \\
\hline 1 & 2,28 & 149,18 & 1,45 & 5,79 & 32,00 & 32,00 \\
\hline 2 & 2,14 & 146,14 & 1,27 & 6,17 & 32,00 & 47,74 \\
\hline 3 & 2,07 & 142,86 & 1,17 & 6,38 & 32,00 & 55,62 \\
\hline 4 & 1,90 & 139,59 & 1,04 & 6,95 & 32,00 & 74,74 \\
\hline 5 & 1,85 & 136,34 & 1,00 & 7,14 & 32,00 & 80,36 \\
\hline 6 & 1,82 & 134,12 & 0,99 & 7,25 & 32,00 & 83,73 \\
\hline 7 & 1,81 & 134,90 & 0,98 & 7,29 & 32,00 & 84,86 \\
\hline 8 & 1,78 & 124,73 & 0,97 & 7,42 & 32,00 & 88,23 \\
\hline 9 & 1,76 & 125,15 & 0,97 & 7,50 & 32,00 & 90,48 \\
\hline 10 & 1,74 & 123,91 & 0,94 & 7,59 & 32,00 & 92,73 \\
\hline 11 & 1,73 & 125,32 & 0,93 & 7,63 & 32,00 & 93,85 \\
\hline 12 & 1,72 & 124,34 & 0,91 & 7,67 & 32,00 & 94,98 \\
\hline 13 & 1,71 & 123,10 & 0,91 & 7,72 & 32,00 & 96,10 \\
\hline 14 & 1,70 & 126,94 & 0,90 & 7,76 & 32,00 & 97,23 \\
\hline 15 & 1,69 & 123,14 & 0,90 & 7,81 & 32,00 & 98,35 \\
\hline 16 & 1,69 & 124,56 & 0,92 & 7,81 & 32,00 & 98,35 \\
\hline 17 & 1,68 & 125,14 & 0,88 & 7,86 & 32,00 & 99,48 \\
\hline 18 & 1,68 & 124,06 & 0,89 & 7,86 & 32,00 & 99,48 \\
\hline 19 & 1,68 & 127,48 & 0,88 & 7,86 & 32,00 & 99,48 \\
\hline 20 & 1,67 & 122,07 & 0,88 & 7,90 & 32,00 & 100,60 \\
\hline 21 & 1,67 & 123,86 & 0,87 & 7,90 & 32,00 & 100,60 \\
\hline 22 & 1,67 & 124,71 & 0,84 & 7,90 & 32,00 & 100,60 \\
\hline 23 & 1,67 & 125,06 & 0,87 & 7,90 & 32,00 & 100,60 \\
\hline 24 & 1,67 & 126,27 & 0,86 & 7,90 & 32,00 & 100,60 \\
\hline
\end{tabular}

Para o segundo teste, vide tabela 18, elevou-se a temperatura do fluido para cerca de $90^{\circ} \mathrm{C}$ e e foram mantidas as variáveis de entrada, como velocidade, tensão aplicada no eletroímã e temperatura ambiente. O tempo de acomodação das variáveis neste caso foi superior, com estabilização após 24 minutos. Com temperatura estimada no eletroímã em $100^{\circ} \mathrm{C}$ aproximadamente, houve uma redução na vazão em torno de $15 \%$. No caso do torque, a redução foi de $40 \%$. A temperatura externa medida no final do teste foi de $124^{\circ} \mathrm{C}$. A diferença entre a temperatura do eletroímã e a temperatura medida na polia foi de aproximadamente $24^{\circ} \mathrm{C}$, diferença esta $14^{\circ} \mathrm{C}$ menor do que a constatada no primeiro teste, indicando o aumento da dificuldade em dissipar calor. A figura 74 apresenta um gráfico com o comportamento da vazão para os dois testes. Importante ressaltar o ponto de origem com a mesma vazão, indicando que a temperatura inicial para ambos os testes foi a mesma. 
Neste momento é importante observar o comportamento do diferencial de pressão do sistema ( $\Delta_{p}$ - entre a pressão de entrada da bomba e a pressão de saída). Isso porque, para que seja possível comparar as potências hidráulicas, é necessário comparar as pressões e vazões. A figura 75 traz, à esquerda, um gráfico dos diferenciais de pressão em função da vazão. $\mathrm{Na}$ faixa operacional do dispositivo a potência hidráulica opera conforme o esperado. Assim como à direita, um gráfico em função do tempo de teste apresenta o comportamento do diferencial de pressão no decorrer do experimento.

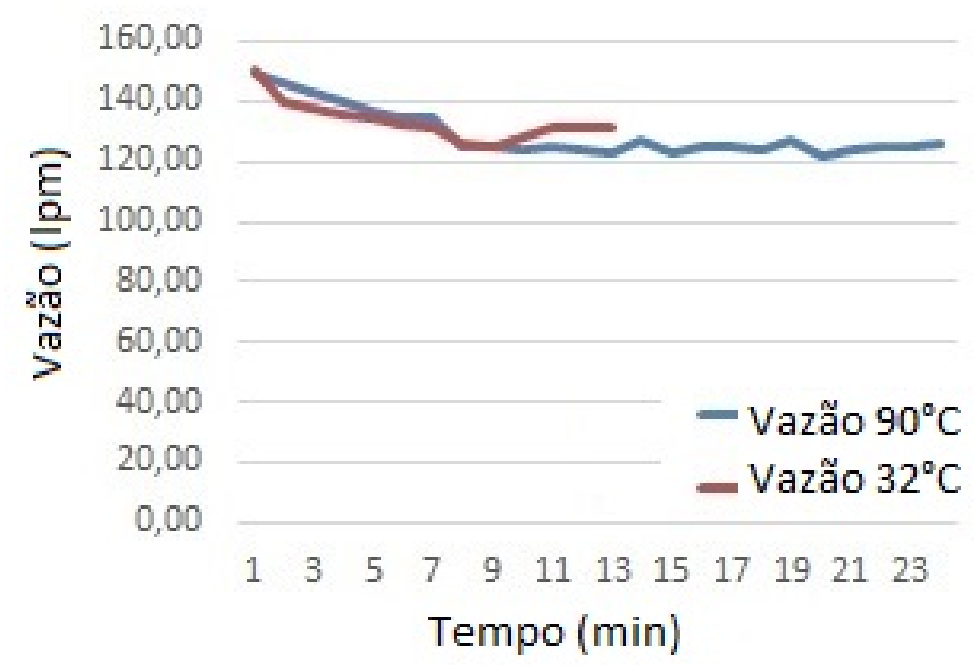

Figura 74 - Comportamento da vazão em função da temperatura e tempo de teste.
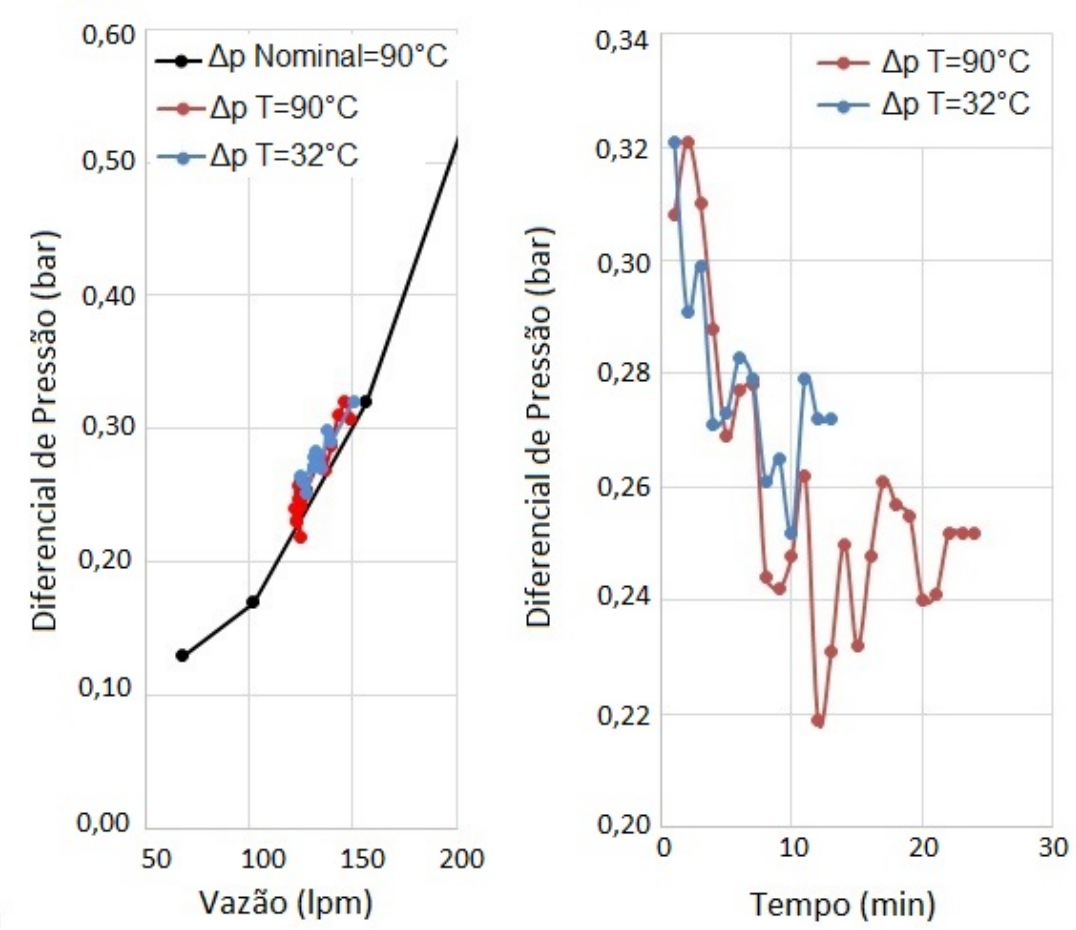

Figura 75 - Variação de pressão $\left(\Delta_{p}\right)$ em função da vazão e temperatura. 
O interessante sobre os resultados obtidos é que não há grande diferença entre as perdas após 13 minutos de teste. A redução da vazão entre esses dois pontos foi de apenas $4 \%$. Outro dado relevante é que a perda de $40 \%$ do torque refletiu em uma redução de apenas $15 \%$ na vazão. De qualquer maneira, é necessário compensar o torque no ponto de projeto, considerando as perdas por temperatura.

\subsection{Comportamento dinâmico do dispositivo}

O último teste realizado mostra o comportamento do dispositivo devido à variação da corrente elétrica, buscando assim controlar a vazão da bomba, evidenciar o torque residual e desligar a bomba. O resultado completo do teste é apresentado pela figura 76, comprovando o funcionamento esperado da máquina. O gráfico mostra a vazão de saída e a corrente elétrica para uma velocidade de entrada estável em 5000 rpm.

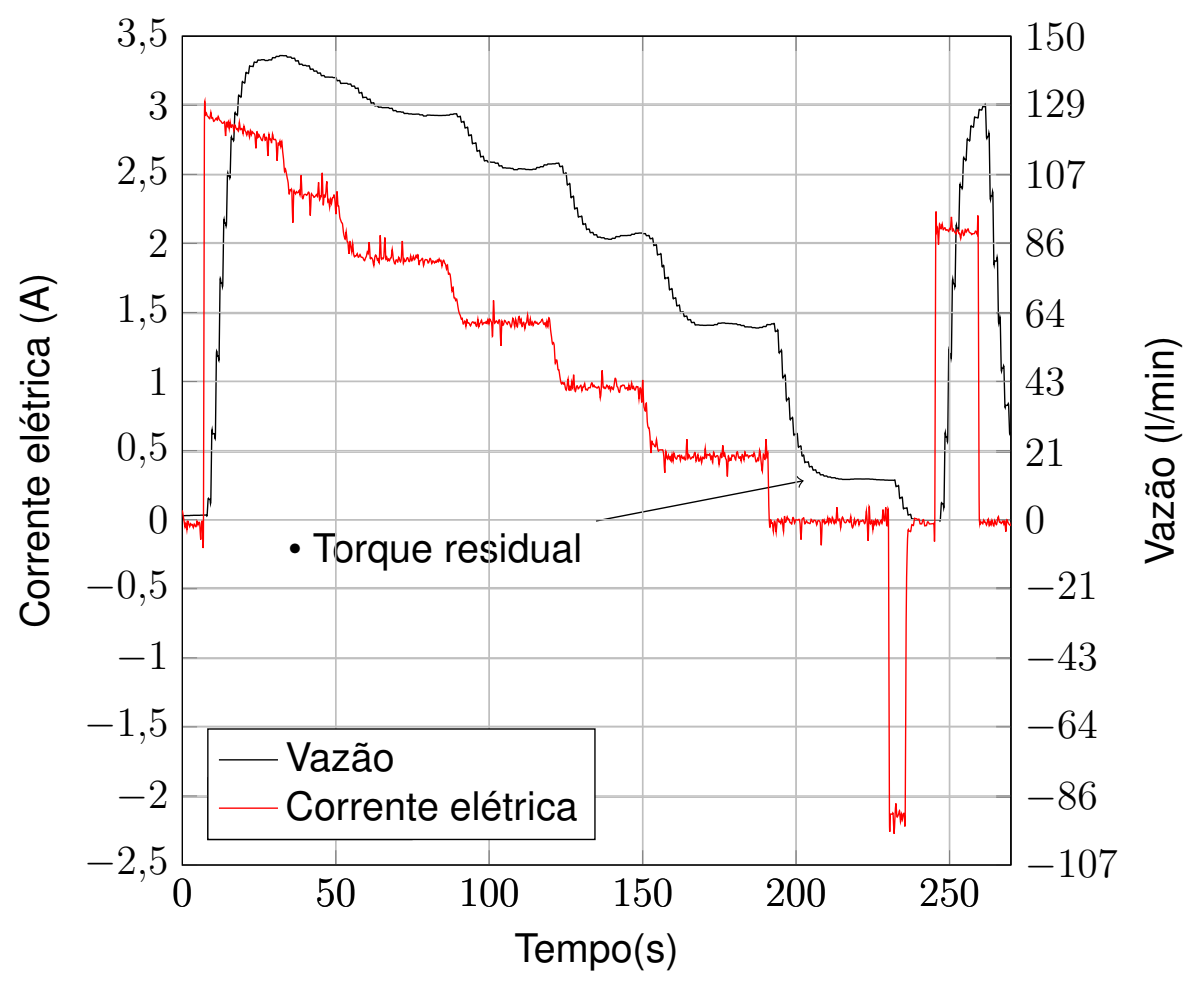

Figura 76 - Resultado do teste evidenciando o controle da vazão, torque residual e desligamento com fluido refrigerante a $25^{\circ} \mathrm{C}$.

A corrente começa em $3 \mathrm{~A}$, sendo reduzida a quase zero, com passos de $0,5 \mathrm{~A}$. Quando a corrente chega a zero, o movimento residual passa a atuar, mantendo uma pequena quantidade de torque (vazão em torno de $15 \mathrm{l} / \mathrm{min}$ ). Ao inverter o sinal de corrente do eletroímã, a bomba é desligada. Nota-se que, após retornar a zero, partindo de $-2 \mathrm{~A}$, o 
torque residual não é produzido como fora no ciclo de corrente positiva. Este efeito precisa ser melhor investigado, mas provavelmente ele ocorre por conta da remanência, efeito que conserva o magnetismo que foi induzido.

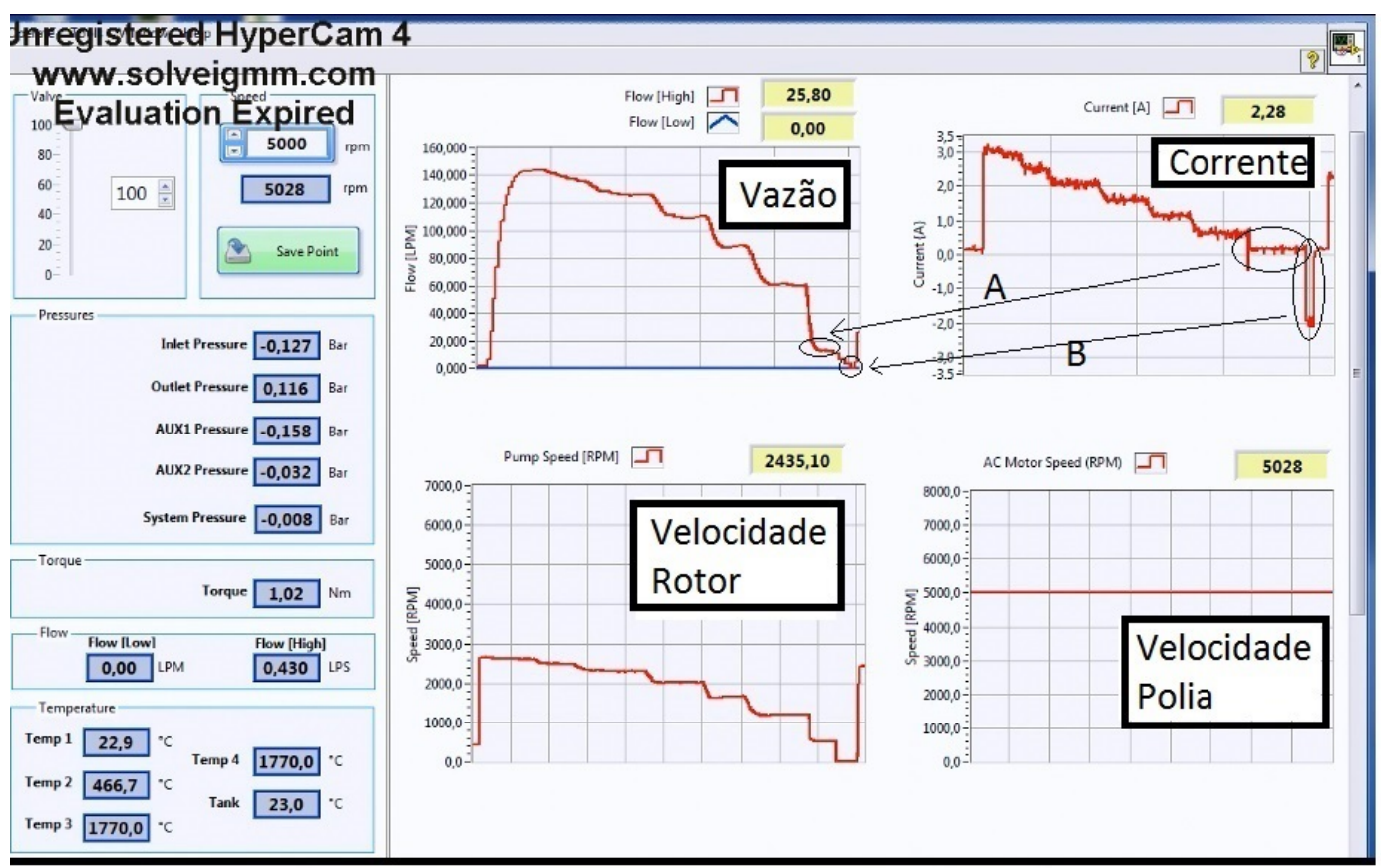

Figura 77 - Ambiente Labview para controle da velocidade da polia e aquisição dos dados.

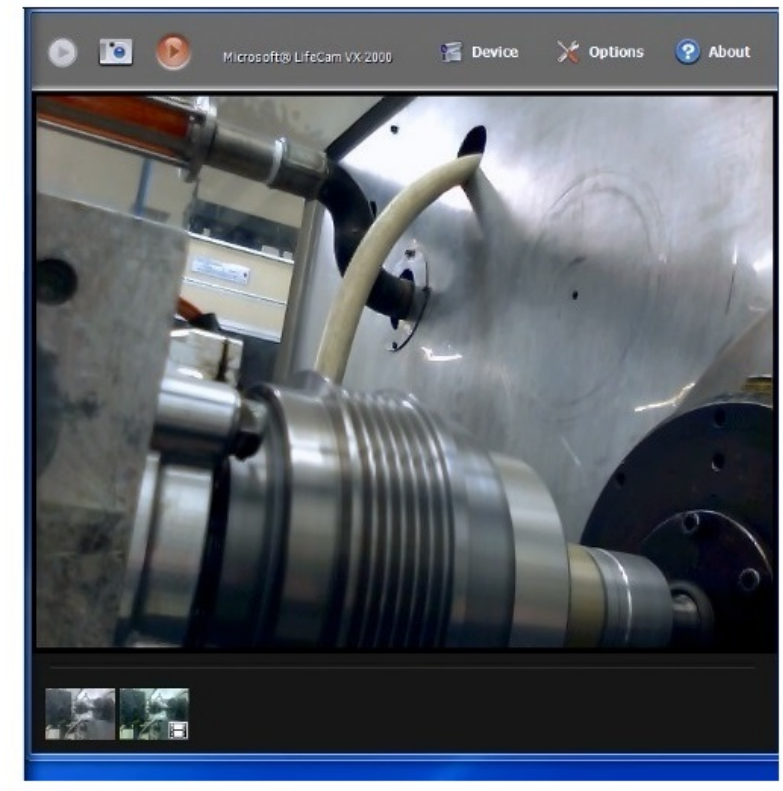

Figura 78 - Foto do dispositivo durante o teste.

Por fim, a figura 77 mostra a tela do sistema elaborado em Labview para controle da máquina de desempenho, onde destaca-se a vazão, corrente, velocidade do rotor do acoplamento e velocidade da polia fixa em $5000 \mathrm{rpm}$. A figura 78 apresenta uma foto da bomba durante o teste dinâmico. 


\subsection{Comparação dos comportamentos para as diferentes tec- nologias}

O dispositivo foi testado com uma corrente elétrica máxima de 4,0 A, o que resulta em $48 \mathrm{~W}$. Mesmo que uma nova proposta consumisse o dobro de corrente elétrica alterandose o projeto do eletroímã, o dispositivo proposto funcionaria com potência elétrica máxima de $96 \mathrm{~W}$. Esse comportamento resultaria em uma economia de $76 \%$ no consumo de energia elétrica quando comparado aos $400 \mathrm{~W}$ consumidos pelo CWA-400.

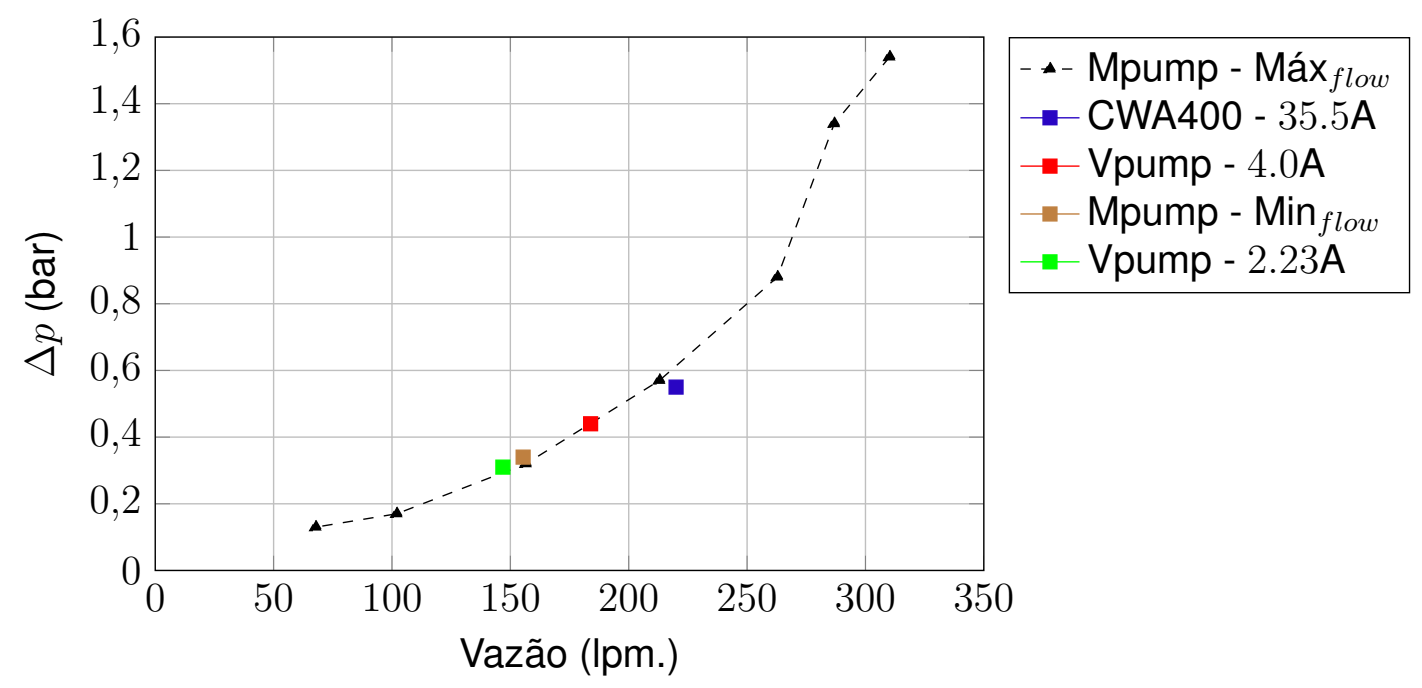

Figura 79 - Comparação do diferencial de pressão $\Delta p$ em função da máxima vazão. Bomba mecânica convencional (Mpump - Máx ${ }_{v a z o}$ ) como referência.

A figura 79 apresenta uma comparação do diferencial de pressão em função da vazão máxima alcançada. Observa-se a proximidade do ponto de operação da bomba variável (Vpump - 4, 0 A) com o ponto de operação CWA-400 (35, 5 A). Também fica evidente o grande desafio em aproximar-se dos valores alcançados pela bomba mecânica (310,0 l/min com 1,54 bar de diferencial de pressão). 


\section{Conclusão}

Este trabalho apresenta todas as etapas para validar uma topologia de acoplamento magnético, tendo como princípio a transferência de torque por correntes induzidas. $O$ primeiro passo foi estabelecer um critério que ajudasse a caracterizar o comportamento do dispositivo proposto e suas limitações iniciais. Para tanto, foi adotado um projeto de bomba d'água convencional como linha de base, o que gerou limites geométricos para o projeto.

Essa limitação inicial impactou no diâmetro interno da região ativa, permitindo, assim, definir uma primeira proposta construtiva. A partir desta definição foi possível construir um modelo simplificado para simulação por elementos finitos e desenvolver um protótipo para testes de desempenho. Como resultado, esse trabalho compara os dados obtidos a partir dos cálculos matemáticos, simulações por elementos finitos e testes de desempenho de um protótipo, que comprovam os métodos utilizados e a boa previsibilidade do comportamento do dispositivo.

Do ponto de vista funcional, a máquina pôde ser controlada com boa estabilidade na transferência de torque. Os três modos de controle funcionaram conforme o esperado. Do ponto de vista do desempenho, notou-se que a relação entre o entreferro superior e inferior fez com que grande parte do fluxo magnético gerado pelos ímãs não fosse bem aproveitado. O reflexo disso é o baixo valor do torque residual, medido na faixa de 0,0 a $0,5 \mathrm{Nm}$. Um aspecto interessante observando durante os testes refere-se à necessidade em anular a transmissão do torque. É possível adotar que o ciclo de desligamento deve manter o torque abaixo de $0,4 \mathrm{Nm}$ ao invés de anulá-lo, o que deve refletir em uma vazão relativamente baixa para o sistema. A proposta para este caso é aumentar a relutância do entreferro inferior e aproveitar melhor a energia magnética gerada pelo eletroímã durante o desligamento da máquina, conforme evidenciado no teste apresentado pela figura 76 durante o ciclo com corrente elétrica negativa.

Outro ponto importante é o estudo para aumentar a área reservada para o eletroímã. Este estudo deve ser baseado no cálculo do $\phi_{a c}$ necessário para o ponto de operação, em função da velocidade de escorregamento. Esse cálculo deve levar em conta todas as perdas evidenciadas, como a reação de armadura e comportamento em função da temperatura do fluido refrigerante. Com essa determinação é possível otimizar o dimensionamento do 
circuito magnético.

Ficou evidente pela figura 71b que uma análise do desempenho hidráulico também precisa ser feita, uma vez que a bomba apresentou um desempenho $18 \%$ menor que o esperado, com velocidade de entrada em $5000 \mathrm{rpm}$, e $10 \%$ menor, com velocidade de 7000 rpm. A boa capacidade de transferência de energia e a estabilidade dinâmica ficaram evidentes nos testes em laboratório. Em ambiente simulado e com o fluido refrigerante a $90^{\circ} \mathrm{C}$, obteve-se perdas de aproximadamente $15 \%$ na vazão, mantendo-se o diferencial de pressão.

O dispositivo foi testado com uma corrente elétrica máxima de 4, $0 \mathrm{~A}$, o que resulta em $48 \mathrm{~W}$. Mesmo que uma nova proposta consumisse o dobro de corrente elétrica, o dispositivo proposto funcionaria com potência elétrica máxima de $96 \mathrm{~W}$. Esse comportamento resultaria em uma economia de $76 \%$ no consumo de energia elétrica quando comparado aos $400 \mathrm{~W}$ consumidos pelo CWA-400.

Ao utilizar a bomba com acoplamento magnético proposto ficou evidente a redução do consumo de energia elétrica, quando comparada com a bomba impulsionada por motor elétrico. Essa redução possibilita vislumbrar novas aplicações onde as bombas elétricas não podem ser aplicadas, dado o limite de corrente consumida por elas. Por aproveitar a energia mecânica disponível no eixo de entrada, o consumo de energia elétrica para este tipo de acoplamento magnético fica totalmente destinado ao controle do fluxo magnético na região ativa. Esse controle de fluxo visa ajustar de forma precisa o torque que será transmitido ao rotor da bomba.

Por fim, este trabalho comprova o potencial para sua aplicação principalmente em motores em que o consumo de energia inviabiliza a aplicação de bombas elétricas. É um primeiro estudo que busca relacionar as ferramentas desenvolvidas para servir de base para análises mais profundas. Também será necessário simplificar sua construção eliminando alguns componentes, já que o peso do protótipo é de $3,80 \mathrm{~kg}$ com um diâmetro externo de 95, 4 mm e um comprimento de 110,3 mm. Para efeito de comparação, o CWA-400 pesa 2, $5 \mathrm{~kg}$ com um diâmetro de 93, $0 \mathrm{~mm}$ e $170,0 \mathrm{~mm}$ de comprimento, portanto, cerca de 60,0 $\mathrm{mm}$ maior no comprimento do que o protótipo. 


\section{Referências}

AGENCY, U. S. E. P. Greenhouse Gas Emissions from a Typical Passenger Vehicle. 2018. Disponível em: <https://nepis.epa.gov/Exe/ZyPDF.cgi?Dockey=P100U8YT.pdf>.

BRONZERI, R. et al. Coolant fluid pump with variable actuation speed. [S.I.]: World Intellectual Property Organization, WIPO, 2019. WO/2019/084637.

BRONZERI, R. B.; CHABU, I. E. Concept validation of an automotive variable flow water pump with an eddy current magnetic coupling. IEEE Transactions on Transportation Electrification, v. 7, n. 4, p. 2939-2950, 2021.

BRUNETTI, F. Motores de Combustão Interna. São Paulo, SP, BR: Blucher, 2012. v. 2.

BRUNETTI, F. Motores de Combustão Interna. São Paulo, SP, BR: Blucher, 2012. v. 1.

CREED, B. T.; BRADSHAW, C. E. Controlling engine coolant flow and valve assembly therefor. [S.I.]: Google Patents, 1990. US Patent 4,930,455.

DAVIES, E. J. An experimental and theoretical study of eddy-current couplings and brakes. IEEE Transactions on Power Apparatus and Systems, v. 82, n. 67, p. 401-419, Aug 1963. ISSN 0018-9510.

DAVIES, E. J. General theory of eddy-current couplings and brakes. Electrical Engineers, Proceedings of the Institution of, v. 113, n. 5, p. 825-837, May 1966. ISSN 0020-3270.

DAVIES, E. J.; JAMES, B.; WRIGHT, M. T. Experimental verification of the generalised theory of eddy-current couplings. Electrical Engineers, Proceedings of the Institution of, v. 122 , n. 1, p. 67-72, January 1975. ISSN 0020-3270.

DIETRICH, A. B. Um estudo de correntes induzidas em meios maciços ferromagnéticos-aplicação no projeto de freios de correntes parasitas. [S.I.]: Universidade de São Paulo, 2000.

FALLER, W.; WOLF, A. Drive member for a water pump of the cooling-water circuit of an internal combustion engine and frictional shift clutch. Google Patents, 2005. US Patent 6,915,887. Disponível em: <https://www.google.com/patents/US6915887>.

FILHO, A. D. A. et al. Temperature control apparatus and method for an automotive cooling system. Google Patents, 2016. US Patent App. 14/914,735. Disponível em: $<$ https://www.google.com/patents/US20160208676>.

FILHO, A. D. A. et al. Temperature control apparatus and method for an automotive cooling system. Google Patents, 2013. US Patent 8,474,419. Disponível em: <https://www.google.com/patents/US8474419>.

HARRIS, N. C.; JAHNS, T. M.; HUANG, S. Design of an integrated motor/controller drive for an automotive water pump application. In: Conference Record of the 2002 IEEE Industry Applications Conference. 37th IAS Annual Meeting (Cat. No.02CH37344). [S.I.: s.n.], 2002. v. 3, p. 2028-2035 vol.3. ISSN 0197-2618. 
ISO, I. 9906: 2012 - rotodynamic pumps - hydraulic performance acceptance tests - grades 1, 2 and 3. International Organization for Standardization: Geneva, Switzerland, 2012. JUNG, D. et al. Analysis of engine temperature and energy flow in diesel engine using engine thermal management. Journal of Mechanical Science and Technology, Springer, v. 27, n. 2, p. 583-592, 2013.

$\mathrm{KIM}, \mathrm{K}$. et al. Active coolant control strategies in automotive engines. International Journal of Automotive Technology, Springer, v. 11, n. 6, p. 767-772, 2010.

LEE, G.-C.; JUNG, T.-U. Design comparisons of bldc motors for electric water pump. In: 2012 IEEE Vehicle Power and Propulsion Conference. [S.I.: s.n.], 2012. p. 48-50. ISSN 1938-8756.

LI, Y. et al. Analytical analysis of a novel brushless hybrid excited adjustable speed eddy current coupling. Energies, Multidisciplinary Digital Publishing Institute, v. 12, n. 2, p. 308, 2019.

MACHIELSE, J. Waxes in thermostats. [S.I.], 2021. Disponível em: <https: //www.paramelt.com/specialty-waxes/thermostat-expansion-waxes/\#wax-in-thermostats>.

MEIRA, J. de C. et al. Pump having an electromagnetic clutch system. Google Patents, 2014. US Patent 8,714,939. Disponível em: <https://www.google.com/patents/US8714939>.

MUKAI, T.; SHICHIJYO, A.; MATSUBARA, S. Rotary electric machine having lundell type pole core. [S.I.]: Google Patents, 1999. US Patent 5,903,083.

OSTOVIC, V. et al. A magnetic-equivalent-circuit-based performance computation of a Lundell alternator. [S.I.]: IEEE, 1999. 825-830 p.

PARK, J. S. et al. Bldc drive control of electric water pump for automotive application. In: 2010 IEEE Vehicle Power and Propulsion Conference. [S.I.: s.n.], 2010. p. 1-5. ISSN 1938-8756.

PARK, J. S. et al. Development of bldc motor and drive of vva module for automotive application. p. 124-127, 2012.

PIERBURG. Eletric Coolant Pumps - Always at the Correct Temperature. [S.I.], 2021. Disponível em: <https://www.rheinmetall-automotive.com/fileadmin/media/kspg/ Broschueren/Poduktbroschueren/Pierburg_Pump_Technology/Wasserumwaelz-_und_ Kuehlmittelpumpen/ppt_elek_kuehlmittelp_e.pdf>.

RIBEIRO, E. G.; FILHO, A. P. de A.; MEIRA, J. L. de C. Electric water pump for engine cooling. SAE International, 2007.

SCOTT, G. Water pump driven by viscous coupling. Google Patents, 2004. US Patent 6,725,812. Disponível em: <https://www.google.com/patents/US6725812>.

TECOMOTIVE. Pierburg CWA400. [S.I.], 2021. Disponível em: <https://www.tecomotive. com/download/datasheets/CWA400_EN.pdf>.

WANG, T. . et al. Optimization of an automotive radiator fan array operation to reduce power consumption. IEEE/ASME Transactions on Mechatronics, v. 20, n. 5, p. 2359-2369, Oct 2015. ISSN 1083-4435. 
WANG, T. T. Investigation of Advanced Engine Cooling Systems-Optimization and Nonlinear Control. Tese (Doutorado) - Clemson University, 2016. 



\section{ANEXO A - Método para cálculo do fluxo} magnético com base na geometria de meio polo magnético.

A figura 80 é a representação do circuito magnético para um ímã. Nela são representadas as relutâncias para o circuito, onde as variáveis a partir de r1 até r7 referem-se ao aço. Já rg1 e rg2 representam as relutâncias de entreferro.

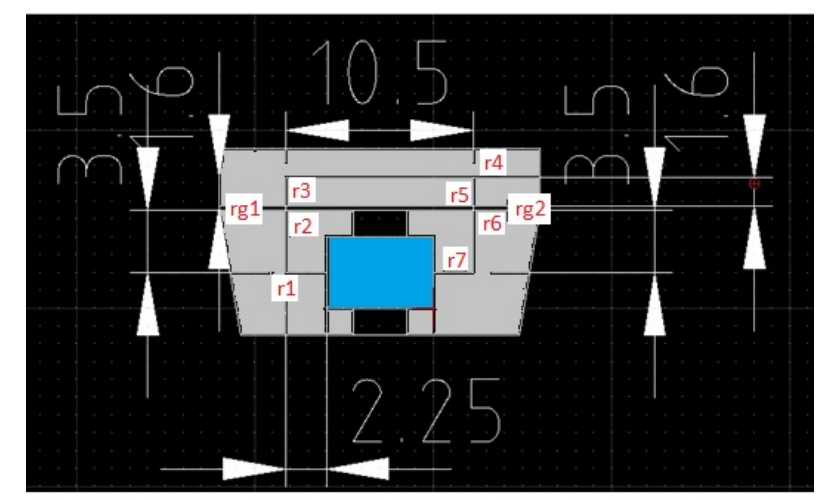

Figura 80 - Circuito magnético para meio polo magnético.

Sendo o objetivo do cálculo considerar as perdas e comparar com o resultado obtido pela simulação, tem-se que:

$$
\begin{gathered}
B m=\mu \mu_{0} H m \\
H m=H c-\left(\frac{H g \cdot L g}{L m}\right)-\left(\frac{\text { Hiron.Liron }}{\text { Lm }}\right)
\end{gathered}
$$

Onde a letra $m$ representa o ímã e iron o material ferromagnético (SAE1020). Sendo o circuito sem entreferro, tem-se que:

$$
\begin{array}{r}
R g 1=R g 2=0 \\
L g=0
\end{array}
$$

Para que seja possível estudar o comportamento do circuito magnético, são apresentadas pela tabela 19 algumas variáveis importantes e suas respectivas definições. 
Tabela 19 - Variáveis para cálculo de Bg.

\begin{tabular}{|l|l|l|}
\hline Variável & Unidade & Valor \\
\hline$S g$ (Área do entreferro) & $m^{2}$ & $1,12.10^{-04}$ \\
\hline$S p m$ (Área do PM) & $m^{2}$ & $6.10^{-05}$ \\
\hline$g$ (Entreferro) & $m$ & $2.0,25.10^{-3}$ \\
\hline$\mu_{r}$ (Máxima energia) & & 1,056 \\
\hline
\end{tabular}

Neste primeiro estudo não existe entreferro, portanto não há uma relutância em série constituída de ar. Uma maneira de estimar o fluxo magnético em um circuito é apresentada a seguir, pela equação A.3. Sendo $L g$ o comprimento do entreferro e apenas servindo como uma estimativa inicial, adotou-se $L g$ com o valor de 1 micrômetro. A partir da estimativa para Bg é possível calcular o fluxo magnético. Com esse valor e conhecendo as áreas que definem a geometria do polo magnético, pode-se encontrar a força magneto motriz $(F m m)$ associada, necessária para calcular o $H m$, vide equação A.2.

$$
\begin{gathered}
B g=\frac{B r}{S g / S p m}+\mu_{r} \frac{L g}{L p m}[T] \\
B g=\frac{1,31}{\left(1,12 \cdot 10^{\left.-04 / 6.10^{-05}\right)}+1,056\left(\frac{1.10^{-6}}{0,006}\right)=0,70[T]\right.} \\
\phi=\frac{B g}{S g}=\frac{0,70}{1,12 \cdot 10^{-04}}=7,86 \cdot 10^{-5}[\mathrm{~Wb}]
\end{gathered}
$$

Com isso pode-se encontrar Hiron relacionando a densidade de fluxo magnético em cada trecho do circuito, conforme indicado na figura 80. A solução consiste em descobrir o valor da densidade e relacioná-lo ao $H$ em $A t / m$ usando a curva caraterística $B x H$ do aço SAE1020. Sabendo-se que a profundidade do objeto simulado possui 15 milímetros, chega-se na tabela 20.

Tabela 20 - Variáveis para cálculo de Bg.

\begin{tabular}{|l|l|l|l|l|l|l|l|}
\hline Rx. & $A\left(m^{2}\right)$ & $L(m)$ & $\phi(W b)$ & $B(T)$ & $\Re(A t / W b)$ & $H(A t / m)$ & $\varepsilon=H . L$ \\
\hline 1 & $1,05 \mathrm{E}-04$ & $2,25 \mathrm{E}-03$ & $7,86 \mathrm{E}-05$ & $7,49 \mathrm{E}-01$ & & $3,65 \mathrm{E}+02$ & $8,21 \mathrm{E}-01$ \\
\hline 2 & $1,16 \mathrm{E}-04$ & $3,60 \mathrm{E}-03$ & $7,86 \mathrm{E}-05$ & $6,80 \mathrm{E}-01$ & & $3,20 \mathrm{E}+02$ & $1,15 \mathrm{E}+00$ \\
\hline 3 & $1,16 \mathrm{E}-04$ & $3,60 \mathrm{E}-03$ & $7,86 \mathrm{E}-05$ & $6,80 \mathrm{E}-01$ & & $3,20 \mathrm{E}+02$ & $1,15 \mathrm{E}+00$ \\
\hline 4 & $4,80 \mathrm{E}-05$ & $1,05 \mathrm{E}-02$ & $7,86 \mathrm{E}-05$ & $1,64 \mathrm{E}+00$ & & $2,80 \mathrm{E}+03$ & $2,94 \mathrm{E}+01$ \\
\hline 5 & $1,16 \mathrm{E}-04$ & $3,60 \mathrm{E}-03$ & $7,86 \mathrm{E}-05$ & $6,80 \mathrm{E}-01$ & & $3,20 \mathrm{E}+02$ & $1,15 \mathrm{E}+00$ \\
\hline 6 & $1,16 \mathrm{E}-04$ & $3,60 \mathrm{E}-03$ & $7,86 \mathrm{E}-05$ & $6,80 \mathrm{E}-01$ & & $3,20 \mathrm{E}+02$ & $1,15 \mathrm{E}+00$ \\
\hline 7 & $1,05 \mathrm{E}-04$ & $2,25 \mathrm{E}-03$ & $7,86 \mathrm{E}-05$ & $7,49 \mathrm{E}-01$ & & $3,65 \mathrm{E}+02$ & $8,21 \mathrm{E}-01$ \\
\hline $\mathrm{g}$ & $1,13 \mathrm{E}-04$ & $1,00 \mathrm{E}-06$ & $7,86 \mathrm{E}-05$ & $6,80 \mathrm{E}-01$ & $7,07 \mathrm{E}+03$ & $5,56 \mathrm{E}+05$ & $5,56 \mathrm{E}-01$ \\
\hline $\mathrm{g}$ & $1,13 \mathrm{E}-04$ & $1,00 \mathrm{E}-06$ & $7,86 \mathrm{E}-05$ & $6,80 \mathrm{E}-01$ & $7,07 \mathrm{E}+03$ & $5,56 \mathrm{E}+05$ & $5,56 \mathrm{E}-01$ \\
\hline
\end{tabular}


Somando a força magneto motriz $(\varepsilon)$ resultante de $r 1$ até $r 7$ obtém-se o valor de 35, 65At. Assim, com base na equação A.2, tem-se que:

$$
H m=H c-\left(\frac{0,55}{0,006}\right)-\left(\frac{35,65}{0,006}\right)=980966[\mathrm{~A} / \mathrm{m}]
$$

Sendo $\mu_{r}=1,056$ e conhecendo $H m$, tem-se que:

$$
B m=980966 . \mu_{0} \mu_{r}=1,30[T]
$$

Comparando assim com o valor obtido pela simulação, vide figura 38, observa-se que a correção foi satisfatória. 



\section{ANEXO B - Método para calcular a}

\section{remanência $(\mathrm{Br})$ dos ímãs permanentes e}

\section{comprovação do sentido de magnetização.}

A primeira verificação foi feita com papel magnético e com ele pôde-se comprovar a direção da magnetização, conforme apresentado pela figura 37. A seguir, vide figura 81 , nota-se a divisória (linha branca) indicando a presença dos dois polos magnéticos. $\mathrm{Na}$ figura são definidos dois eixos, onde y representa a direção ao longo do comprimento de 15 milímetros e $x$ na direção da largura de 6 milímetros. A linha divisória indica ausência de fluxo magnético, ou fluxo nulo. Desta forma, fica evidente que a polarização foi feita no sentido orientado pelo eixo $x$, conforme esperado.

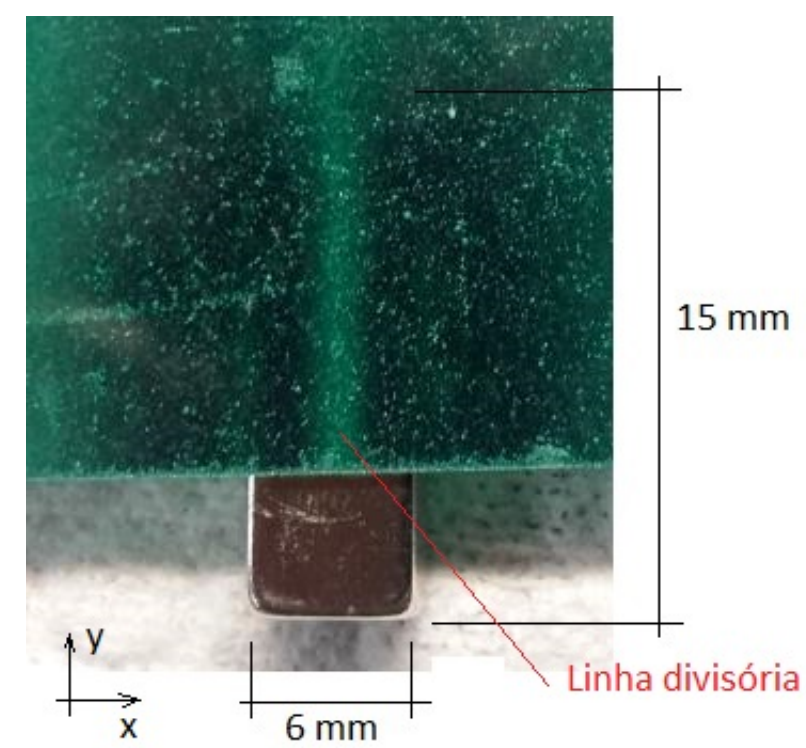

Figura 81 - Comprovação do sentido de magnetização.

Uma vez verificadas as dimensões e sua polarização, o próximo passo é certificar que os ímãs serão capazes de gerar o fluxo magnético esperado, conforme fluxo medido através da simulação. Para essa comprovação foi utilizado um equipamento que coleta informações de uma bobina de Helmholtz (elemento sensor). Com ele, mede-se o fluxo magnético $\lambda$ (mV.s) ao retirar o ímã do centro da bobina. Esse valor, multiplicado pelo fator da bobina e divido pelo volume do ímã, determina a densidade de fluxo intrínseca (Bdi). 
ANEXO B. Método para calcular a remanência $(\mathrm{Br})$ dos ímãs permanentes e comprovação do sentido de 126 magnetização.

Uma foto do equipamento (TLPM, produzido pela Global Mag), da bobina de Helmholtz e uma amostra do ímã (no centro) é apresentada pela figura 82.

Tabela 21 - Variáveis relacionadas com o cálculo a partir da utilização da bobina de Helmholtz.

\begin{tabular}{|l|l|l|}
\hline Item & Valor & Unidade \\
\hline Kh (constante da bobina de Helmholtz) & $4,55 \mathrm{E}-4$ & \\
\hline $\mathrm{R}$ (resistência da bobina de Helmholtz) & 38 & $\Omega$ \\
\hline m (volume do ímã permanente) & 360 & $\mathrm{~mm}^{3}$ \\
\hline L (largura do ímã) & 6 & $\mathrm{~mm}$ \\
\hline H (altura do ímã) & 4 & $\mathrm{~mm}$ \\
\hline $\mathrm{C}$ (comprimento do ímã) & 15 & $\mathrm{~mm}$ \\
\hline PC (Coeficiente de permeabilidade) & 0,83 & \\
\hline$\mu$ rec (permeabilidade) & 1,056 & \\
\hline
\end{tabular}

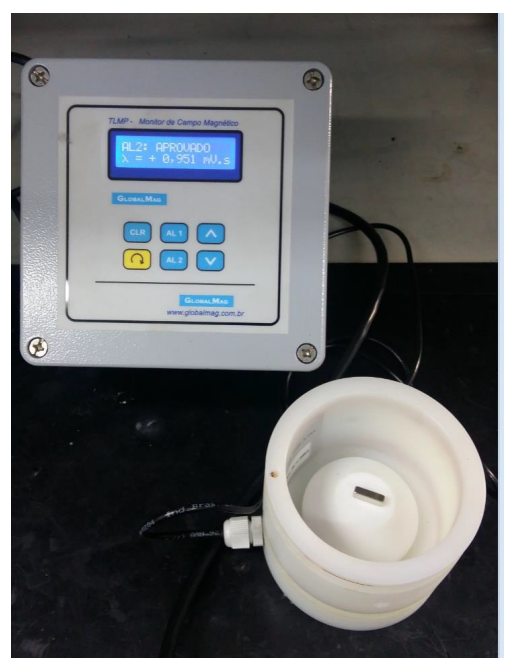

Figura 82 - Comprovação do sentido de magnetização.

Para calcular corretamente o valor $\mathrm{Br}$ é necessário analisar o segundo quadrante da curva de magnetização do ímã. Desta forma é possível entender com clareza as relações das variáveis que serão calculadas. A figura 83, portanto, apresenta esta curva e destaca essas variáveis que estão relacionadas com o comportamento do ímã. Para complementar, na tabela 21 são apresentadas as demais variáveis e seus respectivos valores.

Como mencionado anteriormente, o equipamento mede o fluxo magnético gerado pelo ímã quando retirado do centro da bobina de Helmholtz. Em função desta velocidade, calcula-se $B d i$, definida como densidade de fluxo magnético intrínseca. Esta relação é dada pela equação B.1.

$$
B_{d i}=\frac{K_{h} \cdot \lambda}{m}
$$




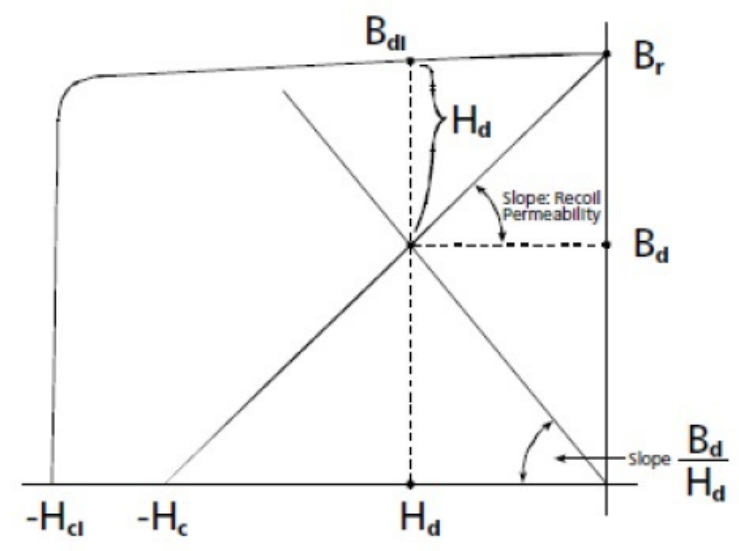

Figura 83 - Segundo quadrante da curva de magnetização de um ímã e a relação das variáveis para cálculo do $B r$.

Conhecendo $B_{d i}$ pode-se calcular $B_{r}$ da seguinte maneira, vide equação B.2:

$$
B_{r}=\frac{B_{d i}(\mu r e c+P C)}{P C+1}
$$

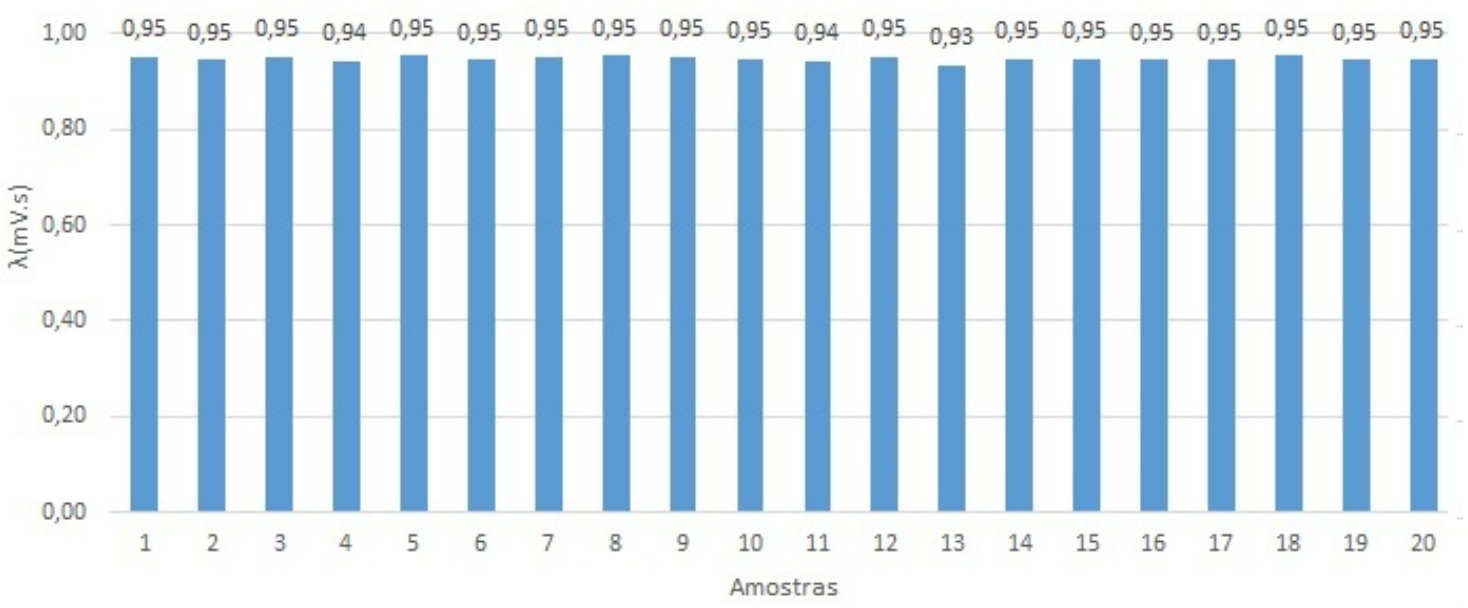

Figura 84 - Valores para o fluxo magnético coletados para 20 amostras.

Assim, a figura 84 apresenta os valores para o fluxo magnético coletados para 20 amostras. A figura 85, considerando um erro no equipamento de mais ou menos $4 \%$, apresenta o resultado comparativo entre o valor de catálogo e os valores obtidos, considerados satisfatórios (em torno de $6 \%$ inferiores para os valores nominais). Dos 20 ímãs estudados, 16 foram selecionados e utilizados na montagem do protótipo. 


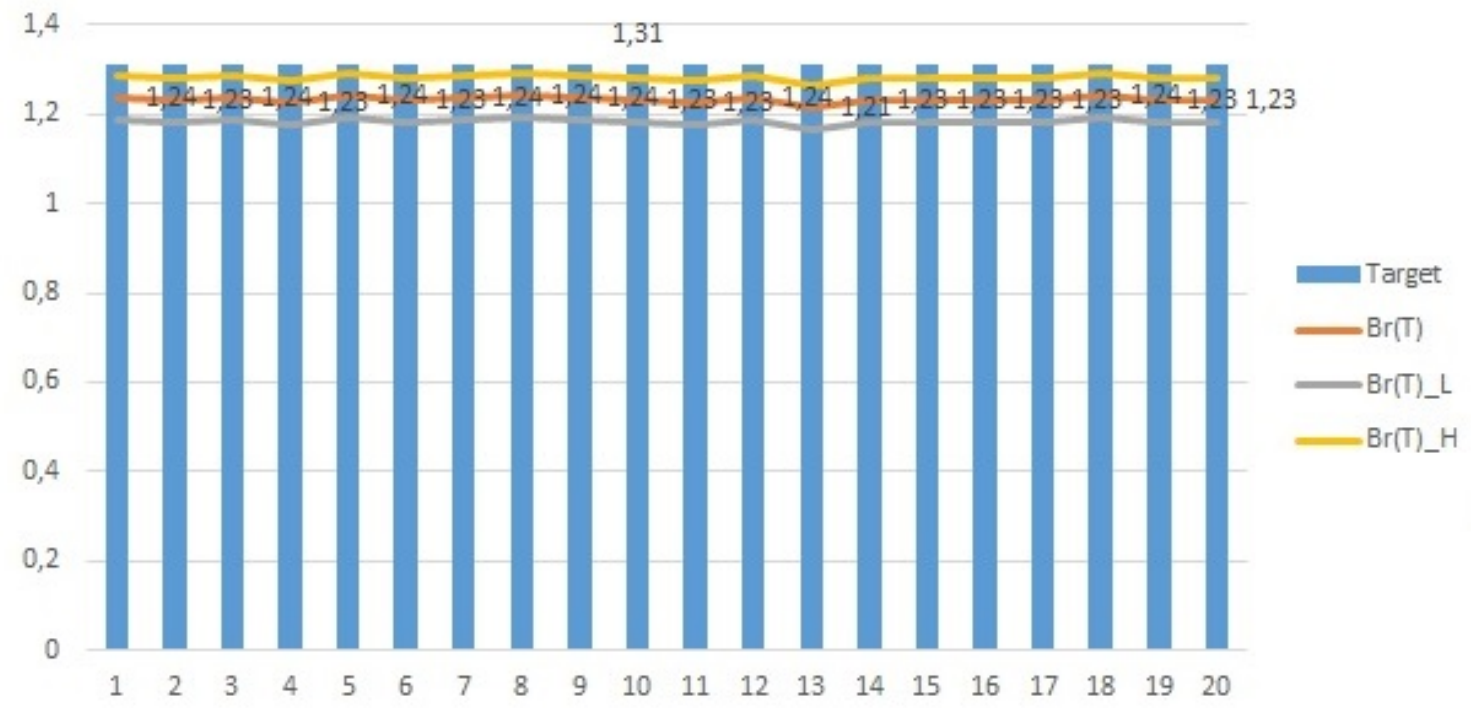

Figura 85 - Comparativo entre o valor de catálogo e os valores obtidos com tolerância de $\pm 4 \%$. 